\begin{abstract}
UNIVERSIDADE DE SÃO PAULO
Escola de Artes, Ciências e Humanidade - EACH

Programa de Pós-graduação em Sistemas de Informação - PpgSI
\end{abstract}

Felipe de Alencar Albuquerque

Detecção interprocedimental de clones semânticos

São Paulo 


\section{Detecção interprocedimental de clones semânticos}

São Paulo

Novembro 2013 
Felipe de Alencar Albuquerque

\title{
Detecção interprocedimental de clones semânticos
}

\author{
Dissertação apresentada à Escola de Artes, \\ Ciências e Humanidades da Universidade de \\ São Paulo para obtenção do título de Mestre em \\ Ciências. Programa: Sistemas de Informação. \\ Versão corrigida contendo as alterações so- \\ licitadas pela comissão julgadora. A versão \\ original encontra-se disponível na Escola de \\ Artes, Ciências e Humanidades.
}

Orientador: Prof. Dr. Marcos Lordello Chaim

São Paulo

Novembro 2013 
Autorizo a reprodução e divulgação total ou parcial deste trabalho, por qualquer meio convencional ou eletrônico, para fins de estudo e pesquisa, desde que citada a fonte.

\section{CATALOGAÇÃO-NA-PUBLICAÇÃO}

Biblioteca

Escola de Artes, Ciências e Humanidades da Universidade de São Paulo

Albuquerque, Felipe de Alencar

Detecção interprocedimental de clones semânticos / Felipe de Alencar Albuquerque ; orientador, Marcos Lordello Chaim. - São Paulo, 2013. [117] f. : il.

Dissertação (Mestrado em Ciências) - Programa de Pós-

Graduação em Sistemas de Informação, Escola de Artes, Ciências

e Humanidades, Universidade de São Paulo.

Versão corrigida.

1. Verificação e validação de software. 2. Geração de código. 3. Inspeção de software . 4. Revisão de software. 5. Engenharia de software. I. Chaim, Marcos Lordello, orient. II. Título.

CDD 22.ed. - 004.24 
Dissertação de mestrado sob o título "Detecção interprocedimental de clones semânticos", defendida por Felipe de Alencar Albuquerque e aprovada em 08 de novembro de 2013, em São Paulo, Estado de São Paulo, pela banca examinadora constituída pelos doutores:

Prof. Dr. Marcos Lordello Chaim Orientador

Prof. Dr. Rosana Teresinha Vaccare Braga Universidade de São Paulo

Prof. Dr. Luciano Vieira de Araújo Universidade de São Paulo 
Dedico este trabalho à minha família, sem a qual eu não teria chegado tão longe. 
Agradeço principalmente ao meu orientador professor doutor Marcos Lordello Chaim pela confiança e paciência.

À professora doutora Fátima de Lourdes dos Santos Nunes Marques pelo auxílio no levantamento bibliográfico.

Ao professor doutor Luciano Vieira de Araújo pelos comentários fornecidos no Exame de Qualificação desta pesquisa. 
"Muitos são os obstinados que se empenham no caminho que escolheram, poucos os que se empenham no objetivo."

(Friedrich W. Nietzsche) 


\section{Resumo}

Fragmentos de código duplicado, ou clones, são inseridos em aplicativos por serem uma maneira simples de reúso, dentre outros motivos. Clones são, portanto, comuns em programas. No entanto, a atividade de manutenção pode ficar custosa se o código do programa analisado possuir muitos clones, principalmente os semânticos, os quais podem possuir códigos distintos, mas realizam tarefas similares. Nesse sentido, a utilização de ferramentas que automatizam a tarefa de detectar clones é desejável. Ferramentas atuais de detecção de clones semânticos são capazes de identificar esses clones com altas taxas de acerto. No entanto, elas não são capazes de identificar clones semânticos considerando também os fluxos dos procedimentos ou funções que são invocados dentro dos fragmentos de código comparados. Essa limitação pode levar as ferramentas a indicarem clones semânticos falso positivos. Este trabalho apresenta uma técnica de detecção de clones semânticos que considera as chamadas de procedimentos presentes nos programas. Essa técnica apresentou uma taxa de acertos 2,5\% maior do que técnicas convencionais de acordo com um benchmark, também desenvolvido neste trabalho. Esse benchmark foi criado com base nas classificações de clones fornecidas por programadores da indústria e da academia. A técnica interprocedimental de detecção de clones semânticos pode ser utilizada para evolução, manutenção, refatoração e entendimento de programas.

Palavras-chave: duplicação de código, clones semânticos, detecção de clones, grafos de dependência de programas. 


\section{Abstract}

Fragments of duplicated code, or clones, are embedded in applications as they are a simple way to reuse code, among other reasons. Clones are therefore common in programs. However, the maintenance activity may be costly if the program code has many clones to analyze, specially semantic clones, which are semantically similar but may have different syntax. In this regard, the use of tools that automate the task of detecting clones is desirable. Current tools for detecting semantic clones are able to identify those clones with high hit rates. However, they are not able to detect semantic clones also considering the flow of procedures or functions that are invoked within the compared code fragments. This limitation can lead the tools to indicate false positive semantic clones. This paper presents a technique that takes into account the procedure calls in programs to detect semantic clones. This technique showed a $2.5 \%$ higher hit rate than conventional techniques according to a benchmark also developed in this work. This benchmark was created based on evaluations provided by programmers from academic and industrial settings. The interprocedural semantic clone detection technique can be used for evolution, maintenance, refactoring and understanding of programs.

Keywords: code duplication, semantic clones, clone detection, program dependence graphs. 


\section{Sumário}

Lista de Figuras $\quad$ xi

Lista de Tabelas $\quad$ xiv

1 Introdução 1

1.1 Motivação . . . . . . . . . . . . . . . . . . . 2

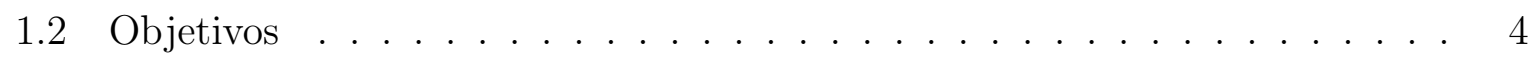

1.3 Organização do texto . . . . . . . . . . . . . . . . . 5

2 Conceitos Fundamentais $\quad 6$

2.1 Grafos de fluxo de controle $(\mathrm{GFC}) \ldots \ldots \ldots \ldots$

2.2 Conceitos de definição e uso de variáveis . . . . . . . . . . . . . . . 7

2.3 Grafos de dependência de programas (GDP) . . . . . . . . . . 8

2.3.1 Dependências de dados . . . . . . . . . . . . . . . . . 9

2.3.2 Dependências de controle . . . . . . . . . . . . . . . 10

2.3 .3 Exemplo de GDP . . . . . . . . . . . . . . . . . . 10

2.3.4 Algoritmos para a criação de GDPs . . . . . . . . . . . . . . . . 11

2.4 Clones . . . . . . . . . . . . . . . . . . . . . . . 12

2.4.1 Similaridade de texto . . . . . . . . . . . . . . . . . 12

2.4.2 Similaridade de funcionalidade . . . . . . . . . . . . . . . . . . . 13

2.5 Detecção de Clones . . . . . . . . . . . . . . . . . . . . . . . . . . 14

2.5.1 Técnicas textuais . . . . . . . . . . . . . . . . 14

2.5.2 Técnicas léxicas . . . . . . . . . . . . . . . . . . 15 
2.5.3 Técnicas sintáticas . . . . . . . . . . . . . . . 15

2.5.4 Técnicas semânticas _. . . . . . . . . . . . . . . 16

2.5.5 Técnicas híbridas . . . . . . . . . . . . . . . . 16

2.6 Conclusão do capítulo . . . . . . . . . . . . . . . . . . . . . . . . . . 17

3 Levantamento Bibliográfico $\quad 18$

3.1 Definição do levantamento bibliográfico . . . . . . . . . . . . . . . . . . 18

3.1.1 Questão que guiou o levantamento . . . . . . . . . . . . . 18

3.1 .2 Escopo dos estudos . . . . . . . . . . . . . . . . . . . . 18

3.1.3 Seleção dos artigos . . . . . . . . . . . . . . . . . . . . . . 19

3.1.4 Critérios de inclusão e exclusão . . . . . . . . . . . . . . . 20

3.1.5 Artigos selecionados . . . . . . . . . . . . . . 20

3.2 Trabalhos relacionados . . . . . . . . . . . . . . . . 21

3.2.1 Komondoor e Horwitz (2001) . . . . . . . . . . . . . . . . 22

3.2 .2 Krinke $(2001) \ldots \ldots \ldots \ldots \ldots \ldots$

3.2 .3 Liu et al. (2006) . . . . . . . . . . . . . . 26

3.2.4 Bellon et al. (2007) . . . . . . . . . . . . . . . 28

3.2.5 Gabel, Jiang e Su (2008) . . . . . . . . . . . . . . . 29

3.2.6 Albuquerque, Neves e Chaim (2012) . . . . . . . . . . . . 30

3.3 Discussão . . . . . . . . . . . . . . . . . . . . . . . 32

3.3.1 Estruturas de dados utilizadas . . . . . . . . . . . . . . . 32

3.3.2 Técnicas de comparação de GDPs . . . . . . . . . . . . . . 32

3.3.3 Pontos fortes e deficiências . . . . . . . . . . . . . . . . . 33

3.3.4 Formas de avaliação . . . . . . . . . . . . . . . . . 34

3.3.5 Reprodutibilidade das avaliações realizadas . . . . . . . . . . . 36

3.4 Conclusão do capítulo . . . . . . . . . . . . . . . . . . . . 36 
4 Benchmark para Detectores de Clones 38

4.1 Metodologia para a criação do benchmark . . . . . . . . . . . . . . . 39

4.1.1 Definição dos tipos de clones considerados . . . . . . . . . . . . . . 39

4.1.2 Obtenção de candidatos a clones de projetos de código aberto . . . 41

4.1.3 Formulação do treinamento sobre clones . . . . . . . . . . . . . . . 43

4.1.4 Critérios para a seleção dos programadores . . . . . . . . . . . . . . 44

4.1.5 Critérios para a classificação de candidatos a clones . . . . . . . . . 45

4.2 Obtenções das classificações dos candidatos a clones . . . . . . . . . . . . 45

4.2.1 Execução da atividade preliminar . . . . . . . . . . . . . . . . . 46

4.2.2 Execução da atividade principal . . . . . . . . . . . . . . . . . . 48

4.2.3 Computação e análise dos resultados fornecidos pelos grupos . . . . 49

4.3 Criação do benchmark . . . . . . . . . . . . . . . . . 58

4.3.1 Criação do projeto com os pares de métodos . . . . . . . . . . . . 58

4.3.2 Mecanismo de análise dos resultados . . . . . . . . . . . . . . . 59

4.4 Conclusão do capítulo . . . . . . . . . . . . . . . . . . 63

5 Detecção Interprocedimental de Clones Semânticos $\quad 65$

5.1 Definição da técnica . . . . . . . . . . . . . . . . 65

5.2 Filtro e heurísticas para análise interprocedimental f . . . . . . . . 66

5.3 Modelagem e desenvolvimento da técnica . . . . . . . . . . . . . . . . . 68

5.3.1 Desenvolvimento de melhorias de desempenho na BJCD . . . . . . 69

5.3.2 Incorporação da detecção interprocedimental de clones na BJCD . . 72

5.4 Validações das técnicas propostas . . . . . . . . . . . . . . . 75

5.4.1 Avaliação do filtro de tamanho mínimo de GDPs . . . . . . . . . 76

5.4.2 Avaliação dos consumos de tempo e memória da análise interprocedimental . . . . . . . . . . . . . . . . . 77 
5.4.3 Comparação da taxa de acerto da análise convencional com a interprocedimental . . . . . . . . . . . . . . . . . . . 79

5.5 Ameaças à validade . . . . . . . . . . . . . . . . . . 80

5.6 Conclusão do capítulo . . . . . . . . . . . . . . . . . . . . . 81

6 Contribuições e Trabalhos Futuros $\quad 84$

$\begin{array}{lr}\text { Referências } & 86\end{array}$

Apêndice A Automação do sorteio de clones $\quad 90$

Apêndice B Formulário de ciência da criação do benchmark 95

Apêndice C Formulário de avaliação da criação do benchmark $\quad 97$

Apêndice D Arquitetura de alto nível da ACDRA $\quad 99$ 


\section{Lista de Figuras}

1 System.out.println() imprime $b$ no console . . . . . . . . . . . . . . 3

2 System.out.println() retorna $b+1 \ldots \ldots \ldots$

3 Corpo do método replaceVariables(). Fonte: Koskela (2008) . . . . . . . . 6

4 Grafo de fluxo de controle do método replaceVariables() . . . . . . . . . . 7

5 Programa sort e seu grafo def-uso . . . . . . . . . . . . . . . 8

6 Dependência de dados . . . . . . . . . . . . . . . . . . . . . 9

7 Dependência de dados com redefinição . . . . . . . . . . . . . . . . . . . . 9

8 Dependência de dados com redefinição dentro de condição . . . . . . . . . . 9

9 Dependência de controle . . . . . . . . . . . . . . . . . . . . . . 10

10 Método foo(String) . . . . . . . . . . . . . . . . . . . 11

11 GDP para o método foo (String) . . . . . . . . . . . . . 11

12 Identificação de números pares original . . . . . . . . . . . . . . . . . . 13

13 Identificação de números pares com similaridade textual . . . . . . . . . . 13

14 Identificação de números pares com similaridade semântica . . . . . . . . . 14

15 Comparação de GDPs utilizando fatiamento de programas. Fonte: Komondoor e Horwitz (2001). Tradução livre. . . . . . . . . . . . . . . . . . . 23

16 Código fonte de exemplo para geração de um GDP granular. Fonte: Krinke

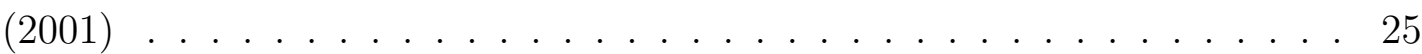

17 Trecho do GDP granular referente ao código fonte da Figura 16. Fonte: Krinke (2001). Tradução livre. . . . . . . . . . . . . . . . . 25

18 Vértices antes da normalização da BJCD. Fonte: Albuquerque, Neves e Chaim (2012) . . . . . . . . . . . . . . . . . . . . 31 
19 Vértices após a normalização da BJCD. Fonte: Albuquerque, Neves e Chaim (2012) . . . . . . . . . . . . . . . . . . . . 31

20 Processo de sorteio de candidatos a clones . . . . . . . . . . . . . . . 43

21 Exibição dos candidatos a clones utilizando o Eclipse . . . . . . . . . . . . 47

22 Tipos de clones detectados pelos programadores . . . . . . . . . . . . . . 47

23 Percentuais dos tipos de clones classificados . . . . . . . . . . . . . . 53

24 fireEditingStopped() e fireEditingCanceled().............. . 54

25 rotate $C W()$ e rotate $C C W \ldots \ldots \ldots \ldots \ldots$

26 createRowRealMatrix(double[]) e createColumnRealMatrix(double[]) . . . . 56

27 PolyKernel.setOptions(String[]) e AdaBoostM1.setOptions(String[]) . . . . 57

28 Experiência dos programadores participantes . . . . . . . . . . . . . 58

29 Ilustração da criação do PCCB . . . . . . . . . . . . . . . . . . . . 59

30 ACDRA - Arquivo de resultados esperados . . . . . . . . . . . . 60

31 ACDRA - Arquivo de resultados reportados . . . . . . . . . . 60

32 ACDRA - Arquivo de configurações . . . . . . . . . . . . . . 61

33 ACDRA - Arquivo de resultados da análise automática dos resultados . . . 62

34 Exemplo de estrutura de diretórios para execução da ACDRA . . . . . . . 63

35 Comando para executar a ACDRA .................... 63

36 Análise interprocedimental em bytecodes . . . . . . . . . . . . 66

37 Análise interprocedimental em bytecodes . . . . . . . . . . . . . 67

38 Análise interprocedimental em bytecodes . . . . . . . . . . . . . 67

39 Análise interprocedimental em bytecodes . . . . . . . . . . . . . . 68

40 Passos para a geração de GDPs na BJCD após as melhorias . . . . . . . . . 69

41 Algoritmo para construir grafos de fluxo de controle . . . . . . . . . . . . 71

42 Exemplo de dependências múltiplas de fluxo de controle . . . . . . . . . . . 71

43 Arquitetura em alto nível do detector interprocedimental de clones semânticos 73 
44 Pseudocódigo de heurísticas de detecção interprocedimental de clones . . 74

45 Métodos com nomes iguais na mesma classe, mas com comportamentos

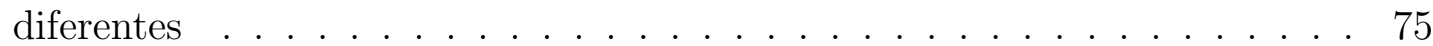

46 Configuração de filtro de tamanho mínimo de GDP na BJCD . . . . . . . . 76

47 Configuração de análise interprocedimental na BJCD . . . . . . . . . . . . 78

48 Novas chamadas a fireEditingStopped() e fireEditingCanceled() . . . . . . . 82

49 Novos códigos para fireEditingStopped() e fireEditingCanceled() . . . . . . 83

50 Arquitetura de alto nível da ACDRA . . . . . . . . . . . . . . . . 100 


\section{Lista de Tabelas}

1 Critérios de busca utilizados na máquina de busca ACM Digital Library . . 20

2 Critérios de busca utilizados na máquina de busca IEEE Xplore . . . . . . 20

3 Critérios de busca utilizados na máquina de busca Springer Link . . . . . . 21

4 Critérios de busca utilizados na base indexada Google Acadêmico . . . . . . 21

5 Critérios de busca utilizados na base indexada ScienceDirect . . . . . . . . 22

6 Tipos de artigos selecionados na revisão . . . . . . . . . . . . . . . . . . . 22

$7 \quad$ Estruturas de dados utilizadas na detecção de clones . . . . . . . . . . . 32

8 Tipos de técnicas de detecção de clones semânticos . . . . . . . . . . . . . 33

$9 \quad$ Filtros heurísticos para melhorar o desempenho das técnicas . . . . . . . . 33

10 Citações de pontos positivos de técnicas de detecção de clones semânticos 34

11 Citações de deficiências de técnicas de detecção de clones semânticos . . . 34

12 Tipos de avaliação de técnicas de detecção de clones semânticos . . . . . . 35

13 Dados para avaliações de detecção de clones semânticos . . . . . . . . . . 36

14 Programas selecionados para compor o benchmark . . . . . . . . . . . . 42

15 Comparação de classificações de candidatos a clones . . . . . . . . . . . . 47

16 Disponibilização de pares de clones a programadores . . . . . . . . . . . . . 49

17 Consolidação de pares de código sorteados . . . . . . . . . . . . . 50

17 Consolidação de pares de código sorteados . . . . . . . . . . . . . . . 51

17 Consolidação de pares de código sorteados . . . . . . . . . . . . . . . 52

18 Consolidação das avaliações dos experimentos . . . . . . . . . . . . . . . . 57

19 Propriedades do arquivo de configurações da ACDRA . . . . . . . . . . . . 61 
20 Comparação das execuções da BJCD baseada na JaBUTi contra a BJCD baseada na ASM . . . . . . . . . . . . . . . . . . . . 72

21 Avaliação de filtro de número mínimo de nós de GDPs para jtopas-0.8 . 77

22 Avaliação de filtro de número mínimo de nós de GDPs para checkstyle-5.5 77

23 Avaliação de tempo da análise interprocedimental para jtopas-0.8 $\quad$. . . . 79

24 Avaliação de tempo da análise interprocedimental para checkstyle-5.5 . . . 79

25 Comparação de resultados da análise convencional com a interprocedimental 80 


\section{Capítulo 1}

\section{Introdução}

Fragmentos de código fonte que são similares segundo um critério pré-definido são chamados de clones [8]. Clones podem existir em códigos fontes de aplicativos por diferentes motivos. Leitão (2004) explica que clones podem ser inseridos em aplicativos por serem uma maneira simples de reúso, o que diminui o tempo de desenvolvimento. Outro motivo que leva à existência de clones é a aplicação de padrões de codificação no aplicativo. No entanto, trechos similares de código fonte não são necessariamente oriundos de cópia e colagem de código. A falta de comunicação entre programadores que estão trabalhando em um mesmo aplicativo também pode levar à introdução de clones. Pode ocorrer de dois ou mais programadores escreverem procedimentos ou funções similares para serem utilizados em partes distintas do mesmo aplicativo. Além disso, programadores inexperientes podem preferir copiar trechos de código fonte complexos e fazer pequenas alterações neles a alterar um outro que seja funcional. Esses motivos, dentre outros não citados, fazem com que a existência de clones seja comum na maioria dos sistemas. Apesar de facilitar o desenvolvimento inicial de sistemas, a clonagem de código tende a dificultar a manutenção.

Por exemplo, faz-se necessário realizar manutenções quando um comportamento indesejado é detectado em uma funcionalidade de um aplicativo. O trecho de código que contém o defeito inserido pelo programador deve ser corrigido e uma nova versão do sistema deve ser gerada e disponibilizada. Quando a clonagem de código é realizada em um aplicativo, há o risco de o fragmento de código fonte defeituoso ser clonado para diversas outras partes dele. Nesse caso, a atividade de manutenção exige que esses clones sejam identificados e que uma análise seja feita para saber se estão tendo o comportamento esperado ou se correções também devem ser feitas nesses trechos de código fonte. O mesmo se aplica quando há outras situações que demandam que o código fonte seja alterado, como uma mudança de requisitos de negócios. Quanto mais clones um aplicativo possuir de um trecho de código fonte que necessite de manutenção, mais custosa será a atividade, pois mais trechos de código e funcionalidades do aplicativo deverão ser analisados. Identificar clones de um fragmento de código fonte em um aplicativo é uma atividade cuja complexidade varia de acordo com o tamanho desse aplicativo e com o tipo de modificações que 
foram realizadas pelos programadores após clonar o código. Se o aplicativo possuir muitos arquivos e procedimentos para serem analisados, será mais trabalhoso encontrar clones.

As modificações realizadas por programadores variam de simples alterações de comentários, espaços em branco e identação a alterações de nomes de parâmetros e variáveis, reordenação de comandos existentes no código original e adição de novos comandos [8]. Clones podem surgir ainda de trechos de código que não foram copiados, mas escritos por programadores diferentes em um mesmo aplicativo. Nesses casos, trechos de código fonte totalmente diferentes sintaticamente podem ainda assim serem similares semanticamente, ou seja, dados os mesmos parâmetros e condições de entrada, os fluxos de dados e controle dos dois trechos podem ser similares. Clones com essa natureza são chamados de clones semânticos. A detecção manual de clones pode não ser intuitiva ou trivial nesses cenários.

Nesse sentido, a utilização de ferramentas que automatizam a tarefa de detectar clones é desejável. Essas ferramentas empregam técnicas sistemáticas de detecção de clones [8]. Por serem processadas por computadores, tendem a ser mais rápidas do que a análise manual de um programador. Como as técnicas aplicadas por essas ferramentas são sistemáticas, o processo de detecção de clones torna-se menos propenso a falhas humanas e clones não triviais de identificar durante o processo de análise manual são mais facilmente identificados.

\subsection{Motivação}

Segundo a avaliação de Roy, Cordy e Koschke (2009), as ferramentas de detecção automática de clones são capazes de identificar clones de acordo com um determinado limite no que se refere às alterações realizadas por programadores. Algumas ferramentas são capazes de detectar somente clones nos quais os comentários, espaços em branco e identação foram alterados. Por outro lado, outras ferramentas são capazes de detectar clones de acordo com a semântica do código fonte ao invés de sua sintaxe. Clones nos quais comandos foram reordenados são detectáveis por essas ferramentas. São as técnicas de detecção de clones e de normalização de código fonte empregadas pelas ferramentas que definem quais tipos de alteração elas podem identificar. Cada grupo de técnicas de deteç̧ão de clones possui vantagens e desvantagens e é aplicável em situações distintas. Em cenários de manutenção de aplicativos, em que também é interessante detectar clones semânticos, a utilização de ferramentas baseadas em técnicas semânticas é indicada.

Segundo Liu et al. (2006) e Gabel, Jiang e Su (2008), as ferramentas atuais de detecção 
de clones semânticos são capazes de identificar esses clones com altas taxas de acerto. No entanto, essas ferramentas não são capazes de analisar os fluxos de dados e controle de fragmentos de código fonte considerando também os fluxos dos procedimentos ou funções que são invocados dentro desses fragmentos. Essa limitação pode levar as ferramentas a indicarem falsos positivos de clones semânticos.

Quanto menos falsos positivos forem reportados pelas ferramentas que automatizam o processo de detecção de clones, menor será o trabalho de análise dos programadores durante o processo de manutenção. Os objetivos desta pesquisa são baseados na motivação exposta.

As ferramentas atuais de detecção de clones semânticos são capazes de detectar clones em procedimentos considerando as dependências de dados e controle presentes em seus Grafos de Dependência de Programas (GDPs) [10]. Essas técnicas, porém, não consideram as chamadas de procedimentos que são realizadas dentro dos nós dos GDPs. Essa deficiência das ferramentas pode levá-las a reportar falsos positivos em alguns casos.

Os exemplos das Figuras 1 e 2 ilustram dois métodos de programas Java cujos GDPs possuem os mesmos fluxos de dados e controle. Esses métodos, porém, fazem internamente chamadas a métodos que realizam tarefas distintas. A chamada System.out.println(b) no metodo1(), da Figura 1, imprime valor de b no console. Já a chamada System.out.println(b) no metodo2(), da Figura 2, utiliza a classe System contida no próprio arquivo Java. Essa chamada soma 1 ao valor de $b$ e retorna o novo valor.

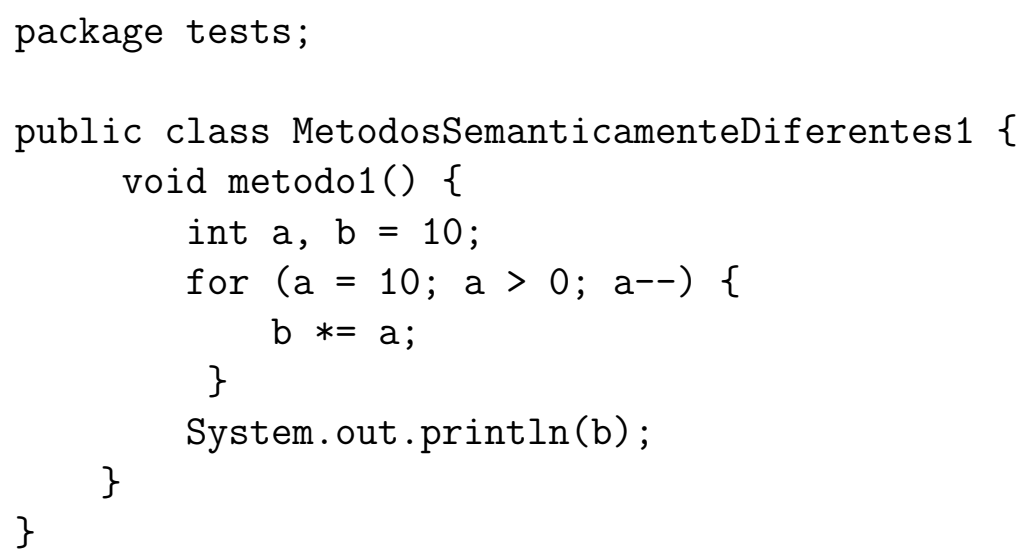

Figura 1 - System.out.println() imprime b no console

Ferramentas de detecção semântica de clones atuais, mesmo as que são baseadas em comparação textual das instruções dos nós dos GDPs, reportariam esses dois métodos como clones semânticos com 100\% de similaridade. Porém, conforme observado nos exemplos, esses métodos possuem comportamentos diferentes se as chamadas internas 


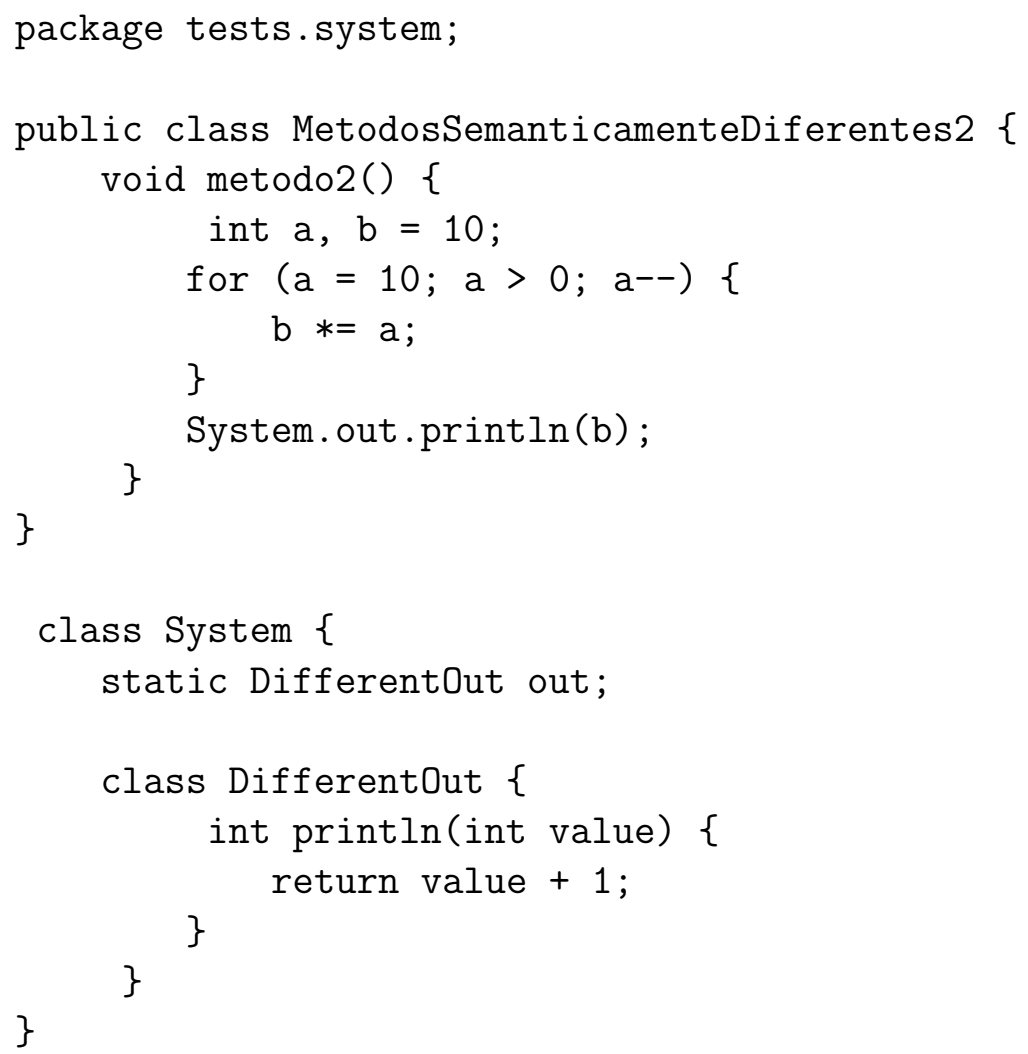

Figura 2 - System.out.println() retorna b +1

de métodos forem consideradas.

\subsection{Objetivos}

O objetivo geral da pesquisa foi elaborar uma técnica de detecção de clones semânticos levando em consideração as chamadas de procedimentos.

Objetivos específicos da pesquisa foram:

- desenvolver uma técnica de análise interprocedimental de clones semânticos;

- desenvolver uma ferramenta capaz de gerar grafos de dependência de programas;

- desenvolver uma ferramenta capaz de identificar clones semânticos a partir de grafos de dependência de programas, realizando análises interprocedimentais;

- elaborar um benchmark para poder avaliar a técnica proposta;

- avaliar a técnica proposta em comparação à não utilização de análises interprocedimentais com a utilização do benchmark criado. 
Uma nova técnica de deteç̧ão de clones semânticos foi proposta nesta pesquisa e uma ferramenta foi criada para validá-la. Essa técnica propõe analisar chamadas de procedimentos dos fragmentos de código fonte comparados para detectar diferenças semânticas. Uma pesquisa foi conduzida com programadores da indústria e da academia para que um benchmark de detectores de clones fosse criado. Esse benchmark foi utilizado para comparar uma abordagem de detecção de clones semânticos sem chamadas interprocedimentais com uma abordagem utilizando essa técnica. Os resultados da comparação mostraram que a técnica de detecção de clones interprocedimentais apresenta uma taxa de acertos maior em comparação às técnicas convencionais. Essa taxa foi de 97,5\% para a técnica interprocedimental contra $95 \%$ da técnica convencional. No entanto ela necessita de um maior tempo para ser executada, sendo que a diferença pode chegar a 33,84\%. A técnica proposta pode ser utilizada para auxiliar na execução de atividades de manutenção, evolução, refatoração [11] e entendimento de programas.

\subsection{Organização do texto}

O restante do texto está dividido como se segue. O Capítulo 2 é dedicado à explicação dos conceitos fundamentais necessários para o entendimento do trabalho desenvolvido. O Capítulo 3 apresenta o levantamento bibliográfico realizado com o intuito de estudar técnicas de detecção de clones semânticos. Esse capítulo também contém um resumo dos artigos estudados. O Capítulo 4 apresenta o processo de criação do benchmark de detectores de clones. O Capítulo 5 descreve a técnica de detecção de clones interprocedimental, assim como seu desenvolvimento na plataforma Java e sua validação. Por fim, o Capítulo 6 contém a conclusão, as contribuições da pesquisa e os trabalhos futuros. 


\section{Capitulo 2}

\section{Conceitos Fundamentais}

Este capítulo tem como objetivo apresentar os conceitos fundamentais para o entendimento da pesquisa realizada. Os conceitos de grafos de fluxo de controle, definições e usos, grafos de dependência de programas, clones e técnicas de detecção de clones são apresentados.

\subsection{Grafos de fluxo de controle (GFC)}

Um GFC é um grafo orientado, com um nó de entrada e um nó de saída, que representa a decomposição de um programa em conjuntos disjuntos de comandos [12]. Segundo Maldonado, Barbosa e Vincenzi (2004), um GFC pode ser representado como $G=(N, E$, $s$ ), onde $N$ é o conjunto de nós, $E$ o conjunto de arestas e $s$ o nó de entrada. Cada nó do grafo representa um bloco de comandos, no qual a execução do primeiro comando resulta nas execuções dos outros comandos existentes nesse mesmo bloco, sequencialmente. Cada bloco tem um ou mais predecessores e um ou mais sucessores, com exceção do primeiro, que não tem predecessor e do último, que não tem sucessor. As arestas do grafo de fluxo de controle representam os possíveis desvios que podem existir entre os blocos.

A Figura 3 ilustra o corpo do método replaceVariables(), retirado de Koskela (2008), com as linhas numeradas e a Figura 4 ilustra o grafo de fluxo de controle desse método. A identificação dos blocos de instruções é o número da linha da primeira instrução contida em cada bloco.

1. String result = this.templateText;

2. for (Entry<String, String> entry : this.variables.entrySet ()$)\{$

3. String regex $=" \backslash \backslash \$ \backslash \backslash\{"+$ entry.getKey ()$+" \backslash \backslash\} "$;

4. result $=$ result.replaceAll (regex, entry.getValue ()$)$;

5. $\}$

6. return result;

Figura 3 - Corpo do método replaceVariables().

Fonte: Koskela (2008) 


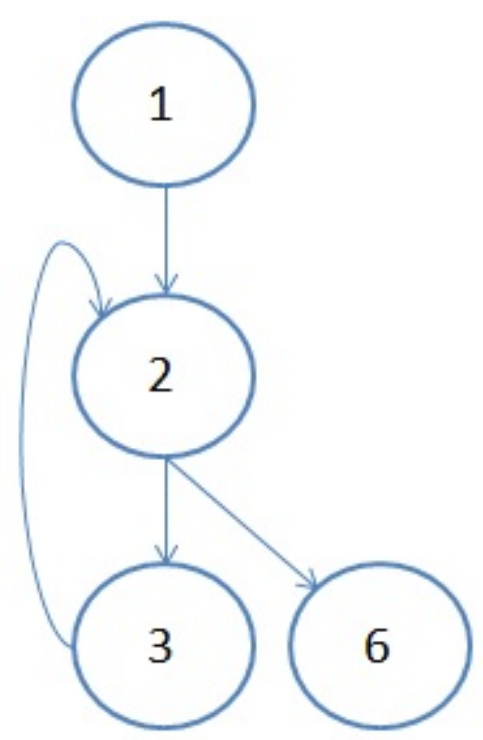

Figura 4-Grafo de fluxo de controle do método replaceVariables()

Os GFCs são utilizados na geração de grafos de dependência de programas, que por sua vez são usados nas técnicas de detecção de clones semânticos.

\subsection{Conceitos de definição e uso de variáveis}

Uma variável é definida, em geral, quando ela está do lado esquerdo de uma operação de atribuição, quando ela está em uma operação de entrada ou quando está em chamadas de procedimentos como parâmetro de saída. Quando uma variável não estiver sendo definida, está ocorrendo um uso dessa variável. Há dois tipos de usos de variáveis, que são o c-uso e p-uso. O c-uso (uso computacional) afeta uma computação que está sendo realizada ou permite a visualização do resultado de uma definição anterior; o p-uso (uso predicativo) afeta o fluxo de controle do programa.

Uma maneira de representar as definições e usos de variáveis é o grafo proposto por Rapps e Weyuker (1982), chamado grafo def-uso, uma extensão do GFC. Sua estrutura básica é a mesma que a do GFC, porém são adicionadas informações de definições e usos de variáveis aos nós e às arestas. A Figura 5 contém um programa elaborado que ordena um vetor de inteiros. Os números inseridos dentro de comentários referem-se aos nós aos quais cada comando está associado. Ela também apresenta o grafo de fluxo de controle obtido a partir do programa.

Os conceitos de definição e uso, assim como GFCs, são utilizados na geração de grafos de dependência de programas. 


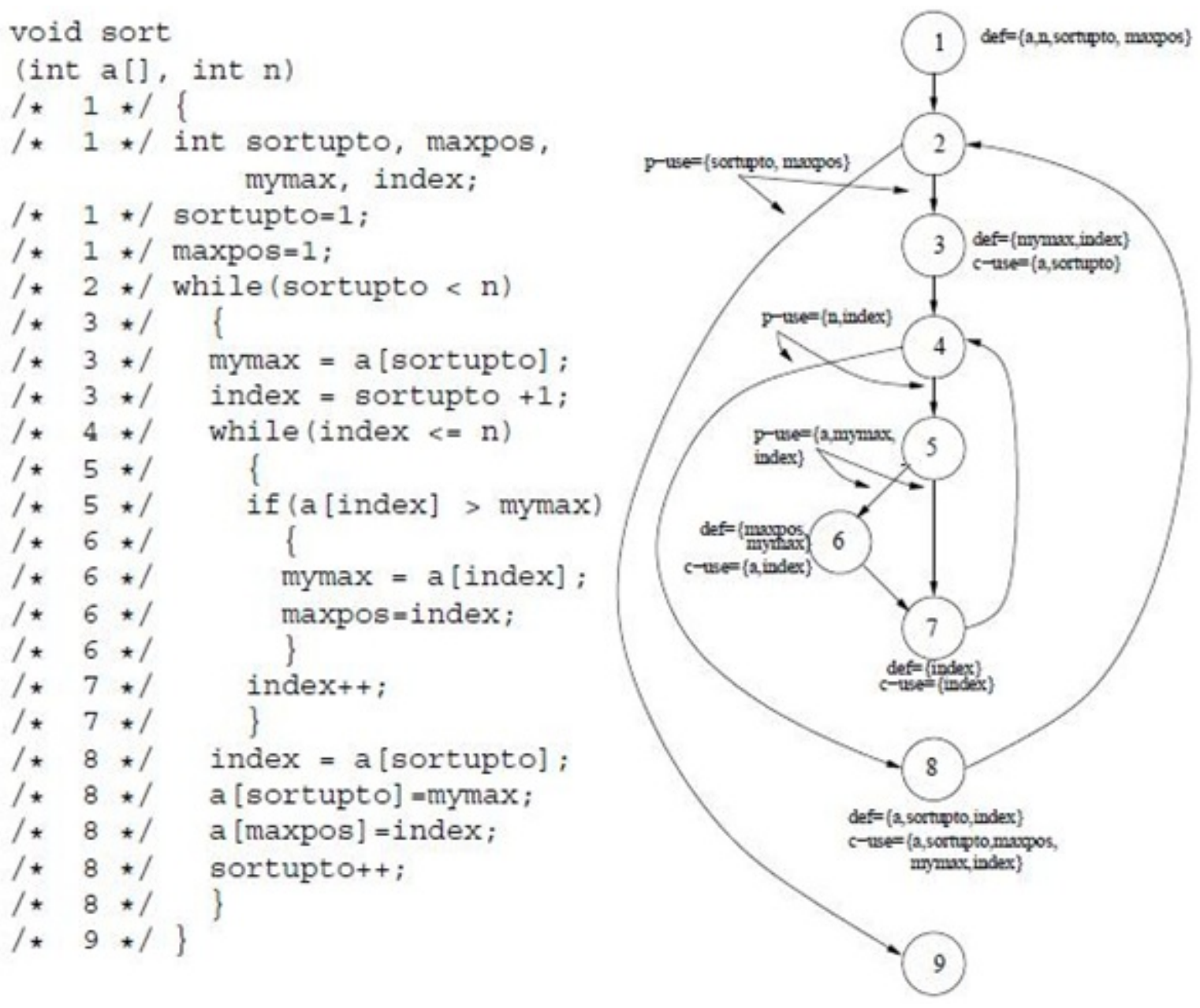

Figura 5 - Programa sort e seu grafo def-uso

\subsection{Grafos de dependência de programas (GDP)}

GDPs são grafos que explicitam tanto as dependências de dados quanto as de controle de programas. Cada vértice de um GDP representa um predicado ou um comando de um programa. As arestas que chegam a um vértice podem ser arestas de dados ou fluxos de controle dos quais o predicado ou comando representado por esse vértice depende [10].

As próximas subseções estão organizadas conforme se segue. A primeira subseção define o conceito de dependência de dados. A subseção seguinte define o conceito de dependência de controle. A terceira subseção é dedicada à ilustração da criação de um GDP, dado um fragmento de código fonte. A subseção final apresenta algoritmos para a criação de GDPs. 


\subsubsection{Dependências de dados}

Uma dependência de dados ocorre quando, dados dois comandos ou predicados $X$ e $Y$, sendo que $X$ ocorre antes que $Y$ no fragmento de código fonte, $X$ define o valor de uma variável que $Y$ utiliza e não existe nenhum outro comando ou predicado entre $X$ e $Y$ que defina essa variável. Um exemplo de dependência de dados ocorre no código ilustrado na Figura 6. A linha 1 define o valor da variável $A$. A linha 2 utiliza a variável $A$ para definir o valor da variável $B$. Como não há nenhum comando ou predicado entre as linhas 1 e 2 que defina a variável $A$, a linha 2 tem uma dependência de dados com a linha 1. Esse exemplo é semelhante ao encontrado no trabalho de Ferrante, Ottenstein e Warren (1987).

$$
\begin{aligned}
& \text { 1: } A=1 \\
& 2: B=A * 3
\end{aligned}
$$

\section{Figura 6 - Dependência de dados}

Já no exemplo da Figura 7 a linha 1 define o valor da variável $A$, porém a linha 2 o redefine antes que a linha 3 a utilize para computar o valor da variável $B$. A linha 3 , portanto, possui dependência de dados somente com a linha 2.

$$
\begin{aligned}
& \text { 1: } A=1 \\
& \text { 2: } A=A+1 \\
& 3: B=A * 3
\end{aligned}
$$

Figura 7 - Dependência de dados com redefinição

Uma exceção para a redefinição de variáveis ocorre quando o valor de uma variável é redefinido dentro de uma condição. Dado que a redefinição está ocorrendo dentro da condição, ela pode não ocorrer se o predicado da condição for falso. O comando que utiliza a variável depende tanto da última definição que está fora da condição quanto da que está dentro dela. A Figura 8 ilustra esse caso. A linha 1 define o valor da variável $A$. A linha 2 redefine esse valor, porém dentro de uma condição. A linha 3 utiliza a variável $A$ para calcular o valor da variável $B$. Nesse caso, linha 3 depende tanto da linha 1 quanto da linha 2.

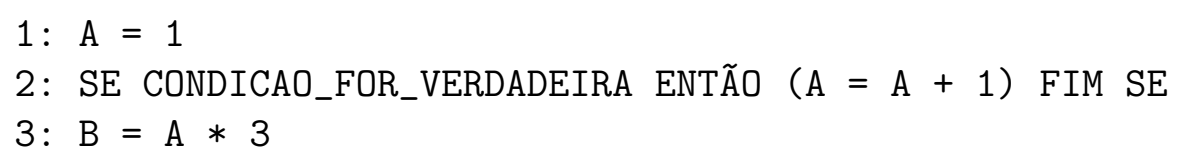

Figura 8 - Dependência de dados com redefinição dentro de condição 


\subsubsection{Dependências de controle}

Uma dependência de controle ocorre quando a execução de um comando ou predicado depende do resultado de outro predicado. É possível observar uma dependência de controle no fragmento de código fonte da Figura 9. O comando da linha 2 somente será executado se o predicado da linha 1 for verdadeiro. A linha 2, portanto, tem uma dependência de controle com a linha 1.

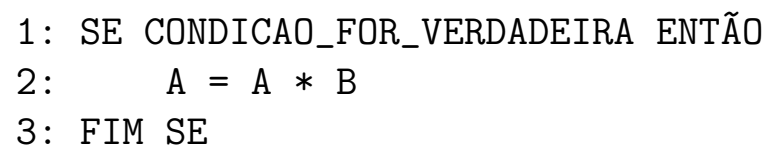

Figura $\boldsymbol{9}$ - Dependência de controle

\subsubsection{Exemplo de GDP}

Segundo Ferrante, Ottenstein e Warren (1987) há diversas maneiras de representar GDPs. Um exemplo de GDP pode ser visualizado na Figura 11. O grafo ilustrado nessa figura representa o método escrito na linguagem Java [15] contido na Figura 10. Um vértice no grafo foi atribuído para cada comando e predicado. As definições do parâmetro do método e da variável de retorno ocorrem no vértice 0 . O vértice 1 representa o predicado que testa o valor do parâmetro de entrada. O vértice 2 define a variável de retorno caso o predicado do vértice 1 seja verdadeiro. O vértice 3 retorna o valor definido no método.

As arestas foram definidas de acordo com o seguinte raciocínio. O vértice 1 depende da definição do parâmetro de entrada, portanto há uma aresta de dependência de dados do vértice 0 para o 1, pois o vértice 0 define esse parâmetro. É necessário que o predicado do vértice 1 seja verdadeiro para o comando no vértice 2 ser executado, portanto há uma aresta de dependência de controle do vértice 1 para o 2 . O comando contido no vértice 3 retorna o valor definido para a variável de retorno. Os vértices 0 e 2 podem definir esse valor, portanto há arestas provenientes desses vértices dirigindo-se para o vértice 3.

Dependências de dados são derivadas das relações de definições e usos de variáveis dos comandos e predicados, enquanto as dependências de controle são obtidas utilizando uma derivação da representação do GFC do programa. 


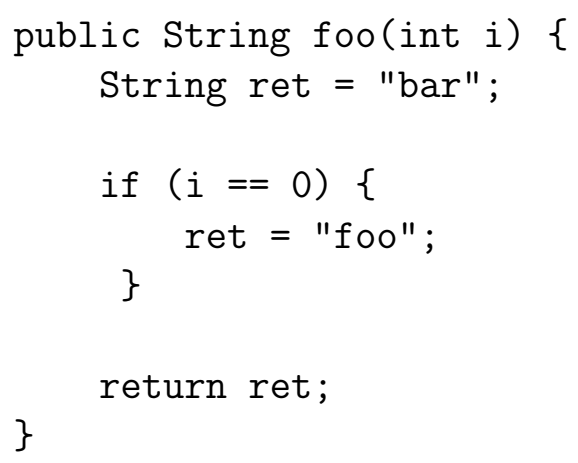

Figura 10 - Método foo(String)

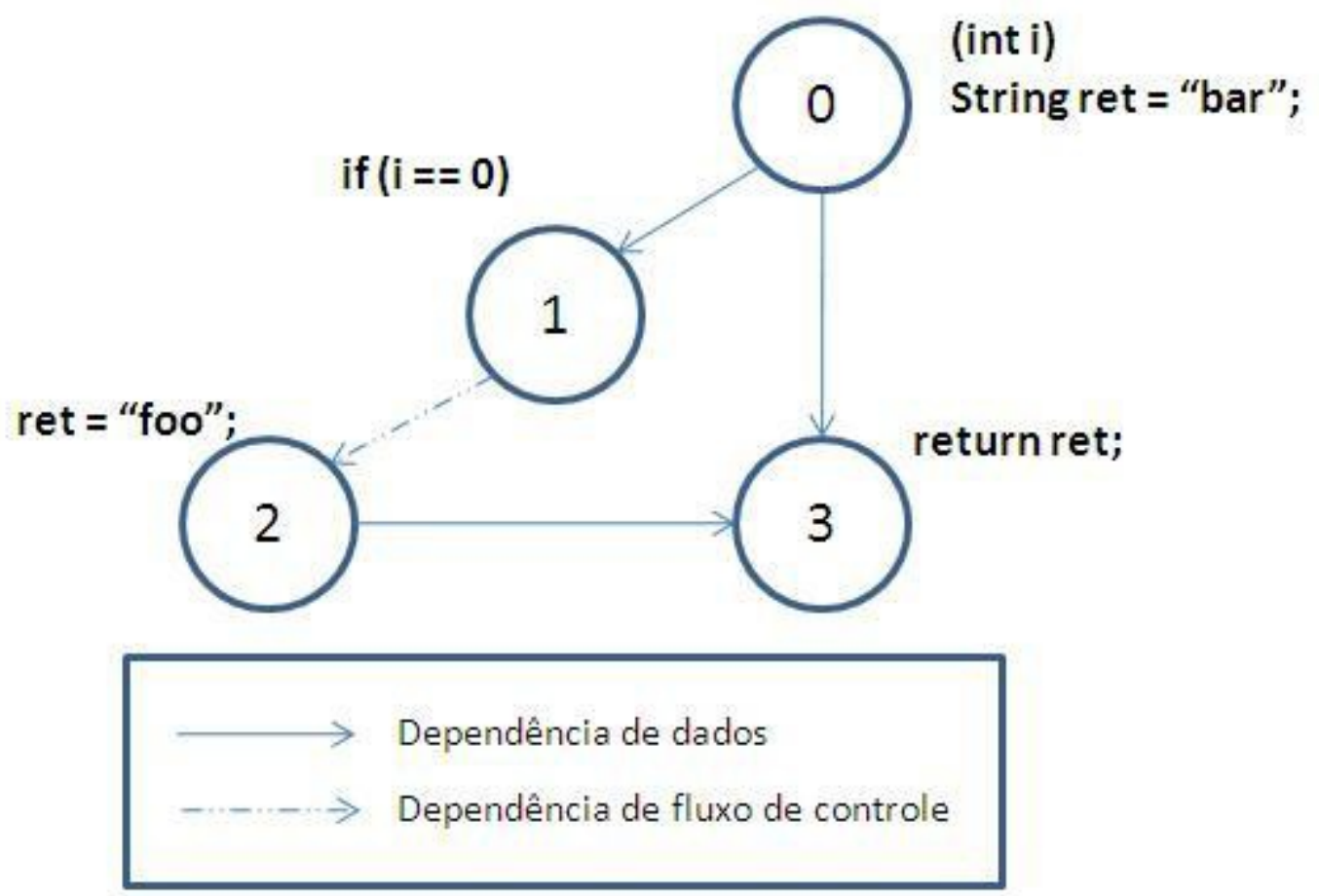

Figura 11 - GDP para o método foo(String)

\subsubsection{Algoritmos para a criação de GDPs}

Ferrante, Ottenstein e Warren (1987) e Harrold, Malloy e Rothermel (1993) propuseram algoritmos para a criação de GDPs.

O algoritmo de Ferrante, Ottenstein e Warren (1987) utiliza grafos de fluxo de controle, árvores de pós-dominância [17] e dados de definição e uso para a criação dos GDPs. O GFC e os dados de definição e uso são recebidos como entrada para o algoritmo. A partir do GFC, a árvore de pós-dominância é criada para então ser percorrida juntamente ao GFC para a definição das dependências de controle. Uma vez criado o subgrafo de dependência de controle, as dependências de dados são obtidas utilizando os dados de 
definição e uso para criação de subgrafos de dependência de dados, conforme descrito em Kuck et al. (1981). O GDP é derivado da união do subgrafo de dependência de controle com o de dependência de dados.

Harrold, Malloy e Rothermel (1993) propuseram um algoritmo que é incorporado ao compilador GNU C Compiler [19] e faz uso de árvores sintáticas abstratas para criar o subgrafo de dependência de controle e para coletar os dados de definição e uso. O algoritmo diferencia programas estruturados dos não estruturados para a construção do subgrafo. Programas não estruturados são aqueles que possuem o comando goto, enquanto os outros são estruturados, de acordo com os autores do algoritmo.

Ferrante, Ottenstein e Warren (1987) ressaltam que o espaço em memória requerido para a criação de GDPs pode ser grande dependendo da quantidade de dependências dados e controle. Harrold, Malloy e Rothermel (1993) destacam que as presenças de grafos de fluxo de controle e de árvores de pós-dominância influenciam no espaço e no tempo necessário para criar o GDP.

As complexidades assintóticas [20] de ambos os algoritmos apresentados para a criação de GDPs são $\mathrm{O}\left(n^{2}\right)$, sendo $n$ o número de nós do grafo de definição e uso que originou o GDP.

GDPs são utilizados por técnicas de detecção de clones semânticos. As próximas seções apresentam os conceitos de clones e detecção de clones, respectivamente. Diferentes tipos de técnicas de detecção de clones são apresentados na próxima seção.

\subsection{Clones}

De acordo com Roy, Cordy e Koschke (2009) dois fragmentos de código fonte são clones se forem similares. Há dois tipos principais de critérios de similaridade: texto e funcionalidade. As próximas subseções definem os tipos de similaridades de texto e de funcionalidade.

\subsubsection{Similaridade de texto}

A similaridade de texto leva em consideração os códigos fontes dos programas. Técnicas baseadas nesse tipo de similaridade podem detectar clones que contenham alterações em nomes de variáveis e funções, inserções de espaços em branco e comentários, formatação e outras alterações que influenciem diretamente no código fonte. Considerem-se os frag- 
mentos de códigos fontes das Figuras 12 e 13 como exemplo. O fragmento de código fonte da Figura 13 contém uma série de alterações realizadas no fragmento de código fonte original cuja função é identificar números pares, ilustrado na Figura 12. Um comentário foi adicionado, o nome da variável do tipo inteiro foi alterado de $i$ para $j$, as linhas em branco foram removidas e o comando if foi escrito em somente uma linha e sem as chaves. Ferramentas baseadas em técnicas de similaridade de texto devem ser capazes de identificar os fragmentos de códigos fontes das Figuras 12 e 13 como clones.

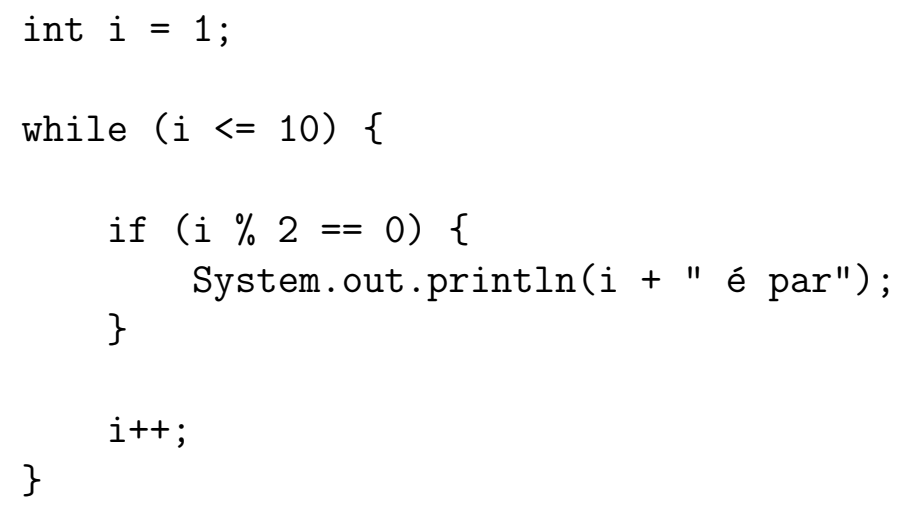

Figura 12 - Identificação de números pares original

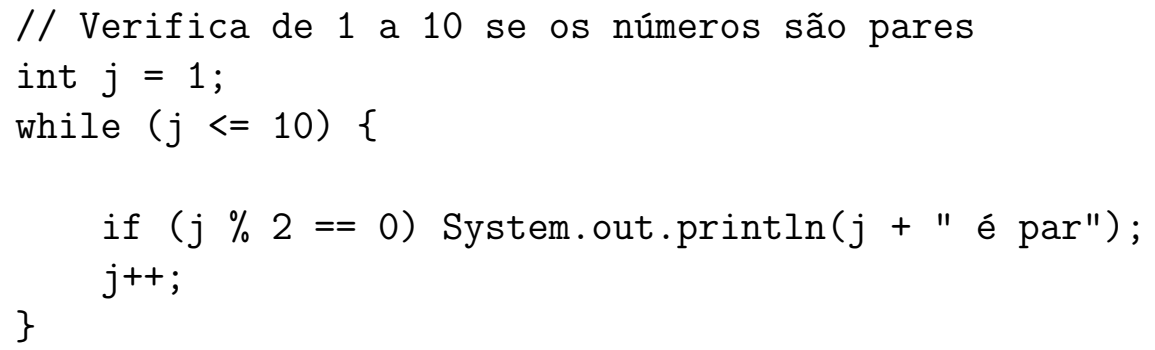

Figura 13 - Identificação de números pares com similaridade textual

\subsubsection{Similaridade de funcionalidade}

As técnicas baseadas em similaridade de funcionalidade, ou semântica, são capazes de detectar clones mesmo que haja grande variação nas sintaxes dos fragmentos de códigos fontes comparados. Considere o fragmento de código fonte da Figura 12.

O fragmento de código fonte da Figura 14 realiza a mesma funcionalidade, porém possui uma estrutura sintática diferente. Ao invés do laço while, um laço for com a mesma funcionalidade foi utilizado. A declaração da variável do tipo inteiro e o incremento dela estão dentro da declaração do laço ao invés de ocorrer uma linha antes e ao final dele, respectivamente. Ferramentas que utilizam técnicas baseadas em similaridade de 
funcionalidade devem ser capazes de identificar os fragmentos de códigos fontes 12 e 14 como clones.

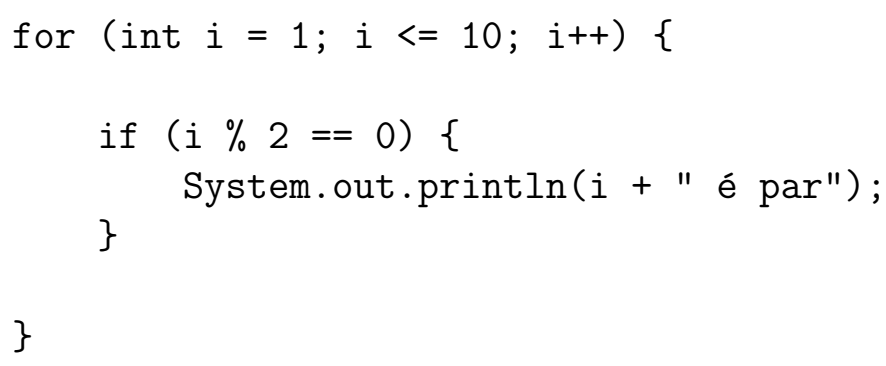

Figura 14 - Identificação de números pares com similaridade semântica

\subsection{Detecção de Clones}

Roy, Cordy e Koschke (2009) dividiram as técnicas de detecção de clones em cinco categorias. Os critérios para a classificação das técnicas foram o tipo de informação analisada e os tipos de técnicas de análise. As subseções seguintes descrevem as categorias de detecção de clones propostas pelos autores.

\subsubsection{Técnicas textuais}

As técnicas textuais utilizam diretamente o fragmento de código fonte do programa para detectar os potenciais clones. Em geral não são realizadas grandes alterações no fragmento de código fonte antes da análise [8].

Uma técnica popular para análise textual é a utilização de "impressões digitais" [21]. Números identificadores são atribuídos a cada fragmento de código fonte, e depois comparados. Fragmentos de códigos fontes clonados são aqueles que possuem números iguais.

Outra técnica utilizada é a proposta por Ducasse, Rieger e Demeyer (1999), conhecida como dot plots. Nessa técnica as linhas dos fragmentos de códigos fontes são inseridas em um plano cartesiano de duas dimensões, onde um ponto é identificado por uma coordenada $(x, y)$. Os valores de $x$ e $y$ são os números identificadores das linhas do primeiro e do segundo fragmento de código fonte, respectivamente. Se $x$ e $y$ forem iguais, as linhas são consideradas clones. Clones podem, portanto, ser identificados como diagonais no plano cartesiano de duas dimensões. 


\subsubsection{Técnicas léxicas}

As técnicas léxicas inicialmente transformam os fragmentos de códigos fontes em tokens léxicos, como os utilizados em compiladores [23]. Os tokens, em seguida, são varridos em busca de réplicas.

Segundo Roy, Cordy e Koschke (2009) técnicas léxicas são, em geral, mais robustas que as textuais quando há alterações menores nos fragmentos de códigos fontes. Formatação, alteração de nomes de variáveis e adição de espaços são exemplos dessas alterações.

As abordagens de Baker (1992) e Kamiya, Kusumoto e Inoue (2002) são exemplos de técnicas de análise léxica. Ambas são capazes de identificar os mesmos tipos de clones. A última técnica difere-se da primeira por ser capaz de remover diferenças superficiais no fragmento de código fonte. A presença ou não de chaves do corpo de um comando if na linguagem Java é um exemplo de diferença superficial.

Baker e Manber (1998) criaram uma técnica que utiliza como base técnicas léxicas para a detecção de clones a partir da leitura de bytecodes compilados para a Java Virtual Machine (JVM) [27].

\subsubsection{Técnicas sintáticas}

As técnicas sintáticas convertem os fragmentos de códigos fontes em árvores sintáticas abstratas [23] ou GFCs antes da análise. Existem dois principais tipos de técnicas sintáticas para detecção de clones: as baseadas em comparação de árvores e as baseadas em métricas.

As técnicas baseadas em comparação de árvores detectam clones utilizando a busca de subárvores similares nas árvores sintáticas abstratas. A ferramenta CloneDr, proposta por Baxter et al. (1998), utiliza uma técnica baseada em comparação de árvores.

O segundo tipo de técnicas de análise sintática são as técnicas baseadas em métricas. As definições de variáveis, funções, classes, comandos e outras formas sintáticas são utilizadas para o cálculo de métricas que servem como base para a comparação de fragmentos de códigos fontes. Em algumas abordagens, como a de Mayrand, Leblanc e Merlo (1996), os nomes atribuídos, as expressões e o fluxo de controle também são utilizados para o cálculo das métricas. 


\subsubsection{Técnicas semânticas}

Essa categoria compreende as técnicas de detecção de clones semânticos. Os GDPs são utilizados para a identificação dos clones na maior parte das abordagens propostas nessa categoria.

Segundo Roy, Cordy e Koschke (2009) as técnicas semânticas diferem das sintáticas na forma de tratar a ordem das expressões e do fluxo de controle no fragmento de código fonte. Nas técnicas semânticas as expressões e o fluxo de controle são considerados independentes, pois as ordens de ocorrência no fragmento de código fonte não importam. Já nas técnicas sintáticas as ordens de ocorrência das expressões e do fluxo de controle são relevantes. Esse aspecto possibilita que clones com comandos reordenados ou com novos comandos entrelaçados possam ser encontrados com essas técnicas, desde que não haja alterações nos fluxos de dados e controle [2].

Komondoor e Horwitz (2001) criaram uma ferramenta que utiliza grafos de dependência de programas para detectar clones utilizando fatiamento de programas [30]. Krinke (2001) desenvolveu um algoritmo para a detecção de clones com grafos de dependência de programas granulares. São grafos de dependência de programas semelhantes a árvores sintáticas abstratas. Liu et al. (2006), Gabel, Jiang e Su (2008) e Albuquerque, Neves e Chaim (2012) também criaram técnicas de detecção de clones semânticos.

A técnica proposta nesta pesquisa pertence ao grupo de técnicas de detecção de clones semânticos, portanto as essas técnicas são analisadas em detalhe na Seção 3.2.

\subsubsection{Técnicas híbridas}

A última categoria contém as técnicas híbridas de detecção de clones. As abordagens dessa categoria combinam as técnicas dos quatro outros grupos.

Leitão (2004) criou uma ferramenta que combina técnicas sintáticas com técnicas semânticas. As técnicas sintáticas utilizam as árvores sintáticas abstratas enquanto as semânticas utilizam grafos de chamadas [31].

Baker e Manber (1998) combinaram as técnicas léxicas utilizadas pela ferramenta Dup [32] com as textuais da ferramenta Siff [33] para detectar clones provenientes de bytecodes. 


\subsection{Conclusão do capítulo}

Os conceitos básicos para a detecção de clones semânticos foram apresentadas neste capítulo. Primeiro, grafos de fluxo de controle e definições e usos foram definidos e explicados. Grafos de dependência de programas foram então apresentados e dois algoritmos para criação de grafos de dependência de programas foram sucintamente apresentados. Os conceitos de clones e de detecção de clones foram definidos. As técnicas de detecção de clones foram apresentadas no final do capítulo.

A técnica proposta nesta pesquisa tem como intuito detectar clones semânticos, portanto um capítulo foi dedicado ao entendimento específico de técnicas semânticas. O próximo capítulo apresenta um levantamento bibliográfico sobre essas técnicas. 


\section{Capítulo 3}

\section{Levantamento Bibliográfico}

Os procedimentos realizados para o levantamento bibliográfico acerca das técnicas de detecção de clones semânticos são explicados neste capítulo. Dados relevantes dos artigos retornados pelo levantamento bibliográfico foram sumarizados e relações entre esses artigos foram analisadas. Uma discussão sobre o levantamento e sobre os artigos retornados por ele é apresentada no final do capítulo.

\subsection{Definição do levantamento bibliográfico}

O levantamento bibliográfico realizado teve como objetivo identificar as técnicas de detecção de clones semânticos existentes. Os pontos fortes e as deficiências das técnicas foram elencados. Outro objetivo do levantamento foi identificar formas de avaliação e comparação de técnicas de detecção de clones semânticos. Benchmarks e comparações entre técnicas já desenvolvidas na literatura estavam no escopo dessa revisão.

\subsubsection{Questão que guiou o levantamento}

Uma questão foi elaborada para que os objetivos do levantamento fossem alcançados:

Quais são as técnicas existentes para realizar a detecção de clones semânticos?

O escopo do levantamento foi definido com base nessa questão.

\subsubsection{Escopo dos estudos}

Os objetos do levantamento foram artigos que apresentam técnicas de detecção de clones semânticos e tenham algum tipo de avaliação delas. Artigos que apresentam novas técnicas de detecção de clones e surveys que citam esses artigos foram selecionados.

Somente os artigos publicados a partir de janeiro de 2006 foram considerados. Essa data foi escolhida para delimitar os resultados retornados pela pesquisa, trazendo apenas 
os artigos mais recentes. Artigos publicados em datas anteriores que foram citados nos artigos mais recentes foram adicionados à revisão.

Somente artigos na língua inglesa estavam no escopo desta revisão. O idioma é amplamente aceito em trabalhos científicos de periódicos e conferências da área. Além disso, todos os principais trabalhos da área estão escritos nesse idioma.

As bases digitais online ACM Digital Library ${ }^{1}$, IEEE Xplore ${ }^{2}$ e Springer Link ${ }^{3}$ e as bases indexadas Google Acadêmico ${ }^{4}$ e ScienceDirect ${ }^{5}$ foram utilizadas como fonte de pesquisa. Trabalhos anteriores relacionados à detecção de clones realizados pelo autor deste trabalho também foram considerados.

A estratégia de seleção dos artigos foi elaborada após a definição do escopo da pesquisa.

\subsubsection{Seleção dos artigos}

Cadeias de busca com palavras-chave definidas de acordo com o escopo de pesquisa e seus sinônimos foram construídas. As cadeias de busca foram submetidas às máquinas de busca das fontes selecionadas.

As cadeias de busca de pesquisa utilizadas para cada máquina de busca, assim como os demais parâmetros de busca estão descritas nas Tabelas 1, 2, 3, 4 e 5. Os termos clone detection e program dependence graph foram utilizados nas buscas. Artigos datados de janeiro de 2006 ou posteriores e publicados em periódicos e conferências foram selecionados. Artigos antigos citados naqueles inicialmente selecionados também foram adicionados. Alguns campos de filtro foram preenchidos, a depender da máquina de busca.

Novas pesquisas com os mesmos parâmetros de busca foram realizadas nas mesmas máquinas de busca, exceto pelo termo program dependence graph, que mudou para program dependency graph.

Após a leitura em alto nível dos artigos e a aplicação dos critérios de inclusão e exclusão, os trabalhos foram selecionados, uma vez que suas relevâncias foram confirmadas pelo revisor (no caso, o aluno). O orientador foi consultado quando houve dúvidas sobre as relevâncias dos artigos. A próxima subseção detalha a aplicação dos critérios de inclusão e exclusão dos artigos.

\footnotetext{
${ }^{1}$ http://dl.acm.org/

${ }^{2}$ http://ieeexplore.ieee.org

${ }^{3}$ http://www.springerlink.com/

${ }^{4}$ http://scholar.google.com.br/

${ }^{5}$ http://www.sciencedirect.com/
} 
Tabela 1 - Critérios de busca utilizados na máquina de busca ACM Digital Library

\begin{tabular}{c|c}
\hline Palavras-chave & "clone detection" "program dependence graph" \\
\hline Publicados desde & 2006 \\
\hline Tipos de publicação & Journal, Proceeding, Transaction e Magazine \\
\hline Texto presente em & Full text e Abstract \\
\hline
\end{tabular}

Tabela 2 - Critérios de busca utilizados na máquina de busca IEEE Xplore

\begin{tabular}{c|c}
\hline Palavras-chave & $\begin{array}{c}\text { AND .QT.clone detection.QT. AND } \\
\text {.QT.program dependence graph.QT. }\end{array}$ \\
\hline & em Todo o texto \& Metadados \\
\hline Editor & IEEE, AIP, IET, AVS e IBM \\
\hline Tipos de publicação & Conferences e Journals \\
\hline Período de publicação & Specify Range from 2006 To Present \\
\hline
\end{tabular}

\subsubsection{Critérios de inclusão e exclusão}

Os seguintes critérios de inclusão foram aplicados nos artigos retornados pela pesquisa:

- trabalhos que proponham técnicas de detecção de clones semânticos;

- surveys sobre detecção de clones que incluam técnicas de detecção de clones semânticos.

Os seguintes critérios de exclusão foram aplicados nos artigos retornados pela pesquisa:

- artigos não publicados em periódicos ou conferências;

- artigos que não contenham avaliações de técnicas de detecção de clones semânticos.

Os artigos que foram aceitos de acordo com os critérios de inclusão e exclusão citados foram sintetizados conforme descrito na próxima seção.

\subsubsection{Artigos selecionados}

Foram retornados 118 artigos na pesquisa. Esses artigos foram lidos e submetidos aos critérios de inclusão e exclusão descritos na Subseção 3.1.4. Após a aplicação dos critérios e descarte de artigos duplicados, oito artigos foram selecionados. Os artigos selecionados foram Liu et al. (2006), Bellon et al. (2007), Gabel, Jiang e Su (2008), Koschke (2008), 
Tabela 3 - Critérios de busca utilizados na máquina de busca Springer Link

\begin{tabular}{c|c}
\hline Palavras-chave & $\{$ clone detection $\}$ \{program dependence graph $\}$ \\
\hline & em Todo o texto \\
\hline Publicados desde & $1 / 1 / 2006$ \\
\hline Categoria & Only Journals \\
\hline
\end{tabular}

Tabela 4 - Critérios de busca utilizados na base indexada Google Acadêmico

\begin{tabular}{c|c}
\hline Palavras-chave & "clone detection" "program dependence graph" \\
\hline Exibir artigos publicados entre & 2006 \\
\hline & Com pelo menos um resumo \\
\hline
\end{tabular}

Roy e Cordy (2008), Roy, Cordy e Koschke (2009), Albuquerque, Neves e Chaim (2012) e Rattan, Bhatia e Singh (2013). Os artigos Komondoor e Horwitz (2001) e Krinke (2001), por serem citados pela maioria dos artigos selecionados e por apresentarem técnicas de detecção de clones semânticos, foram adicionados à revisão bibliográfica.

A Tabela 6 resume os tipos de artigos selecionados. Foram cinco artigos de novas técnicas $[1-3,5,6]$, quatro surveys $[8,34-36]$ e um artigo cujo intuito é avaliar técnicas existentes [4].

Os artigos de técnicas de detecção de clones semânticos são discutidos na próxima seção. A forma de avaliação de técnicas de detecção de clones aplicada por Bellon et al. (2007) também é discutida na próxima seção. As surveys não são apresentadas em detalhes por serem resumos de diversos artigos que apresentam técnicas de detecção de clones, mas seus dados são apresentados na Seção 3.3, de discussão.

\subsection{Trabalhos relacionados}

Esta seção contém resumos e discussões das técnicas de detecção de clones semânticos propostas pelos artigos estudados. As características das técnicas propostas por Komondoor e Horwitz (2001), Krinke (2001), Liu et al. (2006), Gabel, Jiang e Su (2008) e Albuquerque, Neves e Chaim (2012), assim como as formas de avaliação utilizadas pelos autores e suas conclusões são apresentadas. A avaliação realizada por Bellon et al. (2007) também é apresentada. 
Tabela 5 - Critérios de busca utilizados na base indexada ScienceDirect

\begin{tabular}{c|c}
\hline Palavras-chave & "clone detection" $A N D$ "program dependence graph" \\
\hline Incluir & em Todos os campos \\
\hline Período de publicação & Journals \\
\hline
\end{tabular}

Tabela 6 - Tipos de artigos selecionados na revisão

\begin{tabular}{c|c|c|c}
\hline Artigo & Nova Técnica & Survey & Avaliação de técnicas \\
\hline Bellon et al. (2007) & & & $\mathrm{X}$ \\
\hline Koschke (2008) & & $\mathrm{X}$ & \\
\hline Roy e Cordy (2008) & & $\mathrm{X}$ & \\
\hline Roy, Cordy e Koschke (2009) & & $\mathrm{X}$ & \\
\hline Komondoor e Horwitz (2001) & $\mathrm{X}$ & & \\
\hline Krinke (2001) & $\mathrm{X}$ & & \\
\hline Liu et al. (2006) & $\mathrm{X}$ & & \\
\hline Gabel, Jiang e Su (2008) & $\mathrm{X}$ & & \\
\hline Albuquerque, Neves e Chaim (2012) & $\mathrm{X}$ & & \\
\hline Rattan, Bhatia e Singh (2013) & & $\mathrm{X}$ & \\
\hline Total & 5 & 4 & \\
\hline
\end{tabular}

\subsubsection{Komondoor e Horwitz (2001)}

Komondoor e Horwitz (2001) criaram uma técnica baseada em fatiamento de programas para navegar nos GDPs referentes aos fragmentos de códigos fontes dos programas comparados e encontrar subgrafos isomorfos [37]. O algoritmo desenvolvido é dividido em três fases. A primeira é encontrar pares de clones, a segunda é remover pares de clones que estejam contidos em pares de clones maiores e a terceira é a combinação dos pares de clones restantes em busca de montar grupos maiores de clones.

A primeira fase do algoritmo é a mais importante e deve ser observada detalhadamente. Nessa fase, os GDPs dos fragmentos de código fonte são comparados e os nós são divididos em classes de equivalência com base na sintaxe do comando ou predicado presente neles. Os nós dos GDPs são comparados e pares são formados quando dois nós estão na mesma classe de equivalência. A técnica de fatiamento de programas é aplicada recursivamente a partir desses pares para encontrar os próximos nós que serão comparados, navegando pelas arestas de dependência de fluxo de dados e de controle em sentido contrário. Nos casos de nós que representam predicados, o fatiamento de progra- 
mas também é aplicado no sentido direto das dependências. O algoritmo somente para quando os nós comparados não estiverem na mesma classe de equivalência. Os grafos isomorfos são obtidos como resultado desse processo.

A Figura 15, retirada do artigo, ilustra a comparação de dois fragmentos de programas tendo como início os nós contendo o comando ${ }^{*} p++=c$; Esses grafos contém nós que representam esse comando, portanto o fatiamento continua sendo executado para os predecessores desses nós em seus respectivos GDPs. O algoritmo continua até a comparação do nó 5 do fragmento 1 com o 8 do fragmento 2. Por conterem condições diferentes dentro da definição do laço while, os nós foram classificados em classes de equivalência distintas. No final do processo, os conjuntos de nós $C 1=\{1 a, 2 a, 3 a, 4 a\}$ do fragmento 1 e $C 2=$ $\{1 b, 2 b, 3 b, 4 b\}$ do fragmento 2 são retornados como conjuntos de clones.

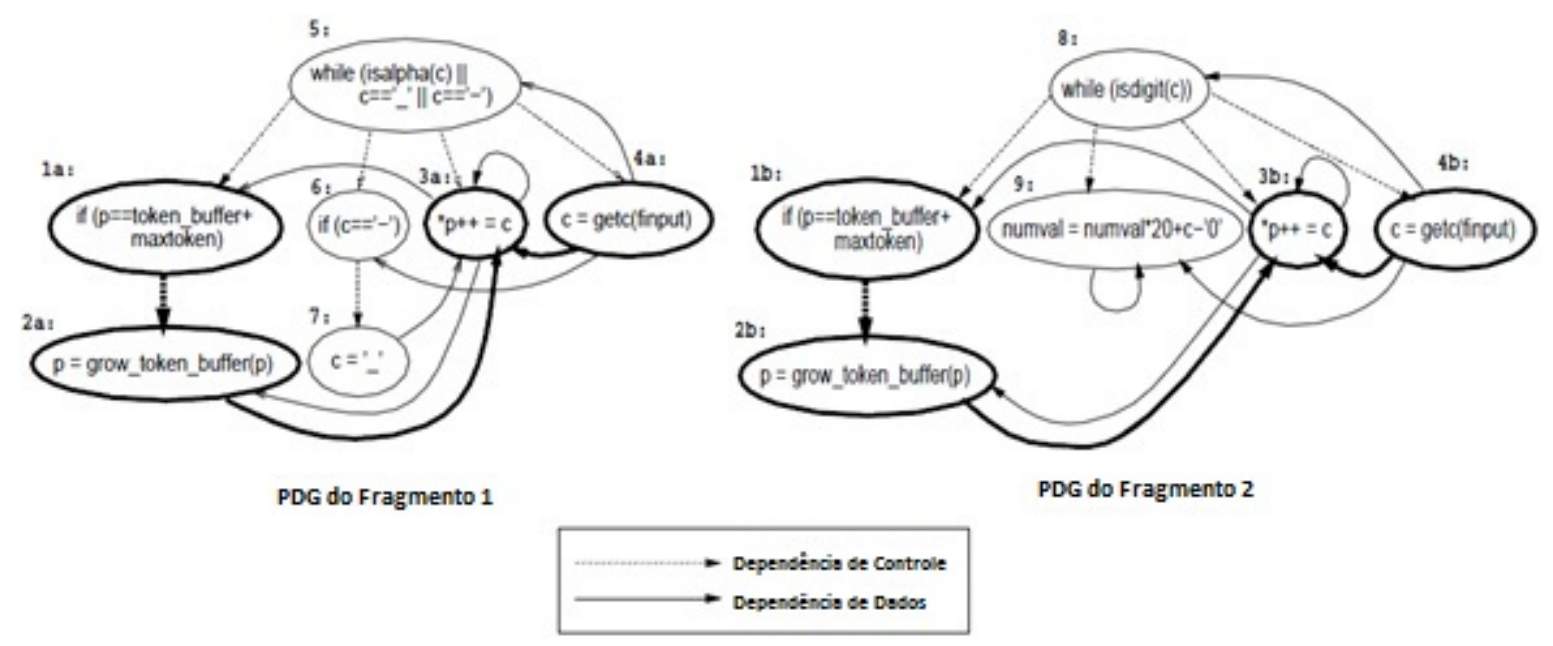

Figura 15 - Comparação de GDPs utilizando fatiamento de programas. Fonte: Komondoor e Horwitz (2001). Tradução livre.

Segundo os autores, os benefícios da abordagem são a capacidade de encontrar clones com comandos fora de ordem, emaranhados com outros comandos e não contíguos e a capacidade de encontrar fragmentos de código fonte candidatos à extração para novas funções.

A avaliação da técnica proposta ocorreu conforme se segue. Primeiramente, uma ferramenta que aplica o algoritmo foi desenvolvida para programas escritos na linguagem C [38]. Essa ferramenta foi submetida aos códigos fontes de três utilitários do Unix [39], que contém de 1.500, 2.445 e 11.540 linhas de código, respectivamente. Os tamanhos dos GDPs referentes aos utilitários e os tempos de execução para cada fase do algoritmo foram obtidos. Os autores analisaram os clones encontrados pela ferramenta e concluíram que ela foi capaz de encontrar os tipos de clones citados nos benefícios da abordagem, apresentados 
previamente. Os autores indicaram ainda uma limitação da ferramenta, que é encontrar muitas vezes variantes de clones ideais (que são aqueles que podem ser identificados por seres humanos) ao invés de encontrarem os próprios clones. Essas ocorrências levam a um número elevado de falsos positivos ${ }^{6}$.

Mais execuções da ferramenta foram realizadas, dessa vez com bibliotecas com menos linhas de código. Os objetivos eram entender o quanto a ferramenta era capaz de encontrar clones ideais ou suas variantes, saber quantos clones "desinteressantes" a ferramenta encontrava e saber a proporção de clones fora de ordem, emaranhados ou não contíguos que ocorriam na prática em programas. Os pesquisadores selecionaram um subconjunto não especificado de clones, analisaram-nos, destacaram manualmente os clones considerados ideais, fora de ordem, emaranhados e não contíguos e mostraram as quantidades encontradas de cada um desses tipos de clone. Finalmente, os autores extraíram os clones do código fonte original e apresentaram o percentual de redução obtido. Esse percentual foi de $1,9 \%$ no pior caso e de $4,9 \%$ no pior caso.

Os autores concluíram que a técnica criada é capaz de encontrar tipos de clones que outras técnicas não conseguiriam encontrar, especialmente os que envolvem clones não contíguos, fora de ordem, emaranhados e com alteração de nomes de variáveis. Ainda segundo os autores, a ferramenta criada raramente deixa de reportar clones ideais e raramente reporta clones desinteressantes. Os autores alegaram que a lentidão na execução da ferramenta ocorreu devido ao modo que o algoritmo foi desenvolvido e não por causa da abordagem de utilização de GDPs com fatiamento de programas. O número de variantes de clones ideais encontrados pela ferramenta também foi apontado como um problema encontrado na ferramenta.

\subsubsection{Krinke (2001)}

Krinke (2001) utilizou GDPs granulares como estrutura de dados para detectar clones. O GDP granular é uma especialização daquele definido por Ferrante, Ottenstein e Warren (1987) e é similar a uma árvore sintática abstrata. Declarações de variáveis e de procedimentos ganham vértices nesse tipo de GDP. Todos os nós possuem uma classe (comando, expressão ou chamada de procedimento, por exemplo), um operador (um tipo ou constante, por exemplo) e um valor. O GDP granular também possui arestas especiais: arestas de dependência imediata de controle, dependência de valor e dependência de referência. A diferença entre as arestas de valor e de referência é que, para um nó

\footnotetext{
${ }^{6} \mathrm{O}$ número não foi apresentado pelos autores
} 
$n$ ser dependente de um nó $p$ por valor, basta o valor de uma variável computada em $p$ ser utilizado por $n$ enquanto a dependência por referência exige que o valor da variável computada em $p$ seja guardado em alguma variável de $n$. A Figura 17 ilustra um trecho de um GDP granular referente ao fragmento de código fonte contido na Figura 16. Ambas as figuras foram retiradas do artigo.

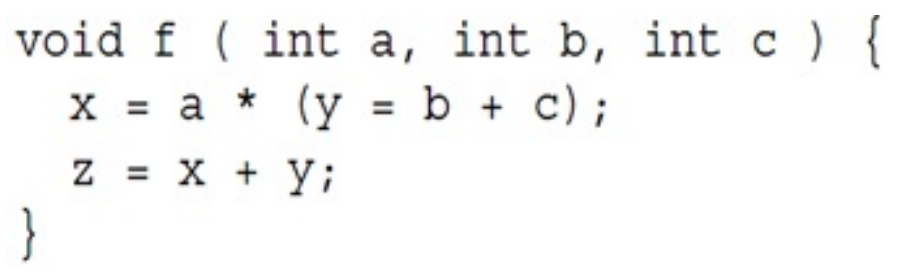

Figura 16 - Código fonte de exemplo para geração de um GDP granular. Fonte: Krinke (2001)

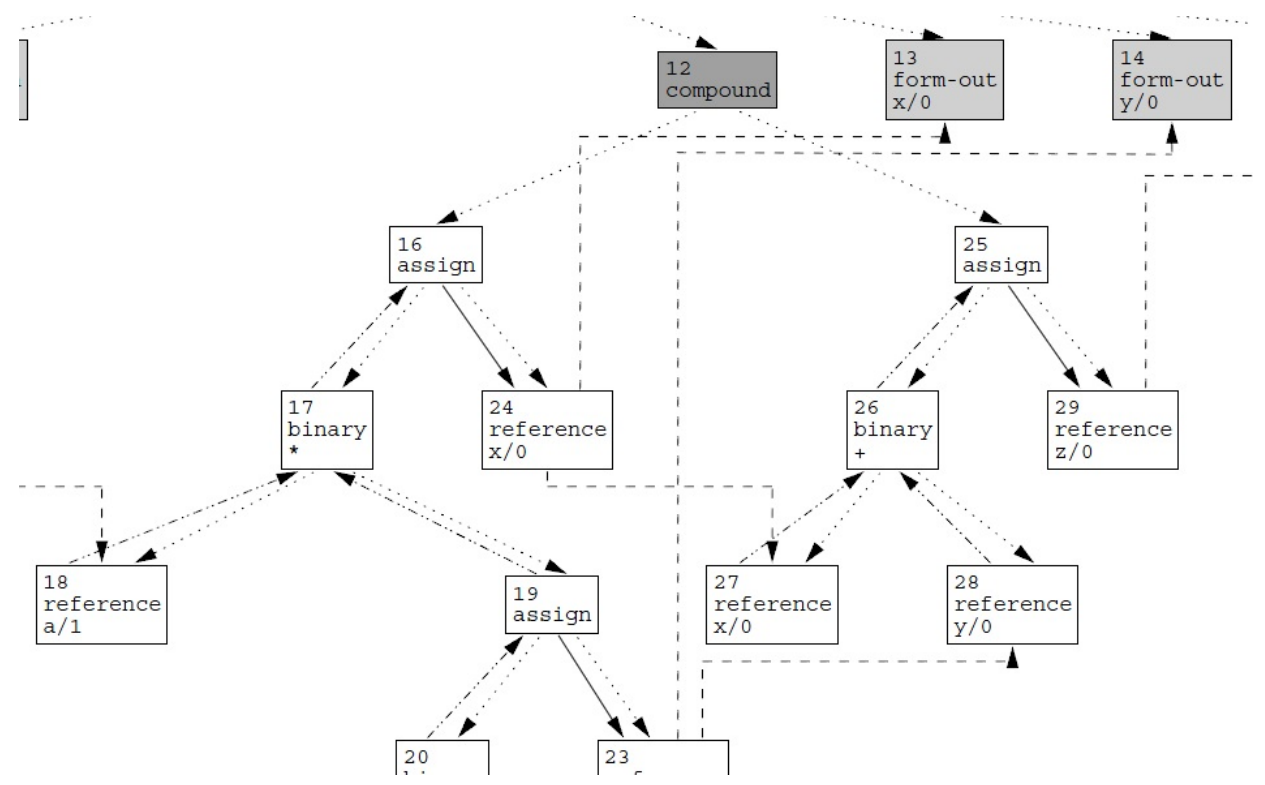

Figura 17 - Trecho do GDP granular referente ao código fonte da Figura 16. Fonte: Krinke (2001). Tradução livre.

Para Krinke, dois grafos de atributos e direcionados são isomorfos se todas as arestas estiverem relacionadas por uma função bijetora na qual a aresta do outro grafo e os atributos das arestas incidentes são os mesmos. Krinke destaca que o problema de saber se dois grafos são isomorfos é NP completo [20]. O problema foi relaxado para que a aplicação da técnica fosse viável. O algoritmo proposto no artigo é o que se segue. Sejam $V_{1}$ e $V_{2}$ nós similares e $E_{1}$ e $E_{2}$ as arestas que saem de $V_{1}$ e $V_{2}$, respectivamente. $E_{1}$ e $E_{2}$ são particionadas em classes de equivalência baseadas nos atributos dos vértices e os nós alcançados por essas arestas são adicionados a $G_{1}$ e $G_{2}$, resultados do algoritmo. 
O algoritmo é executado para cada par de nós similares dos grafos, ou até o número de execuções recursivas chegar a fator de relaxamento $k$. Esse fator define o máximo de subcaminhos que podem ser percorridos nos grafos.

Uma ferramenta que aplica a técnica em programas escritos na linguagem $\mathrm{C}$ foi desenvolvida e avaliada. Primeiramente foram realizados testes para encontrar um valor adequado para $k$. A ferramenta foi executada em 15 utilitários do Unix com diferentes valores de $k$. O tamanho dos utilitários em linhas de código, os números de nós e arestas dos GDPs gerados, os tempos de execução para cada $k$ e os números de clones encontrados foram fornecidos pelo autor do artigo. O autor ainda cita que o valor de $k$ tende a não influenciar muito no resultado do algoritmo quando é muito grande. Ele cita que $k=$ 20 deve ser um bom valor para a maior parte dos casos. Ele analisou um subgrupo não especificado dos clones obtidos pela ferramenta e observou um acerto de $100 \%$.

No final do artigo o autor afirma que a técnica proposta é viável mesmo sendo um problema de complexidade não polinomial. O autor também cita dois obstáculos. O primeiro é o caso em que há um número grande de clones no código fonte, no qual o programa não pode ser aplicado devido ao grande tempo de execução. O segundo é a quantidade de clones pequenos que a ferramenta indica ao invés de indicar os clones maiores, compostos de vários desses clones menores. Ainda segundo o autor, o ideal seria a ferramenta agrupar os diversos clones pequenos em grupos maiores de clones.

\subsubsection{Liu et al. (2006)}

Liu et al. (2006) criaram uma ferramenta capaz de detectar clones semânticos a partir da obtenção dos histogramas de vértices dos GDPs dos códigos fontes como estrutura de dados auxiliar, com o intuito de filtrar os GDPs que são submetidos à análise de isomorfismo. O algoritmo está dividido em dois subproblemas. O primeiro subproblema é identificar quando dois subgrafos são clones e o segundo é identificar quando a maioria, se não todos, os nós de dois GDPs são clones.

A detecção de subgrafos clonados é realizada utilizando análise de isomorfismo entre eles. O problema de encontrar isomorfismo é relaxado em um fator que diz o quanto um GDP pode ser diferente de outro para, mesmo assim, ser considerado clone. O fator é calculado como se segue. Os histogramas $h(g)$ e $h\left(g^{\prime}\right)$ de vértices dos grafos comparados, $g$ e $g$ ' respectivamente, são obtidos. Cada entrada dos histogramas é referente à frequência de um tipo de vértices nos grafos. Os dois histogramas são submetidos a testes de hipóteses como função de similaridade. O objetivo é estimar uma distribuição multinomial $k$ - 
dimensional $P(g)$ de $h(g)$ e verificar se $h\left(g^{\prime}\right)$ pode ser uma observação de $P(g)$. Se for, $(g$, $\left.g^{\prime}\right)$ são submetidos à análise de isomorfismo.

Outros fatores que relaxam o problema de encontrar GDPs clonados são a exclusão de GDPs menores do que um tamanho pré-definido e a exclusão de comparações nas quais o primeiro subgrafo comparado for maior do que o segundo.

Segundo os autores, as características dos GDPs de serem, em geral, de tamanho pequeno, aliadas à sua estrutura e à falta de necessidade de descobrir se todos pares de subgrafos são isomorfos (na maioria dos casos um par já basta) para detectar clones, tornam o algoritmo de busca viável. Os fatores aplicados para relaxar o problema de encontrar subgrafos isomorfos também viabilizam a técnica proposta.

Uma ferramenta, chamada $G P L A G$, foi criada para avaliar a técnica proposta. Essa ferramenta foi comparada com as ferramentas $M o s s^{7}$ e $J P L A G^{8}$. Apesar de também executar para programas em Java, a GPLAG foi validada em programas C. Três testes foram executados pelos autores.

No primeiro teste o programa join ${ }^{9}$ do $\mathrm{C}$ foi clonado com reordenação de comandos, alteração de comandos de controle e inversão de lógicas condicionais, sem alterar o resultado final da execução. As ferramentas Moss e JPLAG foram executadas para o join. O código do programa join foi alterado (sem alterar a semântica) enquanto as ferramentas não errassem em seus apontamentos de clones. Quando as ferramentas falharam em seus reportes, a GPLAG foi executada e os resultados foram comparados.

O segundo teste foi de eficiência. A GPLAG foi executada diversas vezes em vários programas escritos na linguagem C, alternando configurações de parâmetros de execução de fatores de relaxamento (inclusive aplicar ou não aplicar os fatores).

O terceiro e último teste foi a aplicação da GPLAG em bibliotecas maiores do que o join, sem alteração de código fonte, com o intuito de simular uma aplicação mais usual de detecção de clones semânticos.

Os autores afirmam que os experimentos demonstraram que a ferramenta foi mais efetiva e eficiente em comparação às outras, e que ela é aplicável na prática. Afirmam ainda que técnicas semânticas são superiores a outras por encontrarem tipos de clones que envolvem reordenação de código fonte no qual as linhas reordenadas não tem dependência de dados e inserção e remoção de comandos que não influenciam no grafo. A técnica pro-

\footnotetext{
${ }^{7}$ http://www.wisdomandwonder.com/link/1684/moss-a-system-for-detecting-software-plagiarism

${ }^{8}$ https://www.ipd.uni-karlsruhe.de/jplag/

${ }^{9}$ Os autores não especificaram onde encontrá-lo e nem em qual versão ele estava
} 
posta pela $G P L A G$ tem como ponto forte, além disso, a escalabilidade devido à aplicação dos fatores de relaxamento, mantendo uma taxa baixa de falsos negativos.

\subsubsection{Bellon et al. (2007)}

O objetivo de Bellon et al. (2007) foi realizar comparações entre diversas técnicas de detecção de clones. Autores de técnicas de detecção de clones foram contactados para que suas ferramentas fossem submetidas a um benchmark que seria criado por ele. As ferramentas Dup [32], CloneDR [28], CCFinder [25], Duplix [2], CLAN [40] e Duploc [22] foram submetidas ao benchmark.

O primeiro teste foi realizado com ferramentas de pequeno porte, com o objetivo de detectar potenciais problemas na execução principal. Alguns problemas foram encontrados, o que levou a pequenas normalizações nos códigos fontes das bibliotecas que foram submetidas às ferramentas.

O segundo passo foi a execução do teste principal, no qual as ferramentas foram executadas a fim de analisar bibliotecas escritas nas linguagens C e Java. Os autores das ferramentas avaliadas tiveram a oportunidade de executá-las duas vezes durante o teste principal. A primeira vez foi sem configurações iniciais nas ferramentas, e a segunda vez foi com direito a adaptar estas configurações aos experimentos conduzidos. Essa adaptação das configurações teve um tempo pré-definido de cinco semanas para ser efetuada. Os candidatos a clones reportados pelas ferramentas foram obtidos como resultado das execuções.

O benchmark foi criado após a coleta dos candidatos a clones reportados pelas ferramentas. Houve uma distribuição automática dos candidatos a clones para que o oráculo (o próprio Bellon) pudesse escolhê-los de forma que não soubesse qual ferramenta os reportou. O oráculo selecionou manualmente dois por cento dos clones enviados pelas ferramentas para fazer parte do benchmark. Um conjunto adicional de clones, escritos manualmente por Bellon, foi inserido ao conjunto formado pelos clones previamente selecionados.

Os conjuntos de clones reportados pelo oráculo e o conjunto de candidatos a clones reportados pelas ferramentas foram aplicados a métricas e os dados resultantes destas aplicações foram analisados. Taxas de precisão e de recuperação e quantidade de candidatos a clones rejeitados (ou seja, considerados não clones) pelas ferramentas são exemplos de métricas.

Não foi tirada conclusão definitiva sobre uma ferramenta ser melhor do que outra. O 
autor destacou características das ferramentas. Seguem as considerações do autor sobre a ferramenta de análise semântica.

A ferramenta de análise semântica avaliada [2] somente é sensível a clones com adições e remoções de linhas e inversões de comandos no código fonte e não executou para todas as bibliotecas devido a problemas de esgotamento de memória. A não execução para algumas bibliotecas diminuiu o número de candidatos submetidos pela ferramenta, o que também degradou sua avaliação. A ferramenta de Krinke também mostrou um baixo de desempenho em termos de velocidade de execução.

A definição de clones como sendo blocos seguidos de texto também teve influência negativa na avaliação da ferramenta Duplix, que é baseada em GDPs, o que faz sua definição de clones ser baseada em funções.

O material utilizado durante a pesquisa e os resultados estão disponíveis na internet ${ }^{10}$.

\subsubsection{Gabel, Jiang e Su (2008)}

Os autores do artigo separam GDPs em subgrafos, chamados por eles de threads semânticas, baseando-se no conceito de componentes fracamente conectados. Esses componentes são trechos de um GDP que não dependem um do outro. Esses subgrafos são obtidos utilizando fatiamento de programas. Segundo os autores, a técnica proposta gera conjuntos de árvores a partir das threads semânticas encontradas. Essas árvores são então submetidas à análise da ferramenta $D E C K A R D$ [41]. A DECKARD é capaz de encontrar semelhanças em árvores por meio de transformação delas em vetores numéricos de características e posterior análise de proximidade de vetores vizinhos.

Os autores do artigo separaram a validação em geração de GDPs e detecção de clones. O ambiente de execução foi um sistema operacional Fedora 6/64bit com um processador 2.66GHz Core 2 Duo e 4GB de memória RAM. A ferramenta CodeSurfer 2.1p $1^{11}$ foi utilizada para a geração de GDPs. A JVM Sun Java 1.6.0u1 64-bit Server ${ }^{12}$ foi utilizada como plataforma para a execução dos experimentos. Após a geração dos GDPs, a ferramenta criada foi executada em bibliotecas escritas na linguagem C. Dados foram coletados e uma análise qualitativa foi realizada.

Segundo os autores, a taxa de falsos positivos reportados pela ferramenta foi relativamente baixa e dependente do número mínimo de nós de comandos do GDP configurado

\footnotetext{
${ }^{10} \mathrm{http}: / /$ www.bauhaus-stuttgart.de/clones/

${ }^{11} \mathrm{http}: / /$ www.grammatech.com/products/codesurfer/overview.html

${ }^{12} \mathrm{http}: / /$ www.oracle.com/technetwork/java/javaee/downloads/index.html
} 
antes da execução da ferramenta. Quando esse número foi configurado para 4, a taxa de falsos positivos foi para zero. A ferramenta proposta encontra mais clones com tamanho médio maior. Foi observado que diversos clones semânticos estavam contidos em clones sintáticos.

Os pontos fortes relatados pelos autores foram a eficiência da ferramenta, a capacidade de encontrar comandos reordenados e com substituição de comandos de controle e a possibilidade de utilizá-la para detectar defeitos e para entendimento do código. A capacidade de encontrar clones em fragmentos de código que são menores do que procedimentos e funções também foi ressaltada pelos autores do artigo, visto que outras técnicas baseadas em grafos encontram clones tendo funções como unidade mínima de trabalho. Os autores citam a técnica proposta como sendo uma técnica escalável de detecção de clones, baseando-se em comparações do tempo de execução dela com tempos citados em outros artigos, de outras ferramentas.

\subsubsection{Albuquerque, Neves e Chaim (2012)}

Albuquerque, Neves e Chaim (2012) criaram uma ferramenta chamada Bytecode Java Clone Detector $(B J C D)$ para detectar clones semânticos a partir dos bytecodes dos programas escritos para a plataforma Java. Esse é um trabalho publicado com participação do autor desta pesquisa, porém foi desenvolvido anteriormente a ela.

Os passos do algoritmo são os que se seguem. Primeiramente é realizada uma integração com a ferramenta Java Bytecode Understanding and Testing (JaBUTi) [42], que lê os bytecodes e gera GFCs. A partir desses GFCs o algoritmo de criação de GDPs proposto por Ferrante, Ottenstein e Warren (1987) é executado. Os GDPs gerados são submetidos à análise de isomorfismo da ferramenta. O algoritmo desenvolvido para detectar subgrafos isomorfos é baseado no de Komondoor e Horwitz (2001), no qual os GDPs são navegados com aplicação do fatiamento de programas. A função de similaridade de Albuquerque, Neves e Chaim (2012) é baseada nas instruções bytecode existentes no nós dos GDPs.

Os bytecodes dos GDPs são normalizados para que os tipos de variáveis e a ordem de definição ou uso de variáveis sejam ignorados. As Figuras 18 e 19, retiradas do trabalho, representam a normalização de dois nós de GDPs. Na Figura 18, o nó 1 contém os opcodes (códigos de instruções bytecode) ILOAD da variável 1, ILOAD da variável 2, IADD e ISTORE na variável 3. O nó 2 contém as instruções $L L O A D$ da variável 2, $L L O A D$ da variável 1, LSUB e LSTORE na variável 3. Após a normalização, conforme ilustrado na Figura 19, o nó 1 fica com os opcodes LOAD, LOAD, ADD e STORE. O nó 2 
fica com as instruções $L O A D, L O A D, S U B$ e STORE. Todos os opcodes dos dois vértices são similares, exceto as instruções $A D D$ do nó 1 e a $S U B$ do nó 2.
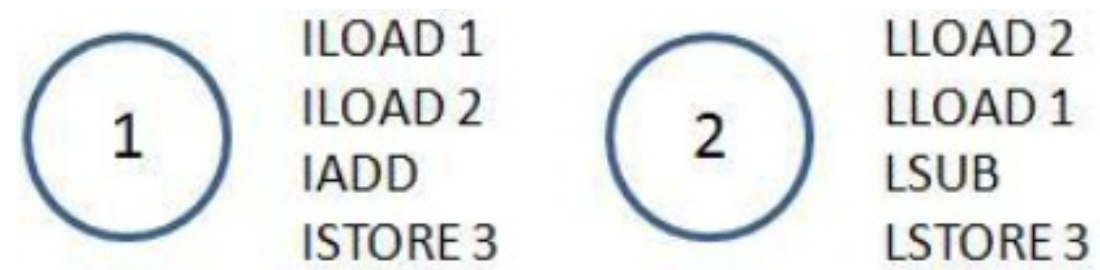

Figura 18 - Vértices antes da normalização da BJCD.

Fonte: Albuquerque, Neves e Chaim (2012)
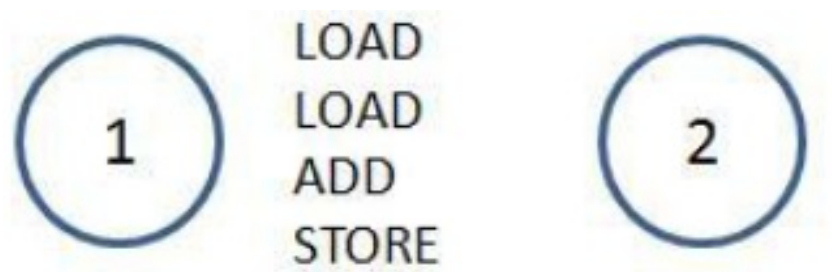

LOAD

LOAD

SUB

STORE

Figura 19 - Vértices após a normalização da BJCD.

Fonte: Albuquerque, Neves e Chaim (2012)

Um percentual de opcodes devem ser iguais após a normalização dos nós dos GDPs para que esses nós sejam considerados clones. É possível configurar esse percentual na ferramenta. Esse mecanismo oferece a possibilidade de calibrar a ferramenta para uma biblioteca específica na qual, por exemplo, os métodos não são idênticos somente por um ter retorno e o outro não.

A avaliação da ferramenta ocorreu como se segue. Os cenários levantados por Roy, Cordy e Koschke (2009) foram escritos na linguagem Java. A BJCD foi executada para esses cenários. A execução inicial para cada cenário foi de $100 \%$ de similaridade, sendo que a cada execução onde a ferramenta não detectou um clone o percentual foi diminuído, até que o clone fosse encontrado.

Os autores destacam como pontos positivos da ferramenta a capacidade de encontrar clones nos quais o código esteja reordenado ou com inserções de linhas. Por trabalhar com bytecodes, a ferramenta detecta clones mesmo quando grandes alterações no código fonte são realizadas, uma vez que os fluxos de dados e controle são mantidos. Por outro lado, a ferramenta não tem boa eficácia em cenários nos quais linhas de código são removidas entre o código original e o clone. 


\subsection{Discussão}

Esta seção tem como objetivo apresentar uma discussão sobre as técnicas de detecção de clones apresentadas. Dados presentes nas surveys retornadas pela revisão também são discutidos nesta seção.

\subsubsection{Estruturas de dados utilizadas}

Diferentes técnicas de detecção de clones e heurísticas aplicadas para melhorar o desempenho de execução são apresentadas nos artigos estudados. Uma das técnicas utilizadas para encontrar GDPs isomorfos é a transformação deles em estruturas parecidas com árvores, utilizada por Krinke (2001) e Gabel, Jiang e Su (2008). As técnicas apresentadas nos dois artigos possuem, segundo seus autores, desempenhos distintos. A técnica baseada na transformação de GDPs em árvores e dessas árvores em vetores para posterior análise de vizinhança [5] é escalável, enquanto a técnica de transformar GDPs em estruturas mais granulares, parecidas com árvores [2] tem como pontos fracos justamente os desempenhos de tempo e memória. Outras técnicas de detecção de clones transformam os GDPs em vetores de características [3] ou mantêm o GDP em seu estado inicial [1, 6]. A Tabela 7 descreve as estruturas de dados utilizadas nos artigos. A técnica de Liu et al. (2006) transforma GDPs em vetores. As técnicas que mantêm o GDP em seu estado inicial $[1,6]$ possuem problemas no desempenho de tempo de execução, segundo seus autores.

Tabela 7 - Estruturas de dados utilizadas na detecção de clones

\begin{tabular}{c|c}
\hline Estrutura & Artigos \\
\hline GDP sem transformações & $\begin{array}{c}\text { Komondoor e Horwitz (2001) } \\
\text { Albuquerque, Neves e Chaim (2012) }\end{array}$ \\
\hline Transformação em vetores & Liu et al. (2006) \\
& Gabel, Jiang e Su (2008) \\
\hline GDPs como árvores & Krinke (2001) \\
& Gabel, Jiang e Su (2008) \\
\hline
\end{tabular}

\subsubsection{Técnicas de comparação de GDPs}

As três técnicas que utilizam navegação nas estruturas de dados criadas $[1,2,6]$ apresentam pouco desempenho em relação ao tempo de execução da deteç̧ão de clones. Por outro lado, transformar as informações de fluxo de dados e controle dos trechos de 
código fonte analisados em vetores numéricos para posteriores análises utilizando funções de análise de distanciamento desses vetores é uma técnica empregada em artigos de autores que afirmam que as técnicas propostas são escaláveis $[3,5]$. A Tabela 8 associa as técnicas de detecção de clones aos artigos que as utilizam. Os filtros aplicados nas ferramentas de detecção de clones semânticos também influenciam no desempenho.

Tabela 8 - Tipos de técnicas de detecção de clones semânticos

\begin{tabular}{c|c}
\hline Técnica & Artigos \\
\hline Navegação na estrutura de dados & Komondoor e Horwitz (2001) \\
& Krinke (2001) \\
& Albuquerque, Neves e Chaim (2012) \\
\hline Análise de distância de vetores & Liu et al. (2006) \\
& Gabel, Jiang e Su (2008) \\
\hline
\end{tabular}

Um filtro comumente utilizado pelos autores de artigos [3, 5] é a definição de um tamanho mínimo dos GDPs que serão analisados. Se o GDP do trecho de código fonte analisado não possuir um tamanho mínimo, não será submetido à detecção de clones. Os autores ainda afirmam que essa técnica auxilia na redução do número de falsos positivos encontrados pelas ferramentas criadas. Outra técnica utilizada para melhorar o desempenho é filtrar pares de GDPs nos quais o candidato a código original é maior do que o GDP do candidato a clone. Gabel, Jiang e Su (2008) definem que, em geral, o código original é maior do que o copiado. A Tabela 9 descreve os filtros utilizados nos artigos.

Tabela 9 - Filtros heurísticos para melhorar o desempenho das técnicas

\begin{tabular}{c|c}
\hline Filtro & Artigos que utilizam \\
\hline Tamanho mínimo do GDP & $\begin{array}{c}\text { Liu et al. (2006) } \\
\text { Gabel, Jiang e Su (2008) }\end{array}$ \\
\hline Não comparar GDPs grandes com menores & Liu et al. (2006) \\
\hline
\end{tabular}

\subsubsection{Pontos fortes e deficiências}

Os artigos estudados indicam pontos fortes e deficiências tanto de técnicas semânticas de detecção de clones em geral [4, 8, 34-36] quanto das técnicas propostas nos artigos $[1-3,5,6]$. Dentre os pontos positivos, os principais citados são as capacidades de detectar clones com reordenação de comandos na qual não há alteração nos fluxos de dados e controle $[1-6,8,34]$ e clones nos quais comandos são inseridos ou removidos $[1-6,34]$. 
Um ponto positivo levantado tanto por Liu et al. (2006) quanto por Gabel, Jiang e Su (2008) é a escalabilidade das técnicas propostas. Rattan, Bhatia e Singh (2013) também mencionam a escalabilidade como ponto positivo dessas ferramentas de detecção de clone semântico. Esses autores também mencionam a baixa quantidade de falsos positivos reportados pelas ferramentas. A detecção de clones menores do que funções e procedimentos (funcões e procedimentos são o escopo de um GDP típico) é destacada por Gabel, Jiang e $\mathrm{Su}$ (2008). A Tabela 10 exibe o total de artigos que citam cada ponto positivo apresentado.

Tabela 10 - Citações de pontos positivos de técnicas de detecção de clones semânticos

\begin{tabular}{c|c}
\hline Ponto positivo & Total \\
\hline Detectar clones com reordenação de comandos & 8 \\
\hline Detectar clones com inserção e remoção de comandos & 7 \\
\hline Escalabilidade & 3 \\
\hline Poucos falsos positivos & 3 \\
\hline Detectar clones em trechos menores do que procedimentos e funções & 1 \\
\hline
\end{tabular}

A principal deficiência destacada pelos autores dos artigos estudados é a lentidão apresentada nas execuções das ferramentas [1, 2, 4, 8, 34, 36]. A segunda principal deficiência citada sobre as técnicas estudadas é o alto consumo de memória [2, 4, 34]. A alta quantidade de falsos positivos reportados pelas ferramentas analisadas também é uma deficiência citada em artigos estudados $[1,2,8,36]$. A Tabela 11 exibe o total de artigos que citam cada deficiência apresentada.

Tabela 11 - Citações de deficiências de técnicas de detecção de clones semânticos

\begin{tabular}{c|c}
\hline Deficiência & Total \\
\hline Lentidão de execução & 7 \\
\hline Alto número de falsos positivos & 5 \\
\hline Alto consumo de memória & 4 \\
\hline
\end{tabular}

As observações de pontos positivos e deficiências realizadas nos artigos foram baseadas em diferentes formas de avaliação. A próxima subseção apresenta essas formas de avaliação.

\subsubsection{Formas de avaliação}

Benchmarks utilizados nos artigos estudados e comparações com outras ferramentas de detecção de clones semânticos ou com ferramentas que utilizem outros tipos de técnicas 
foram observados. Apenas Bellon et al. (2007) utilizaram um benchmark para avaliar as técnicas de detecção de clones. Liu et al. (2006) também utilizaram ferramentas baseadas em técnicas diferentes da semântica para comparar com a ferramenta de detecção de clones construída. Roy, Cordy e Koschke (2009) utilizaram uma análise baseada em cenários e suposições. Os autores supuseram quais seriam os comportamentos de algumas ferramentas de detecção de clones em diversos cenários de duplicação de código propostos por eles. A partir dessas suposições, notas qualitativas foram dadas às ferramentas para cada cenário avaliado. Nenhuma comparação com outras técnicas de detecção de clones foi realizada em quatro de cinco artigos cujo objetivo principal era propor técnicas de detecção de clones semânticos $[1,2,5,6]$. Nesses artigos os autores executaram suas ferramentas em bibliotecas de teste e analisaram taxas de erros e outros critérios em amostras dos clones reportados pelas ferramentas. A Tabela 12 ilustra os tipos de avaliação observados nos artigos estudados e os artigos que os aplicaram.

Tabela 12 - Tipos de avaliação de técnicas de detecção de clones semânticos

\begin{tabular}{c|c}
\hline Técnica de avaliação & Artigos \\
\hline Sem comparações com & Komondoor e Horwitz (2001) \\
outras ferramentas & Krinke (2001) \\
& Gabel, Jiang e Su (2008) \\
& Albuquerque, Neves e Chaim (2012) \\
\hline Comparações com & Liu et al. (2006) \\
outras ferramentas & Bellon et al. (2007) \\
\hline Benchmark & Bellon et al. (2007) \\
\hline
\end{tabular}

Alguns dados foram coletados e analisados em um número maior de artigos, o que sugere que são importantes para uma avaliação correta de ferramentas de detecção de clones semânticos. Esses dados podem ser vistos na Tabela 13, juntamente aos totais de artigos que os utilizaram em suas avaliações. O tamanho das bibliotecas submetidas aos testes (em linhas de código) foi o dado mais utilizado em avaliações [1-6], seguido pelos clones reportados pelas ferramentas [2-6] e o tempo de execução da detecção de clones $[1,2,4-6]$. O número de nós dos GDPs processados [1-3], os tipos dos clones reportados pelas ferramentas $[3,4]$ e os tamanhos dos clones encontrados (em linhas de código) $[4,5]$ também foram considerados relevantes por mais de um artigo. Como os outros dados foram citados por apenas um artigo, não são apresentados.

A próxima subseção apresenta uma discussão acerca da reprodutibilidade das avaliações realizadas nos artigos. 
Tabela 13 - Dados para avaliações de detecção de clones semânticos

\begin{tabular}{c|c}
\hline Dado & Total de artigos \\
\hline Tamanhos das bibliotecas validadas (em linhas de código) & 6 \\
\hline Clones reportados pela ferramenta & 5 \\
\hline Tempo de execução da detecção de clones & 5 \\
\hline Número de nós dos GDPs processados & 3 \\
\hline Tipos dos clones reportados & 2 \\
\hline Tamanhos dos clones encontrados (em linhas de código) & 2 \\
\hline
\end{tabular}

\subsubsection{Reprodutibilidade das avaliações realizadas}

Finalmente, quanto à capacidade de reproduzir os experimentos executados nos artigos estudados, somente Bellon et al. (2007) deixam disponíveis os dados de teste e as amostras de clones consideradas nas avaliações, mas as versões dos programas Java são antigas, o que faz com que avaliações nessas versões de programas não sejam mais aplicáveis. Os demais autores não especificaram quais candidatos a clones foram considerados nas avaliações das ferramentas. Os ambientes de execução das ferramentas e as versões das bibliotecas submetidas a testes também não foram especificados, o que dificulta a reprodução dos experimentos.

\subsection{Conclusão do capítulo}

Um levantamento bibliográfico realizado com o objetivo de identificar técnicas de detecção de clones semânticos, assim como as formas mais comuns de avaliar estas técnicas e seus pontos fortes e deficiências, foi apresentada neste capítulo. Uma questão foi elaborada para guiar a revisão bibliográfica. Cadeias de busca e filtros de pesquisa foram submetidos a diferentes máquinas de busca. Os resultados das pesquisas foram submetidos a critérios de inclusão e exclusão de artigos, e os artigos que passaram nesses últimos filtros foram analisados. Os conteúdos dos artigos foram sintetizados e características relevantes para responder a questão formulada foram extraídas e analisadas.

Cinco artigos nos quais os autores apresentaram propostas de novas técnicas de detecção de clones semânticos, um artigo no qual diversas técnicas de detecção de clones (semânticos e não semânticos) foram avaliadas por meio de um benchmark e quatro surveys foram analisados.

Foi possível separar as técnicas de detecção de clones em grupos durante as análises dos 
artigos. Tanto grupos de estruturas de dados utilizadas quanto de técnicas de análise de similaridade foram destacados. Técnicas que transformam os GDPs em vetores numéricos tendem a ser mais escaláveis do que técnicas que navegam pelos nós dos GDPs, segundo os autores. Ambos os grupos de técnicas compartilham os pontos positivos de detectar clones com comandos reordenados e com inserções e remoções de linhas de comando. No que se refere aos desempenhos de memória e tempo de execução, no entanto, as técnicas baseadas em vetores numéricos são mais eficazes do que as técnicas de navegação nas estruturas de dados. A técnicas baseadas em vetores numéricos também apresentam um número menor de falsos positivos do que as técnicas de navegação em GDPs. Os pontos positivos e as deficiências levantados são baseados, porém, em análises realizadas pelos autores dos artigos as quais tem pouca possibilidade de reprodução, pois somente Bellon et al. (2007) tornaram os dados utilizados em suas comparações disponíveis e informaram detalhadamente o ambiente no qual as ferramentas foram executadas.

Apenas Bellon et al. (2007) utilizaram um benchmark para avaliar técnicas de detecção de clones semânticos. Porém, esse benchmark tende a favorecer técnicas que analisam os clones textualmente ao invés de semanticamente, segundo os próprios autores do artigo. Além desse artigo, que comparou ferramentas de detecção de clones semânticos com outras ferramentas, baseadas em outras técnicas, somente Liu et al. (2006) compararam ferramentas de detecção de clones semânticos com outras ferramentas. O restante dos autores realizaram análises sem comparações ou com comparações baseadas em cenários e suposições. Não houve comparações de ferramentas que utilizam técnicas baseadas em GDPs com outras ferramentas do mesmo tipo, nas quais ambas as ferramentas foram executadas e os resultados confrontados, em nenhum dos artigos estudados.

Nenhuma das técnicas apresentadas prevê chamadas de procedimentos dentro dos nós dos GDPs, o que pode levar a um número elevado de falsos positivos. A proposta deste trabalho é criar uma técnica capaz de detectar clones com a capacidade de analisar as chamadas de procedimentos. A forma de avaliação será baseada em um benchmark, assim como apresentado por Bellon et al. (2007). Os próximos capítulos apresentam um benchmark criado para avaliar técnicas de detecção de clones semânticos e uma técnica que leva em consideração as chamadas de procedimentos durante a análise dos trechos de código candidatos a clone. 


\section{Capítulo 4}

\section{Benchmark para Detectores de Clo-}

\section{nes}

Avaliações de ferramentas de detecção automática de clones em sistemas com várias linhas de código são atividades que demandam tempo e critério dos avaliadores, conforme pode ser observado em artigos analisados [1-5, 8, 34, 35]. Diversos pares de fragmentos código candidatos a clones devem ser analisados e classificados como clones ou não clones. As comparações de candidatos a clones são comumente simplificadas por autores de artigos presentes na literatura por serem trabalhosas. Por exemplo Bellon et al. (2007) analisaram apenas dois por cento dos candidatos a clones reportados em seus experimentos e Roy, Cordy e Koschke (2009) aplicaram análises qualitativas e subjetivas para comparar detectores de clones. A pouca reprodutibilidade de experimentos também é um problema encontrado em alguns trabalhos. Por exemplo, Komondoor e Horwitz (2001) obtiveram amostras aleatórias de candidatos a clones para analisarem a técnica proposta, o que dificulta a exata reprodução do experimento realizado. A utilização de benchmarks que possuam conjuntos previamente estabelecidos de clones para serem analisados e que avaliem automaticamente os resultados retornados pelos detectores de clones é uma solução para mitigar os problemas de tempo de execução, subjetividade e reprodutibilidade dos experimentos, pois benchmarks dessa natureza não exigem a extensa participação de pessoas no processo de análise. Benchmarks são, portanto, conjuntos de programas e operações pré-definidos com o intuito de avaliar determinada característica de um outro programa. No contexto desta pesquisa, a taxa de acertos das ferramentas de detecção de clones será avaliada com auxílio do benchmark, que será composto por um conjunto de métodos candidatos a clones.

Um benchmark de detectores de clones foi criado nesta pesquisa. Esse benchmark disponibiliza diferentes tipos de clones para análise, de acordo com as diversas definições de clones existentes na literatura. O benchmark é também capaz de ler os resultados dos detectores de clones quando exportados em um formato específico e calcular as taxas de acertos. 


\subsection{Metodologia para a criação do benchmark}

Foi necessário definir os tipos de clones considerados no experimento. Para tanto, um estudo foi realizado na literatura sobre tipos de clones reportados por outros autores. Esses tipos de clones foram agrupados em um novo conjunto de tipos de clones, proposto na pesquisa atual.

Projetos de código aberto foram selecionados e os candidatos a clones foram extraídos deles no passo seguinte. Um dos objetivos da atividade é que esses candidatos a clones sejam analisados por programadores, portanto foi necessário preparar um treinamento para que eles tivessem conhecimento suficiente para realizar a atividade. Critérios foram definidos para a seleção dos programadores envolvidos na pesquisa e para a classificação de candidados a clones por parte desses programadores.

As seções a seguir detalham os passos supracitados.

\subsubsection{Definição dos tipos de clones considerados}

Os tipos de clones propostos nesta seção são baseados em leituras de artigos sobre detecção de clones. Dois artigos de survey sobre detecção de clones, um de avaliação de detectores de clones utilizando benchmark e outro no qual uma técnica de detecção de clones é proposta foram avaliados e os tipos de clones definidos nesses artigos foram analisados.

Rattan, Bhatia e Singh (2013) realizaram uma revisão sistemática sobre técnicas de detecção de clones e propuseram os seguintes tipos de clones:

- Tipo 1: cópias exatas

- Tipo 2: cópias com variações nos nomes dos identificadores, nas constantes ou nos tipos de variáveis e retornos de funções;

- Tipo 3: cópias com adição ou remoção de linhas de código;

- Tipo 4: clones similares funcionalmente sem necessariamente serem similares textualmente (clones semânticos).

Roy, Cordy e Koschke (2009) realizaram uma survey sobre técnicas de detecção de clones e, baseados nos estudos realizados, definiram os seguintes tipos de clones: 
- Tipo 1: cópias nas quais linhas em branco ou comentários foram adicionados ou que tiveram mudanças na identação;

- Tipo 2: cópias com as modificações do Tipo 1 e adicionalmente com variações nos nomes dos identificadores, nas constantes ou nos tipos de variáveis e retornos de funções;

- Tipo 3: cópias com as modificações do Tipo 2 e adicionalmente com adição ou remoção de linhas de código;

- Tipo 4: cópias que realizam a mesma computação, porém variam sintaticamente, ou seja, são clones semânticos.

O artigo de Liu et al. (2006) apresenta uma técnica de detecção de clones semânticos. Os autores definem os seguintes tipos de clones:

- Tipo 1: cópias nas quais linhas em branco ou comentários foram adicionados ou que tiveram mudanças na identação;

- Tipo 2: cópias com variações nos nomes dos identificadores;

- Tipo 3: cópias com reordenação de comandos;

- Tipo 4: cópias com substituição de comandos de controle.

Bellon et al. (2007) construíram um benchmark para avaliar detectores de clones. Os tipos de clones definidos pelos autores, conforme eles afirmam no artigo, têm foco em alterações textuais. Seguem os tipos de clones definidos no artigo:

- Tipo 1: cópia exata;

- Tipo 2: cópias com variações nos nomes dos identificadores e nos tipos de variáveis e retornos de funções;

- Tipo 3: cópias com alteração, adição ou remoção de comandos.

É possível observar que alguns tipos de alterações, como por exemplo a alteração dos nomes dos identificadores e a inserção de espaços em branco e comentários estão presentes em mais de um artigo. Alterações inerentes a clones semânticos podem ser observadas nos artigos de Rattan, Bhatia e Singh (2013), Roy, Cordy e Koschke (2009) e Liu et al. (2006). 
Bellon et al. (2007) definiram também o tipo de clone mais básico, que é a cópia exata do código. Os tipos de clones a seguir são uma contribuição do trabalho atual e são baseados naqueles encontrados nos artigos estudados. Esses tipos de clones serão utilizados para classificar os clones encontrados nesta pesquisa:

- Tipo 1: cópia exata;

- Tipo 2: cópias nas quais linhas em branco ou comentários foram adicionados ou que tiveram mudanças na identação;

- Tipo 3: cópias com variações sintáticas leves, como alterações nos nomes dos identificadores, nas constantes utilizadas e na disposição do código;

- Tipo 4: cópias com alterações nos tipos de variáveis e retornos de funções;

- Tipo 5: cópias com adição ou remoção de linhas de código;

- Tipo 6: cópias com reordenação de comandos;

- Tipo 7: cópias com substituições simples de estruturas de controle. Por exemplo, uma substituição de um comando while por um for é considerada uma substituição simples de estruturas de controle;

- Tipo 8: cópias com substituições lógicas na estrutura de controle, por exemplo a inversão lógica de um comando if (a) then $b$ else $c$ por if (!a) then $c$ else $b$.

Os tipos de clones mais granulares do que os presentes na literatura têm como objetivo possibilitar que análises mais específicas quanto à capacidade de detectar clones sejam realizadas.

\subsubsection{Obtenção de candidatos a clones de projetos de código aberto}

Os programas commons-math3-3.0 ${ }^{1}$, weka-3.7. $6^{2}$, jtopas- $0.8^{3}$ e checkstyle- $5.5^{4}$ foram selecionados por possuirem tamanhos variados e lógicas distintas de programação aplicadas. A Tabela 14 apresenta as informações inerentes aos programas. As linhas de código foram contadas utilizando a extensão Metrics $^{5}$ do ambiente Eclipse ${ }^{6}$.

\footnotetext{
${ }^{1}$ http://apache.mirror.pop-sc.rnp.br/apache//commons/math/source/commons-math3-3.0-src.zip

${ }^{2}$ http://sourceforge.net/projects/weka/files/weka-3-7/3.7.6/weka-3-7-6.zip/download

${ }^{3}$ http://sourceforge.net/projects/jtopas/files/jtopas/jtopas-0.8/jtopas-0.8.tar.gz/download

${ }^{4}$ http://sourceforge.net/projects/checkstyle/files/checkstyle/5.5/checkstyle-5.5-bin.zip/download

${ }^{5}$ http://metrics.sourceforge.net/

${ }^{6}$ http://www.eclipse.org
} 
Tabela 14 - Programas selecionados para compor o benchmark

\begin{tabular}{c|c|c|c}
\hline Programa & Tipo & Linhas de código & Métodos \\
\hline jtopas-0.8 & Manipulação de texto & 4.373 & 613 \\
\hline checkstyle-5.5 & Análise estática de código & 47.825 & 3.128 \\
\hline commons-math3-3.0 & Operações matemáticas & 120.424 & 9.184 \\
\hline weka-3.7.6 & Descoberta de conhecimento & 238.514 & 16.877 \\
\hline
\end{tabular}

O procedimento para a obtenção de candidatos a clones foi a execução da ferramenta Bytecode Java Clone Detector (BJCD) [6] para detectar os clones presentes nos programas e a seleção aleatória de pares de candidatos a clones. A $B J C D$ foi selecionada para a execução premilinar pois detecta clones semânticos, além dos habitualmente detectados por outras ferramentas, e pela facilidade de acesso a ela por parte dos pesquisadores responsáveis por este trabalho. Os candidatos a clones reportados pela $B J C D$ foram sorteados e agrupados antes de serem disponibilizados para as análises dos programadores. Quatro rodadas de sorteios foram realizadas, sendo que cada uma ocorreu como se segue.

A Figura 20 ilustra o processo realizado para realizar cada sorteio. Cinquenta pares de clones foram sorteados para cada programa submetido à análise da $B J C D$, totalizando duzentos pares para cada rodada. O objetivo dos sorteios iniciais foi possibilitar que os programas tivessem chances iguais de terem clones sorteados no próximo passo, visto que alguns programas possuem número de clones reportados pela $B J C D$ mais elevado que outros. O segundo passo foi sortear um número aleatório de clones dentre os duzentos selecionados no primeiro passo. Foi definido que esse número aleatório deveria ser maior ou igual a cinco e menor ou igual a quinze para cada rodada.

Candidatos a clones que não foram considerados clones pela $B J C D$ foram sorteados após o sorteio dos clones. Um procedimento análogo foi adotado, conforme explicado a seguir. Cinquenta pares de código classificados como não clones foram sorteados para cada programa submetido à análise da $B J C D$, totalizando duzentos pares para cada rodada. Um número de pares foi sorteado dentre esses duzentos, sendo que esse número deveria completar um total de vinte pares de código que deveriam ser analisados se somados aos pares de clones previamente sorteados em cada rodada. Vinte pares de código, dentre clones e não clones, foram destacados ao final de cada rodada de sorteios.

O processo de sorteio de clones foi automatizado e a classe utilizada está disponível no Apêndice A. O resultado final do processo de sorteios foi a seleção de oitenta candidatos a clones. Os candidatos a clones foram agrupados em quatro grupos de vinte candidatos 


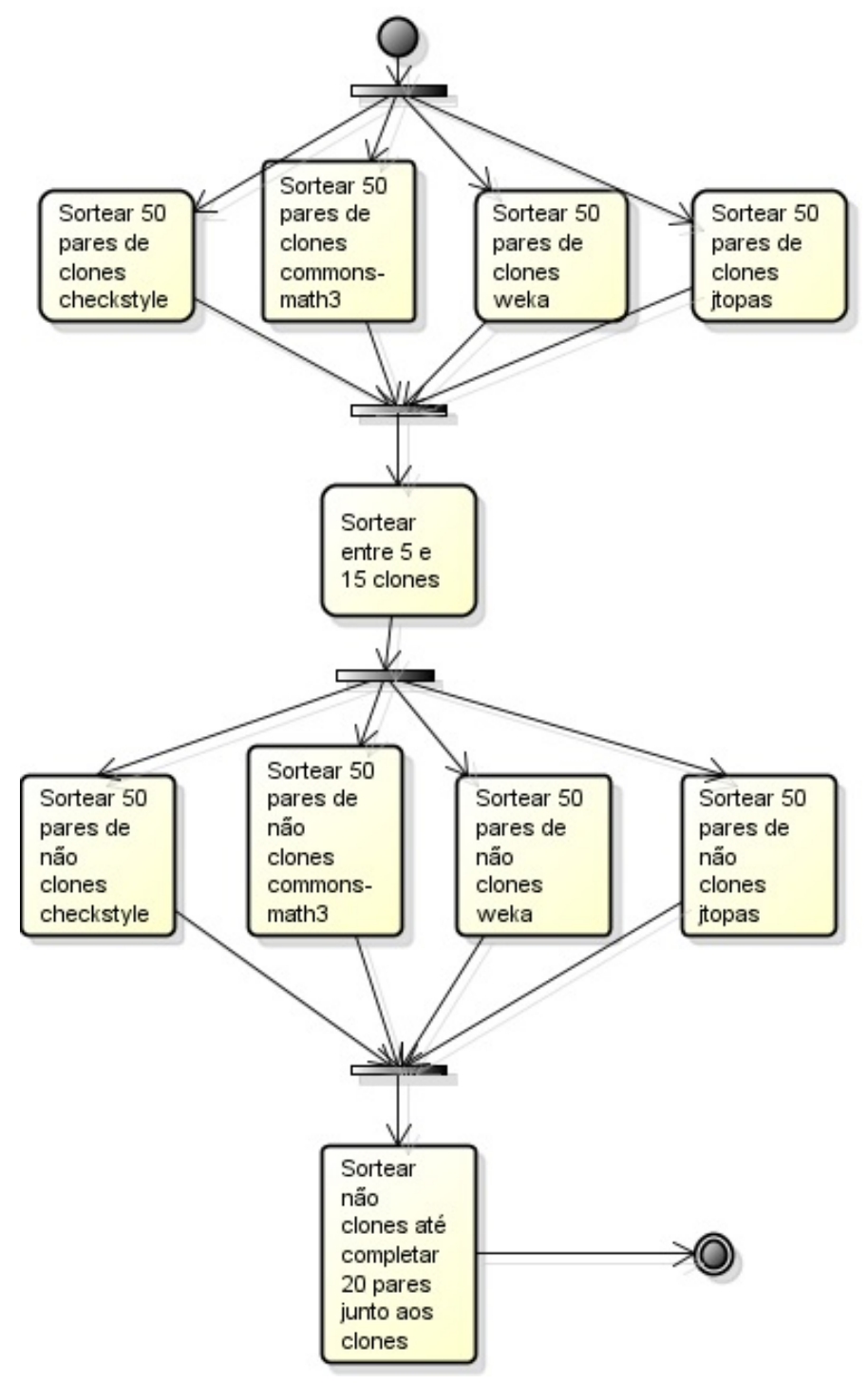

Figura 20 - Processo de sorteio de candidatos a clones

a clones.

\subsubsection{Formulação do treinamento sobre clones}

Os treinamentos dos programadores foram realizados antes dos experimentos. Os locais de realização dos experimentos foram variados, a depender da facilidade de acesso aos programadores. Os grupos de programadores da indústria foram compostos de pessoas que trabalham na mesma empresa, o que possibilitou que o treinamento fosse realizado em uma sala da empresa. Os grupos de programadores de projetos acadêmicos foram compostos de pessoas vinculadas à mesma universidade, o que possibilitou que o treinamento desses grupos fosse realizado em uma sala da própria universidade. Os grupos 
foram treinados separadamente.

Os treinamentos duraram trinta minutos para cada grupo treinado e foram compostos por aulas expositivas com duração de vinte minutos seguida de dez minutos para realizar exercícios em grupo. Dúvidas podiam ser esclarecidas durante toda a duração do treinamento.

A aula expositiva abordou os seguintes temas:

1. definição básica de clonagem de código;

2. motivos comuns para a existência de clones;

3. diferenciação entre clones de texto e de funcionalidade (semânticos), de acordo com as definições apresentadas em Roy, Cordy e Koschke (2009);

4. os tipos de clones definidos na Seção 4.1.1 foram apresentados e explicados.

Os exercícios em grupo tiveram a seguinte dinâmica. Exemplos de candidatos a clones previamente sorteados foram apresentados aos programadores sem que a classificação e o tipo fossem informados. Os programadores discutiram em grupo sobre cada exemplo e definiram se os candidatos eram clones de fato e, se fossem clones, quais eram os tipos de clone aos quais os exemplos pertenciam. Os treinamentos foram considerados bem sucedidos visto que todos os grupos classificaram corretamente todos os exemplos de clones apresentados. O procedimento de treinamento seria modificado e adaptado aos grupos treinados se houvesse treinamentos mal sucedidos. Nesse caso novos treinamentos deveriam ser agendados com os grupos.

Salas que comportassem ao menos cinco pessoas e que tivessem a possibilidade de projeção de uma apresentação compilada no formato PDF no ambiente de trabalho dos programadores da indústria e salas com as mesmas características na universidade onde os programadores acadêmicos atuavam foram necessárias para a realização dos treinamentos.

Esperava-se que os programadores estivessem aptos a classificar candidatos a clones sorteados como clones ou não clones e a definir quais eram os tipos dos clones após a realização de treinamentos bem sucedidos.

\subsubsection{Critérios para a seleção dos programadores}

Programadores que tivessem conhecimento da linguagem de programação Java foram selecionados para a realização da atividade. Esse critério foi adotado pois todos os 
candidatos a clones selecionados para o experimento foram escritos nessa linguagem de programação. A experiência de pelo menos dois anos de programação nessa linguagem foi exigida para que o programador possuísse conhecimento técnico e vivência suficientes para realizar a atividade.

Não houve a definição do número específico de programadores da indústria ou de projetos acadêmicos que poderiam participar da atividade. No entanto, um total de doze programadores foi definido como o mínimo para suprir a necessidade da atividade, sendo que o máximo era de vinte programadores. Dessa maneira cada grupo de candidatos a clones sorteados teria no mínimo três análises e no máximo cinco, visto que cada grupo de candidatos a clones sorteados era composto por vinte candidatos a clones.

\subsubsection{Critérios para a classificação de candidatos a clones}

Os programadores poderiam classificar os candidatos a clones segundo qualquer critério de similaridade que julgassem conveniente. Essa abordagem foi utilizada com o objetivo de que o benchmark resultante da atividade contivesse classificações de clones que estivessem próximas da interpretação de diferentes programadores, independente das técnicas aplicadas para a detecção de clones e da análise dos pesquisadores responsáveis pelo projeto. Essa abordagem possibilita também a discussão sobre os diferentes critérios de similaridade aplicados por programadores na detecção de clones.

\subsection{Obtenções das classificações dos candidatos a clo- nes}

Projetos de desenvolvimento e manutenção de software podem possuir programadores com diferentes experiências de programação. O objetivo deste passo da pesquisa foi conduzir experimentos nos quais grupos de programadores com diferentes experiências, medidas em tempo de conhecimento de programação, foram formados para analisar os candidatos a clones sorteados.

Uma atividade piloto e uma atividade principal foram realizadas. Os procedimentos básicos foram similares nas duas atividades. Os indivíduos dos grupos receberam treinamentos prévios sobre clones e analisaram candidatos a clones apresentados a eles. Os indivíduos classificaram os candidatos entre clones e não clones, classificando também os tipos dos clones. Os grupos possuíram números variados de pessoas, sendo que esse 
número de pessoas variava de três a cinco programadores na atividade principal e foi de duas pessoas na atividade piloto. Todos que participaram da pesquisa assinaram o formulário de ciência e o formulário de avaliação da atividade. Os formulários de ciência e de avaliação estão no Apêndice B e no Apêndice C, respectivamente.

As seções a seguir detalham as execuções das atividades.

\subsubsection{Execução da atividade preliminar}

Uma atividade piloto foi realizada com programadores de projetos acadêmicos, com o intuito de validar o método de condução da atividade principal e detectar antecipadamente melhorias. As melhorias detectadas foram aplicadas na atividade principal, que foi conduzida posteriormente. O procedimento adotado foi o que se segue. O treinamento descrito na Seção 4.1.3 foi apresentado para os programadores. A condução do treinamento juntamente aos exercícios durou vinte e sete minutos.

Os candidatos a clones foram apresentados aos programadores após a condução dos treinamentos e dos exercícios. Ambos os programadores foram conduzidos ao mesmo tempo ao mesmo computador e os pares de candidatos a clones previamente sorteados foram apresentados a eles. Os pares de clones foram apresentados utilizando o ambiente Eclipse e foram dispostos um método ao lado do outro, conforme ilustrado na Figura 21. Os programadores analisaram os pares de candidatos a clones e novos pares de candidatos foram apresentados a eles após as classificações dos anteriores. Os programadores conseguiram classificar onze clones no período limite de trinta minutos definido para a classificação dos candidatos a clones.

Dois formulários de avaliação, cada um preenchido por um programador, foram entregues ao condutor da atividade. O treinamento conduzido foi suficiente para que a atividade de classificação dos candidatos a clones fosse realizada, segundo os conteúdos preenchidos pelos programadores. Quanto às classificações dos candidatos a clones, houve diferença entre os clones reportados pela ferramenta e os classificados pelos programadores. A Tabela 15 e a Figura 22 resumem o cenário obtido. Enquanto a BJCD reportou nove métodos como clones e dois como não clones, os programadores reportaram consensualmente que cinco candidatos eram clones enquanto seis não eram. Esse resultado indicou a presença de falsos positivos na ferramenta. Por outro lado, não houve resultados falsos negativos. Foi observado também que a ferramenta detectou com sucesso clones dos tipos 3,4 e 6 . 


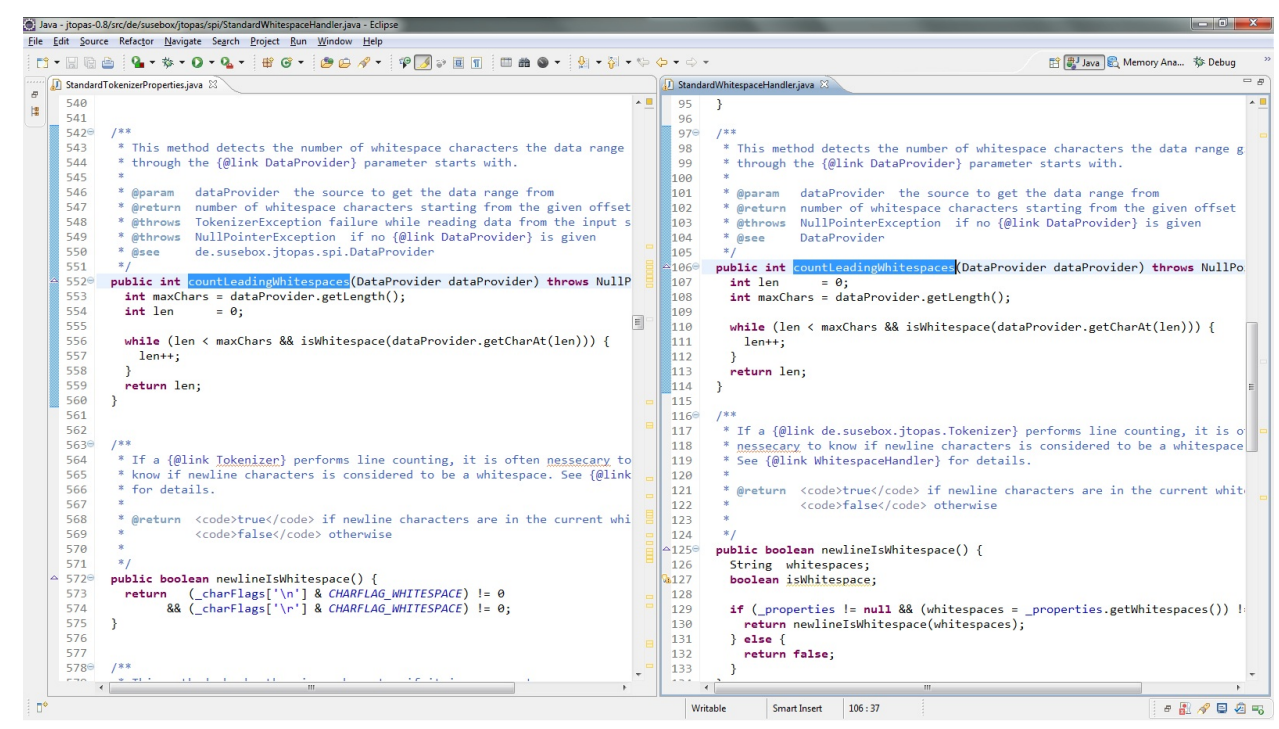

Figura 21 - Exibição dos candidatos a clones utilizando o Eclipse

Tabela 15 - Comparação de classificações de candidatos a clones

\begin{tabular}{c|c|c}
\hline Classificador & Clones & Não Clones \\
\hline$B J C D$ & 9 & 2 \\
\hline Programadores & 5 & 6 \\
\hline
\end{tabular}

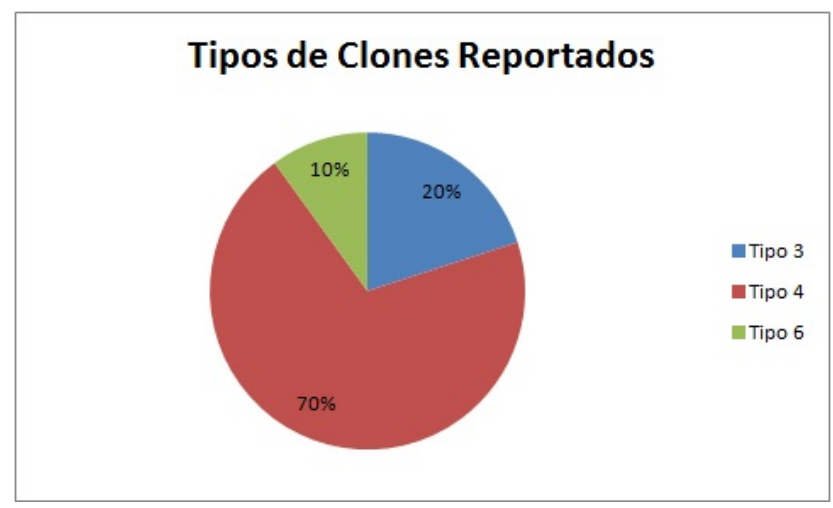

Figura 22 - Tipos de clones detectados pelos programadores

Melhorias foram identificadas no método de condução da atividade. A apresentação dos clones conjuntamente para os programadores em um mesmo computador foi considerada uma maneira inadequada de condução da atividade por dois motivos. O primeiro é a possibilidade da decisão de um programador influenciar a do outro por eles estarem visualizando os mesmos candidatos a clones ao mesmo tempo e estarem próximos. Outro motivo é que os programadores podem ter ritmos diferentes. Da maneira como o experimento piloto foi conduzido, um programador que leva mais tempo para analisar os clones 
pode atrapalhar andamento das análises dos outros. Além disso, abrir os candidatos a clones no Eclipse consumiu um tempo que poderia ter sido utilizado para a classificação de mais candidatos a clones. A impressão dos pares de clones em folhas de papel e a distribuição individual aos programadores foi considerada no método de condução da atividade principal para sanar esses problemas.

A necessidade de realizar correções na $B J C D$ também foi identificada devido à presença de falsos positivos. Essas correções foram aplicadas na BJCD antes da execução da atividade principal. O restante do método, inclusive o treinamento, seguiu como foi definido inicialmente.

\subsubsection{Execução da atividade principal}

A obtenção de clones teve duração mínima de uma hora e máxima de uma hora e trinta minutos por grupo e o procedimento foi realizado separadamente para os grupos. Os locais de execução do procedimento, a exemplo do treinamento, foram salas da empresa de atuação dos grupos de programadores corporativos ou da universidade de atuação dos programadores acadêmicos.

Quatro sorteios foram realizados previamente conforme definido na Seção 4.1.2, disponibilizando oitenta pares de código para serem analisados. Os pares de clones resultantes dos sorteios foram disponibilizados em folhas de papel sulfite, um par de clones por folha. Métodos maiores demandaram mais de uma folha para impressão.

Os programadores receberam vinte candidatos a clones cada um para analisar, sendo que esses vinte candidatos a clones obrigatoriamente continham os pares de códigos sorteados em uma mesma rodada de sorteios. A distribuição dos pares de códigos é exemplificada na Tabela 16. Os grupos foram nomeados de Grupo A, Grupo B, Grupo C e Grupo D para facilitar a leitura. Os programadores foram nomeados de Programador 1 a Programador 12. Os pares de códigos sorteados foram distribuídos aos programadores em ordem sequencial de rodada de sorteios, de modo que a ocorrência de programadores de um mesmo grupo analisando pares de código de uma mesma rodada sorteios fosse minimizada. Essa precaução foi necessária para evitar que as decisões de um programador influenciassem as dos outros. Programadores de um mesmo grupo que analisaram candidatos a clones de uma mesma rodada de sorteios foram dispostos na sala de modo que a visão de um programador à análise do outro fosse dificultada. Essa estratégia de distribuição dos candidatos a clones também garantiu que todos os candidatos sorteados fossem analisados três vezes. 
Tabela 16 - Disponibilização de pares de clones a programadores

\begin{tabular}{c|c|c}
\hline Programador & Grupo & Sorteio \\
\hline 1 & $\mathrm{~A}$ & 1 \\
\hline 2 & $\mathrm{~A}$ & 2 \\
\hline 3 & $\mathrm{~A}$ & 3 \\
\hline 4 & $\mathrm{~A}$ & 4 \\
\hline 5 & $\mathrm{~A}$ & 1 \\
\hline 6 & $\mathrm{~B}$ & 2 \\
\hline 7 & $\mathrm{~B}$ & 3 \\
\hline 8 & $\mathrm{~B}$ & 4 \\
\hline 9 & $\mathrm{~B}$ & 1 \\
\hline 10 & $\mathrm{C}$ & 2 \\
\hline 11 & $\mathrm{C}$ & 3 \\
\hline 12 & $\mathrm{C}$ & 4 \\
\hline
\end{tabular}

As execuções do procedimento foram monitoradas por um pesquisador responsável pelo projeto, porém ele não pôde influenciar nas decisões dos grupos e nem tirar dúvidas sobre clonagem de código durante o procedimento.

Os resultados das análises foram escritos pelos programadores nas folhas referentes aos candidatos a clones. Discussões sobre as análises realizadas foram as últimas atividades. Os resultados das análises foram computados e analisados conforme descrito na próxima seção.

\subsubsection{Computação e análise dos resultados fornecidos pelos gru- pos}

As classificações dos pares de clones fornecidas pelos grupos foram agrupadas por sorteio e os resultados foram analisados da seguinte maneira. Como houve três classificações para cada par de código, foi possível tomar a decisão entre clone e não clone utilizando uma votação. Se um par de código tivesse mais classificações como clones, foi decidido que esse par era um clone. Caso contrário, a decisão era que o par não era um clone. Ou seja, um par de código foi considerado clone se tivesse no mínimo duas classificações como clone. A Tabela 17 exibe as consolidações realizadas para os pares de códigos sorteados. 
Tabela 17 - Consolidação de pares de código sorteados

\begin{tabular}{|c|c|c|c|c|}
\hline Par & "Clone" & "Não clone" & Programadores & BJCD \\
\hline 1 & 2 & 1 & Clone & Clone \\
\hline 2 & 3 & 0 & Clone & Clone \\
\hline 3 & 3 & 0 & Clone & Clone \\
\hline 4 & 0 & 3 & Não clone & Não clone \\
\hline 5 & 0 & 3 & Não clone & Não clone \\
\hline 6 & 0 & 3 & Não clone & Não clone \\
\hline 7 & 0 & 3 & Não clone & Não clone \\
\hline 8 & 0 & 3 & Não clone & Não clone \\
\hline 9 & 0 & 3 & Não clone & Não clone \\
\hline 10 & 0 & 3 & Não clone & Não clone \\
\hline 11 & 0 & 3 & Não clone & Não clone \\
\hline 12 & 0 & 3 & Não clone & Não clone \\
\hline 13 & 0 & 3 & Não clone & Não clone \\
\hline 14 & 0 & 3 & Não clone & Não clone \\
\hline 15 & 0 & 3 & Não clone & Não clone \\
\hline 16 & 3 & 0 & Clone & Clone \\
\hline 17 & 2 & 1 & Clone & Clone \\
\hline 18 & 3 & 0 & Clone & Clone \\
\hline 19 & 3 & 0 & Clone & Clone \\
\hline 20 & 3 & 0 & Clone & Clone \\
\hline 21 & 0 & 3 & Não clone & Não clone \\
\hline 22 & 0 & 3 & Não clone & Não clone \\
\hline 23 & 3 & 0 & Clone & Clone \\
\hline 24 & 1 & 2 & Não clone & Clone \\
\hline 25 & 3 & 0 & Clone & Clone \\
\hline 26 & 0 & 3 & Não clone & Não clone \\
\hline 27 & 3 & 0 & Clone & Clone \\
\hline 28 & 2 & 1 & Clone & Clone \\
\hline 29 & 0 & 3 & Não clone & Não clone \\
\hline 30 & 0 & 3 & Não clone & Não clone \\
\hline 31 & 0 & 3 & Não clone & Não clone \\
\hline 32 & 0 & 3 & Não clone & Não clone \\
\hline
\end{tabular}


Tabela 17 - Consolidação de pares de código sorteados

\begin{tabular}{|c|c|c|c|c|}
\hline Par & "Clone" & "Não clone" & Programadores & BJCD \\
\hline 33 & 0 & 3 & Não clone & Não clone \\
\hline 34 & 0 & 3 & Não clone & Não clone \\
\hline 35 & 1 & 2 & Não clone & Clone \\
\hline 36 & 2 & 1 & Clone & Clone \\
\hline 37 & 1 & 2 & Não clone & Clone \\
\hline 38 & 1 & 2 & Não clone & Clone \\
\hline 39 & 3 & 0 & Clone & Clone \\
\hline 40 & 3 & 0 & Clone & Clone \\
\hline 41 & 0 & 3 & Não clone & Não clone \\
\hline 42 & 3 & 0 & Clone & Clone \\
\hline 43 & 3 & 0 & Clone & Clone \\
\hline 44 & 3 & 0 & Clone & Clone \\
\hline 45 & 3 & 0 & Clone & Clone \\
\hline 46 & 3 & 0 & Clone & Clone \\
\hline 47 & 3 & 0 & Clone & Clone \\
\hline 48 & 0 & 3 & Não clone & Não clone \\
\hline 49 & 0 & 3 & Não clone & Não clone \\
\hline 50 & 0 & 3 & Não clone & Não clone \\
\hline 51 & 0 & 3 & Não clone & Não clone \\
\hline 52 & 0 & 3 & Não clone & Não clone \\
\hline 53 & 0 & 3 & Não clone & Não clone \\
\hline 54 & 0 & 3 & Não clone & Não clone \\
\hline 55 & 3 & 0 & Clone & Clone \\
\hline 56 & 3 & 0 & Clone & Clone \\
\hline 57 & 2 & 1 & Clone & Clone \\
\hline 58 & 3 & 0 & Clone & Clone \\
\hline 59 & 3 & 0 & Clone & Clone \\
\hline 60 & 3 & 0 & Clone & Clone \\
\hline 61 & 0 & 3 & Não clone & Não clone \\
\hline 62 & 0 & 3 & Não clone & Não clone \\
\hline 63 & 3 & 0 & Clone & Clone \\
\hline 64 & 3 & 0 & Clone & Clone \\
\hline
\end{tabular}


Tabela 17 - Consolidação de pares de código sorteados

\begin{tabular}{c|c|c|c|c}
\hline Par & "Clone" & "Não clone" & Programadores & BJCD \\
\hline 65 & 3 & 0 & Clone & Clone \\
\hline 66 & 0 & 3 & Não clone & Não clone \\
\hline 67 & 3 & 0 & Clone & Clone \\
\hline 68 & 3 & 0 & Clone & Clone \\
\hline 69 & 0 & 3 & Não clone & Não clone \\
\hline 70 & 0 & 3 & Não clone & Não clone \\
\hline 71 & 0 & 3 & Não clone & Não clone \\
\hline 72 & 1 & 2 & Não clone & Não clone \\
\hline 73 & 0 & 3 & Não clone & Não clone \\
\hline 74 & 2 & 1 & Clone & Clone \\
\hline 75 & 2 & 1 & Clone & Clone \\
\hline 76 & 3 & 0 & Clone & Clone \\
\hline 77 & 3 & 0 & Clone & Clone \\
\hline 78 & 3 & 0 & Clone & Clone \\
\hline 79 & 3 & 0 & Clone & Clone \\
\hline 80 & 3 & 0 & Clone & Clone \\
\hline
\end{tabular}

As consolidações tiveram como objetivo definir se os pares de código eram considerados clones ou não pelos programadores, mas também foi útil para validar a eficácia da ferramenta BJCD. Os experimentos indicaram 95\% de acerto da ferramenta. A Figura 23 ilustra os tipos de clones detectados corretamente pela $B J C D$ e analisados pelos programadores. É possível notar que os clones dos tipos 3 e 4 foram os mais reportados pelos programadores, totalizando juntos $82,35 \%$ do total, sendo que os outros tipos de clones, se somados os percentuais, totalizam 17,65\%. É notável também que não houve acordo total nas classificações dos candidatos a clones para os quais os programadores discordaram da classificação da BJCD. Dois programadores discordaram da BJCD, enquanto um concordou nos pares 24, 35, 37 e 38. Isso pode indicar que, se mais programadores classificassem os candidatos a clones, os resultados poderiam variar, aumentando a taxa de acertos da BJCD.

As classificações dos programadores não foram iguais às da BJCD em quatro pares de candidatos a clones. Esses pares foram analisados e foi observado que eles possuem carac- 


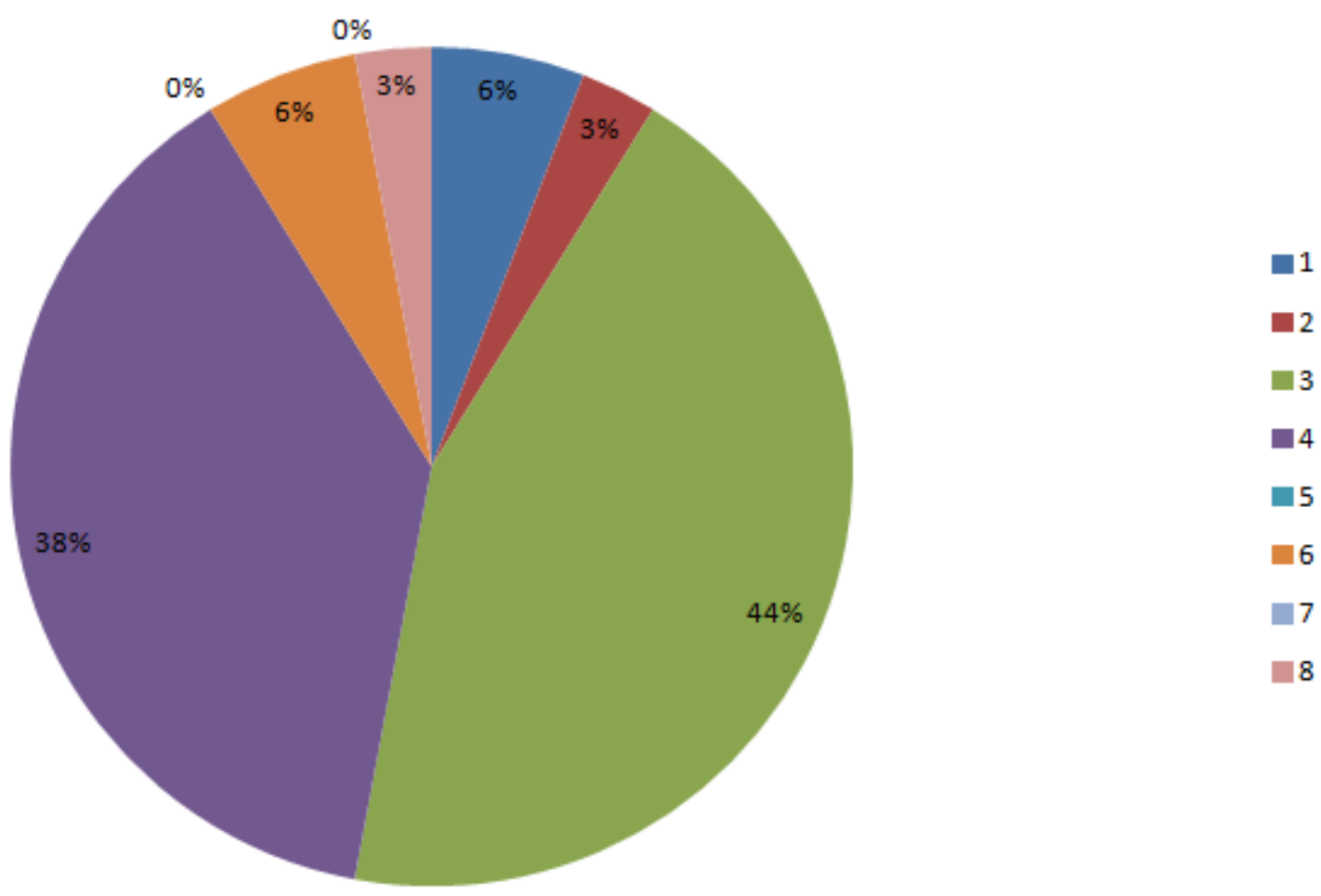

Figura 23 - Percentuais dos tipos de clones classificados

terísticas semelhantes. Todos os pares são métodos semelhantes, mas possuem chamadas que são distintas. A BJCD classificou esses métodos em clones enquanto os programadores os classificaram como não clones. A Figura 24 ilustra o primeiro par de candidatos com essas características. Os métodos fireEditingStopped() e fireEditingCanceled() possuem lógicas de execução similares com exceção das chamadas a editingStopped(ChangeEvent) e editingCanceled(ChangeEvent), respectivamente.

A Figura 25 ilustra o segundo par de candidatos a clones. Nesse caso a diferença entre os métodos rotate $C W($ ) e rotate $C C W($ ) é a maneira como ambos manipulam o atributo element. Ambos os métodos utilizam de maneira inversa os elementos left e right. Nesse caso não há invocações de métodos, mas sim manipulações semelhantes de atributos.

A Figura 26 apresenta os métodos createRowRealMatrix(double[]) e createColumnRealMatrix(double[]). Os métodos diferem por conta do primeiro realizar operações com linhas enquanto o último realiza operações com colunas. As lógicas dos métodos, no entanto, são similares. Inclusive o método invocado por ambos os métodos é o mesmo, createRealMatrix(int, int). A maior variação que pode ser notada é a posição na qual a variável $i$ é fornecida ao método setEntry(int, int, int). Enquanto ele é fornecido como segundo parâmetro no método createRowRealMatrix(double[]), o método createColumnRealMatrix(double[]) o fornece como primeiro parâmetro. Nesse caso a diferença não está 


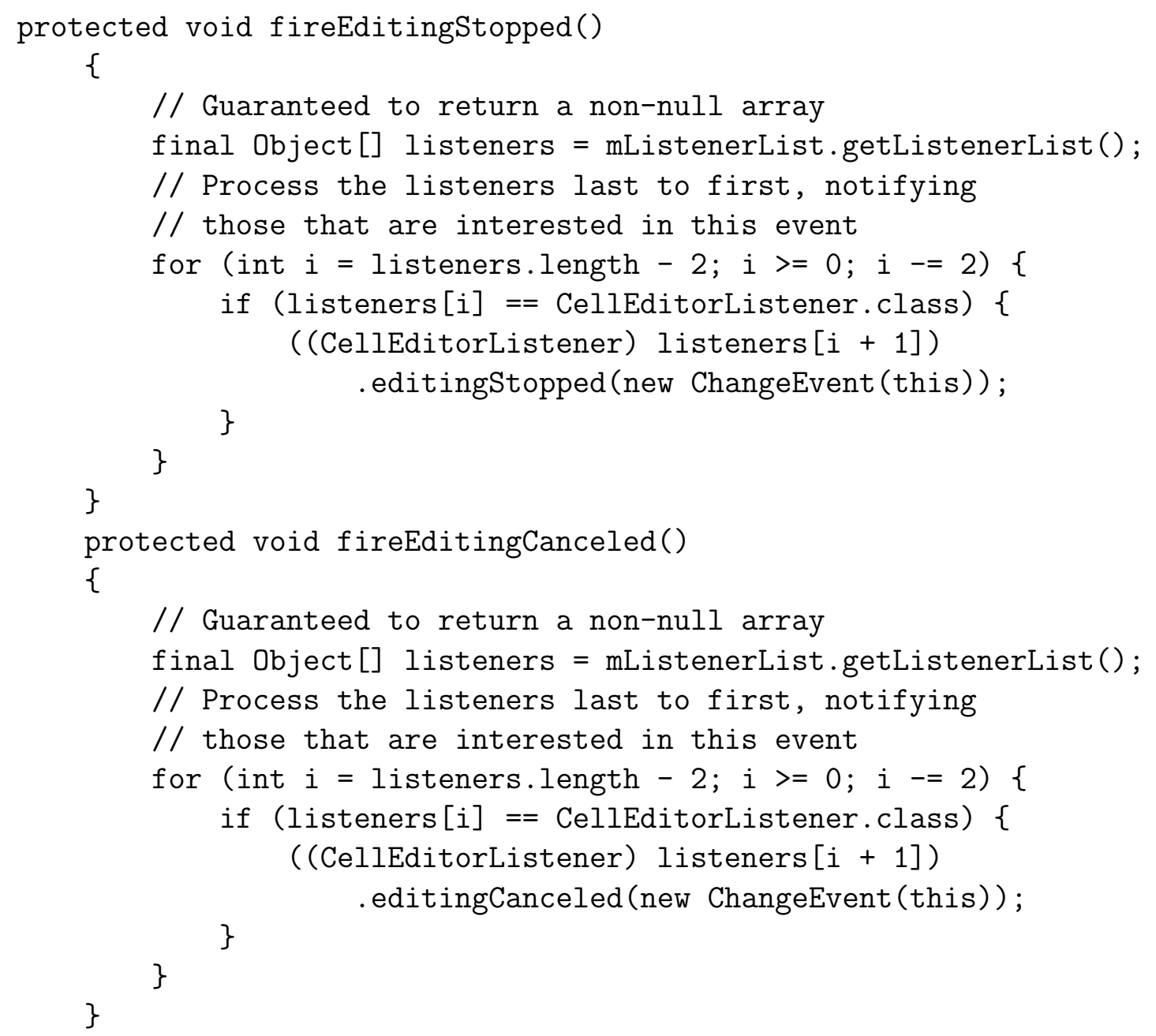

Figura 24 - fireEditingStopped() e fireEditingCanceled()

no método invocado, mas sim na ordem dos parâmetros que são fornecidos.

A Figura 27 apresenta os métodos PolyKernel.setOptions(String[]) e AdaBoostM1.setOptions(String[]). Ambos possuem lógicas semelhantes, porém os métodos que eles invocam são distintos. Enquanto PolyKernel.setOptions(String[]) invoca setExponent(double) e setUseLowerOrder(boolean), o método AdaBoostM1.setOptions(String[]) invoca setWeightThreshold(int) e setUseResampling(boolean).

Não houve divergências entre os programadores para nenhum dos pares de candidatos a clones para os quais a BJCD não acertou o resultado, ou seja, três programadores decidiram que os pares não eram clones. Esses pares sugerem que os programadores que os classificaram consideram que, apesar da lógica ser semelhante, códigos que resultam em processamentos diferentes não devem ser considerados clones. Ou seja, a BJCD, na visão desses programadores, apresenta falsos positivos nesses cenários. No entanto, é importante ressaltar a importância da detecção desses tipos de clones em atividades de 


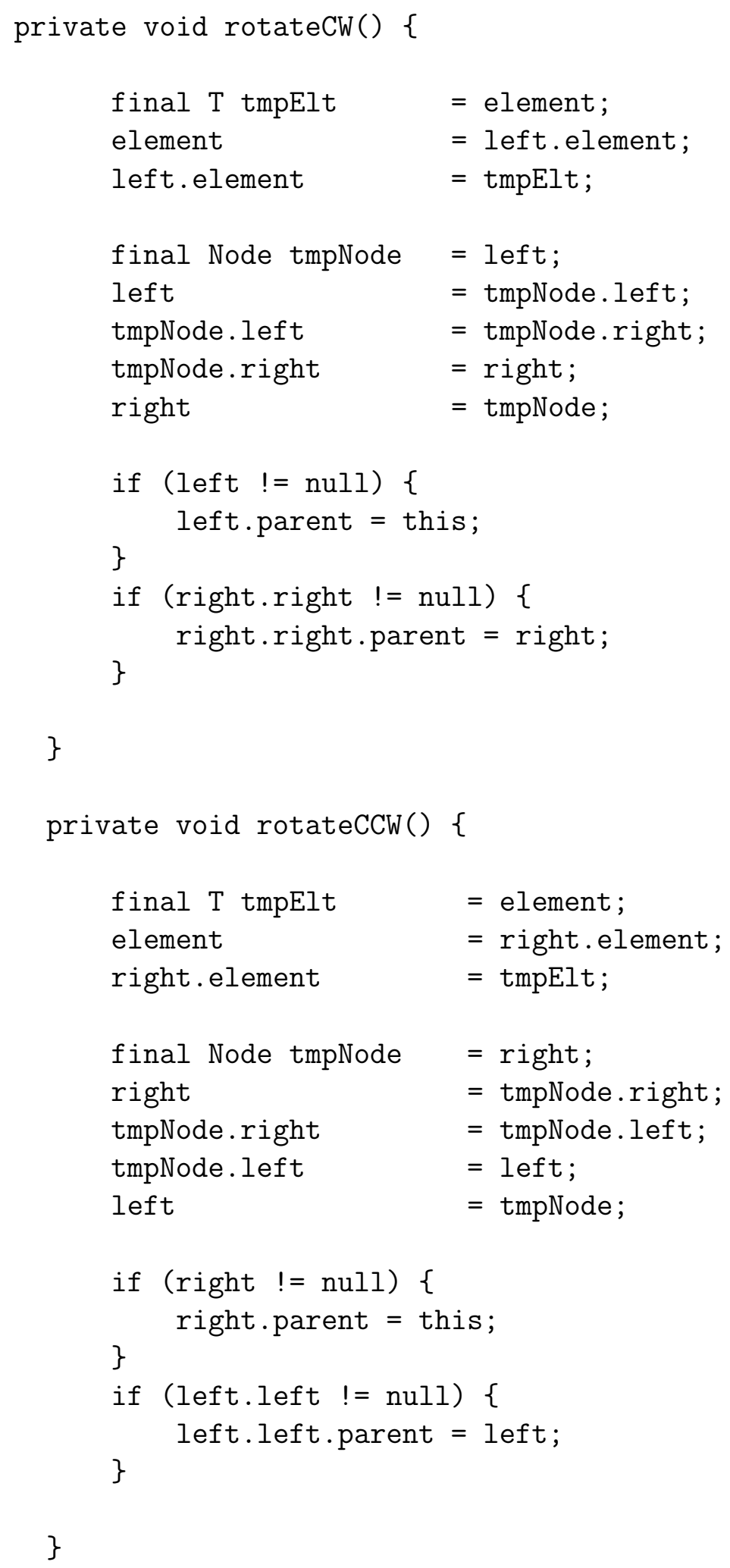

Figura 25 - rotateCW() e rotateCCW

entendimento de código e refatoração, por exemplo. É possível, por exemplo, identificar os trechos de código similares, extrair as chamadas distintas e centralizar o que é comum 


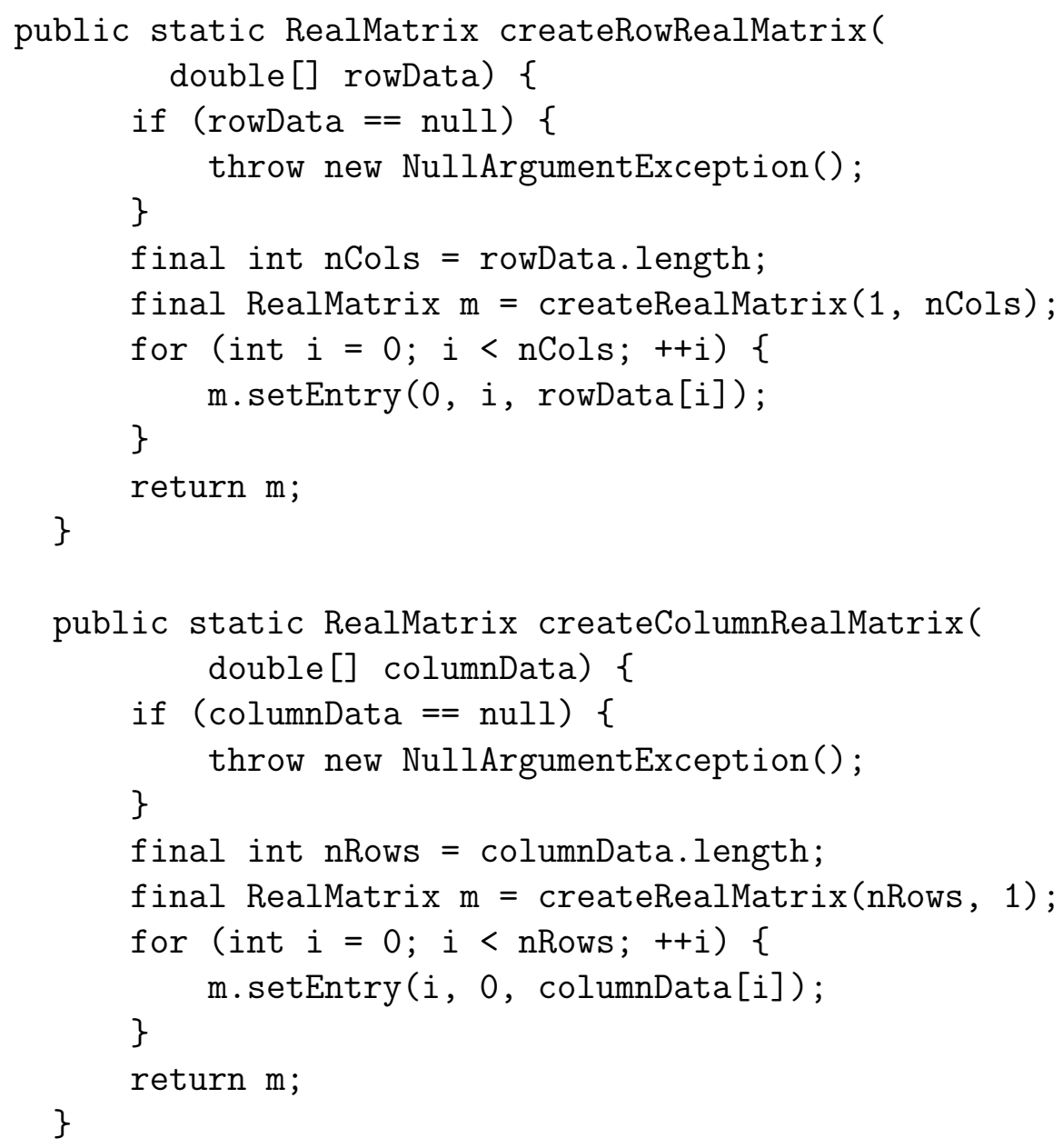

Figura 26 - createRowRealMatrix(double[]) e createColumnRealMatrix(double[])

para que o código duplicado não exista mais.

Nesse sentido, propomos neste trabalho mais um tipo de clones: o clone interprocedimental. Define-se o clone interprocedimental como uma cópia de um código que é similar em sua lógica de execução, mas que contém invocações com comportamentos distintos, gerando portanto diferença semântica. Esse tipo de clone pode ser estudado com maiores detalhes em trabalhos futuros.

Formulários de avaliação do experimento foram preenchidos pelos programadores. Os resultados consolidados por grupo estão presentes na Tabela 18. Todos os programadores consideraram que o treinamento fornecido a eles foi suficiente para que conseguissem classificar os candidatos a clones e nenhum programador encontrou clones que não pertecessem aos oito tipos definidos e apresentados a eles. Conforme ilustrado na Figura 28, setenta e cinto por cento dos programadores participantes dos experimentos possuem mais do que cinco anos de experiência com programação. 


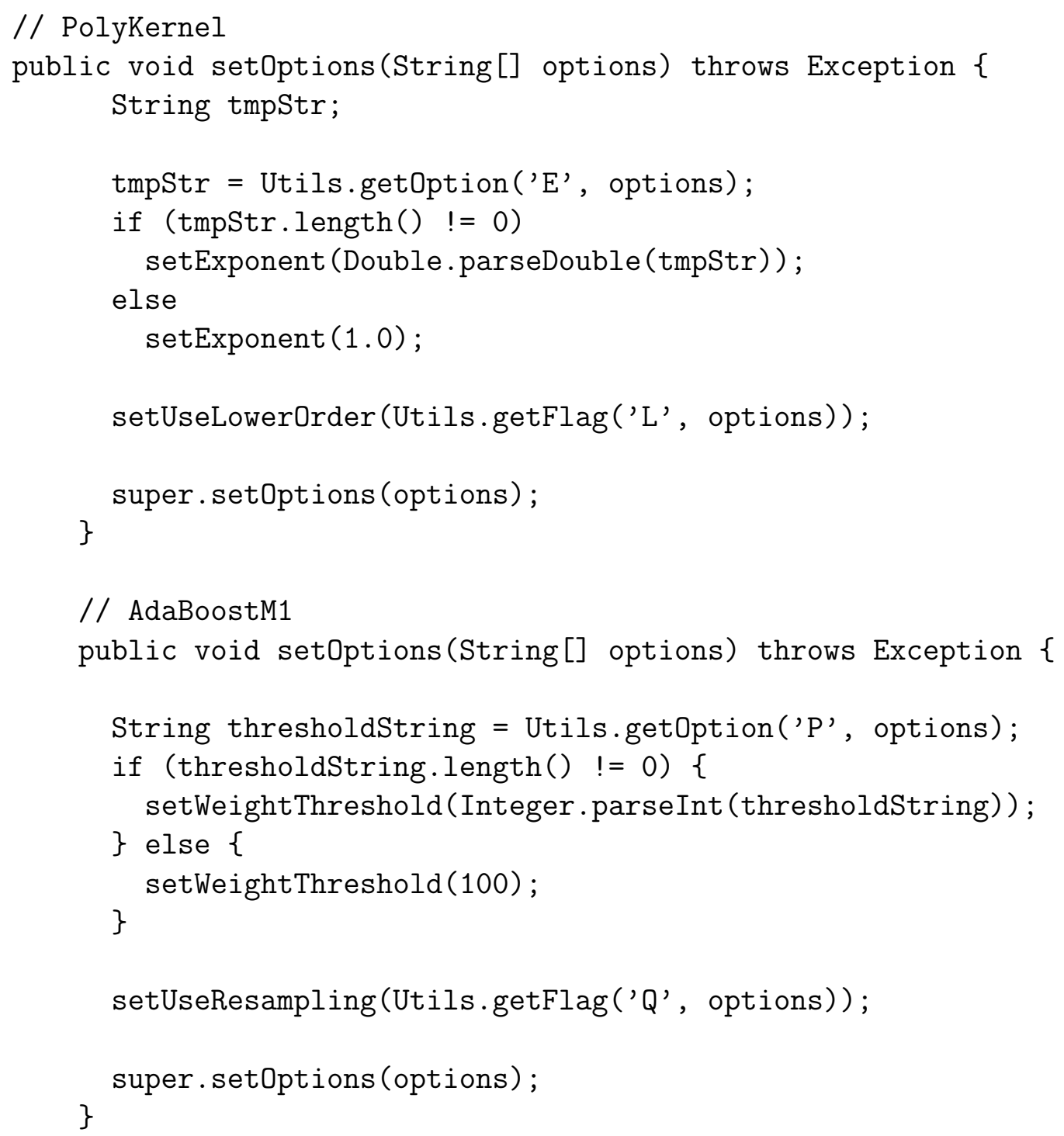

Figura 27 - PolyKernel.setOptions(String[]) e AdaBoostM1.setOptions(String[])

Tabela 18 - Consolidação das avaliações dos experimentos

\begin{tabular}{c|c|c|c|c|c}
\hline Grupo & $\begin{array}{c}\text { Treinamento } \\
\text { suficiente }\end{array}$ & $\begin{array}{c}\text { Treinamento } \\
\text { insuficiente }\end{array}$ & $\begin{array}{c}\text { Clones } \\
\text { sem Tipo }\end{array}$ & $\begin{array}{c}\text { Menos de } \\
\mathbf{5} \text { anos } \\
\text { com Java }\end{array}$ & $\begin{array}{c}\text { Mais de } \\
\mathbf{5} \text { anos } \\
\text { com Java }\end{array}$ \\
\hline A & 5 & 0 & 0 & 2 & 3 \\
\hline B & 4 & 0 & 0 & 1 & 3 \\
\hline C & 3 & 0 & 0 & 0 & 3 \\
\hline Total (\%) & $\mathbf{1 0 0 , 0 0}$ & $\mathbf{0 , 0 0}$ & $\mathbf{0 , 0 0}$ & $\mathbf{2 5 , 0 0}$ & $\mathbf{7 5 , 0 0}$ \\
\hline
\end{tabular}

Todos os pares de código analisados pelos programadores foram adicionados ao benchmark criado e as classificações foram utilizadas como base para a análise automática dos resultados obtidos pelas ferramentas submetidas a esse benchmark. A próxima seção 


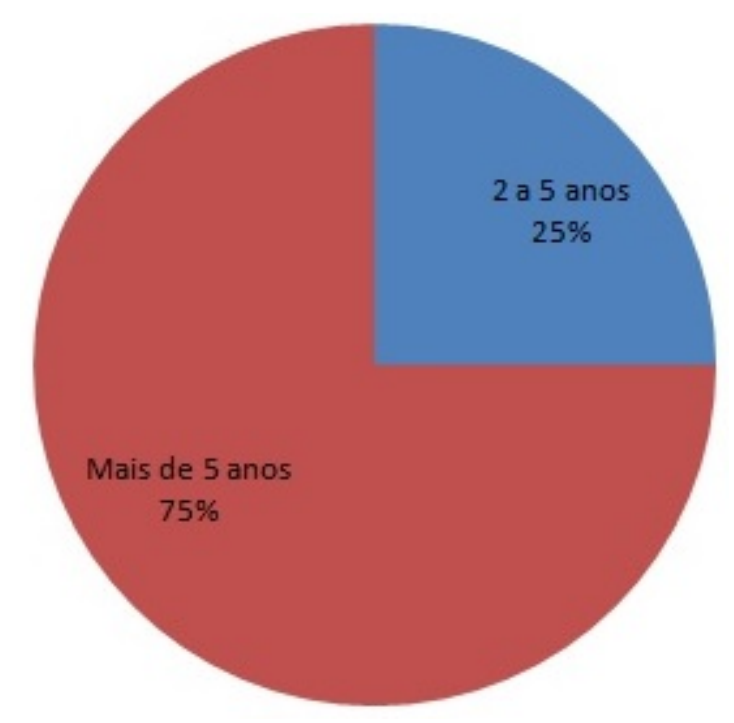

Figura 28 - Experiência dos programadores participantes

detalha o processo de criação do benchmark.

\subsection{Criação do benchmark}

O benchmark foi criado com base nos resultados obtidos dos experimentos realizados com os programadores e com base nos clones adicionados pelos pesquisadores. As próximas seções detalharão os passos realizados para a utilização do benchmark, desde a compilação dos pares de métodos em um mesmo projeto à construção do mecanismo de análise automática.

\subsubsection{Criação do projeto com os pares de métodos}

Um projeto contendo os oitenta pares de clones sorteados durante o experimento foi criado. O nome desse projeto é Programmer Classified Clone Benchmark (PCCB), pois foi criado com base nas classificações de clones fornecidas por programadores ao invés de opiniões dos pesquisadores. A complexidade da tarefa residiu nas origens e especialidades distintas dos programas selecionados para a realização do experimento. Por exemplo, os pares de métodos da weka-3.7.6 não são compatíveis com os da jtopas-0.8, pois enquanto a primeira biblioteca contém algoritmos de inteligência artificial a última trata de operações com cadeias de texto.

Ficou definido portanto que o PCCB conteria apenas os códigos compiláveis dos candidatos a clones e suas dependências básicas. Isso significa que ele é compilável, mas 
não executável segundo uma semântica objetiva, ou seja, não realiza de fato uma tarefa. Esse aspecto pode impossibilitar análises de possíveis ferramentas de detecção de clones baseadas em análise dinâmica de código [43].

O procedimento para criar o projeto está ilustrado na Figura 29 e é o que se segue. O procedimento foi realizado para todos os pares de métodos sorteados para o experimento. Para cada um dos métodos do par, a classe que possui o método foi criada no PCCB com seu nome completo, ou seja, pacote e nome da classe. O método em seguida foi copiado para dentro da classe. As classes e os métodos dos quais o método em questão depende também foram criadas no projeto. Quando as dependências também apresentaram erros de compilação, suas dependências também foram criadas no projeto.

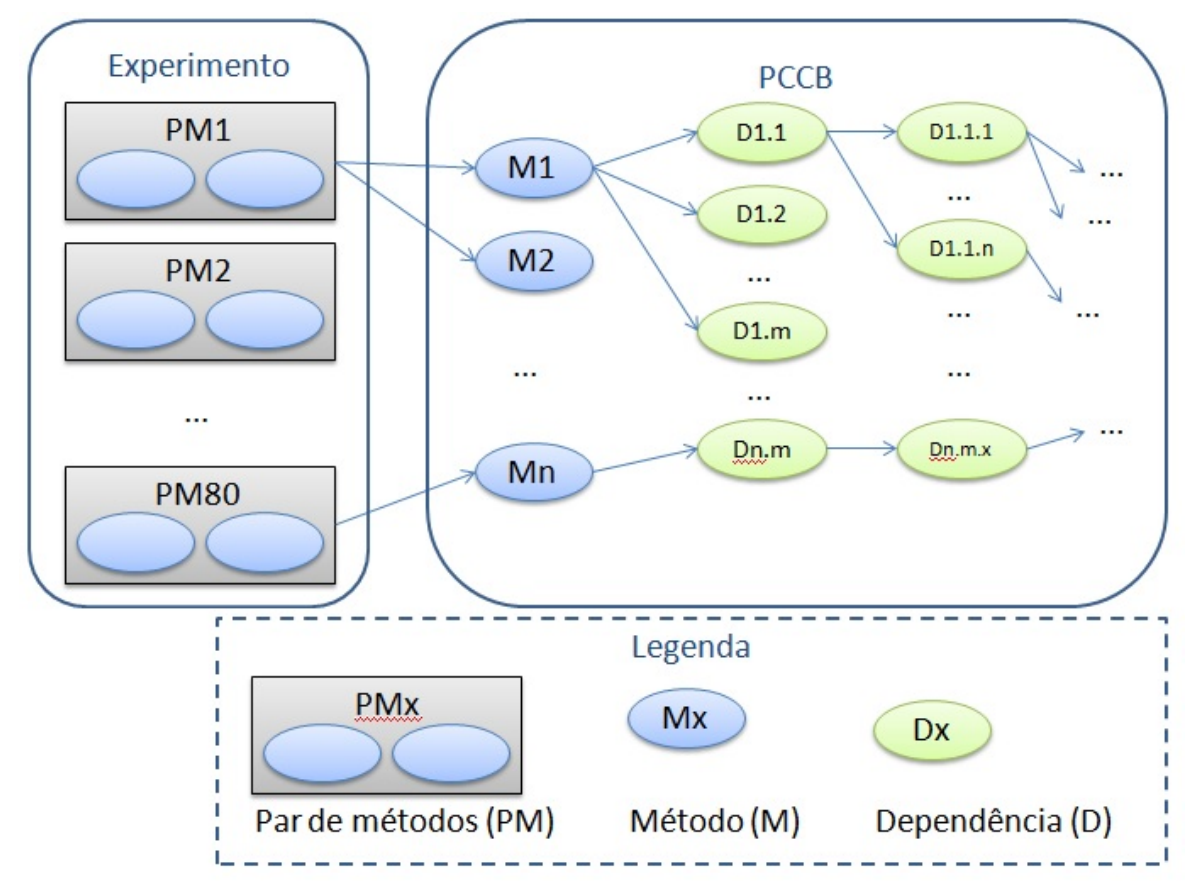

Figura 29 - Ilustração da criação do PCCB

O resultado final foi o PCCB, um projeto que possui tanto os pares de métodos analisados pelos programadores que participaram do experimento quanto suas dependências. O objetivo dele é servir como benchmark para ferramentas de análise de clones. O próximo passo foi a modelagem e criação do mecanismo de análise automática dos resultados reportados pelos detectores de clones.

\subsubsection{Mecanismo de análise dos resultados}

Automação na análise de resultados reportados por diferentes ferramentas é um requisito para um benchmark, pois mitiga os problemas de escassez de tempo, de erros humanos 
e de falta de reprodutibilidade dos experimentos. O mecanismo de análise automática de resultados de detectores de clones, Automatic Clone Detection Result Analysis (ACDRA), foi criado nesta pesquisa com o intuito de automatizar as análises realizadas. A ACDRA recebe como entrada dois arquivos delimitados por vírgulas, sendo que um deles contém os resultados reportados pela ferramenta que está sendo submetida ao benchmark e o outro arquivo contém os resultados esperados pelo benchmark.

A ACDRA processa um arquivo de resultados esperados que segue um padrão de disposição dos dados. O delimitador do arquivo é o caractere vírgula (,). Cada linha do arquivo refere-se a um par de métodos, sendo que a primeira coluna é o nome do primeiro método comparado, a segunda coluna é o nome do segundo método e a terceira coluna é o resultado esperado. O resultado esperado deve ser true para linhas nas quais espera-se que clones sejam reportados ou false caso o par de métodos não seja referente a um clone. O arquivo não contém cabeçalhos ou rodapés, conforme pode ser visualizado na Figura 30. Essa figura ilustra o cenário no qual dois resultados são esperados. O primeiro é um resultado positivo para clones na comparação entre foo.A.metodo1 e bar.B.metodo2. O segundo é um resultado negativo na comparação entre foo.A.método1 e foo.A.método3.

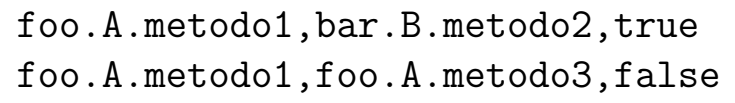

Figura 30 - ACDRA - Arquivo de resultados esperados

O arquivo de resultados, ou seja, aquele no qual os resultados das ferramentas submetidas ao benchmark estarão presentes, possui formato idêntico ao arquivo de resultados esperados. A Figura 31 ilustra um arquivo de resultados reportados. Se esse arquivo fosse comparado ao da Figura 30, a análise automática reportaria um acerto de cinquenta por cento, pois a classificação da comparação entre foo.A.metodo1 e bar.B.metodo2 estaria correta, porém a classificação resultante da comparação entre foo.A.método1 e foo.A.método3 estaria incorreta, uma vez que reportou o par como clone (true) quando deveria ter reportado como métodos incompatíveis (false).

foo.A.metodo1, bar.B.metodo2, true

foo.A.metodo1, foo.A.metodo3, true

Figura 31 - ACDRA - Arquivo de resultados reportados

A ACDRA processa um arquivo de configurações para encontrar os arquivos de resultados esperados e o de resultados reportados. Além disso é possível definir o local onde o arquivo contendo os resultados da análise será criado. O arquivo de configurações 
deve estar no formato de arquivo de propriedades (properties), sendo que as propriedades esperadas por ele são descritos na Tabela 19. A Figura 32 ilustra um arquivo de configurações com o qual a ACDRA tentará localizar o arquivo de resultados reportados em /home/johndoe/reported.csv e os resultados esperados em /home/johndoe/expected.csv e criará o arquivo de resultados da análise automática em /home/johndoe/benchmarkresults.csv.

Tabela 19 - Propriedades do arquivo de configurações da ACDRA

\begin{tabular}{c|c}
\hline \multicolumn{1}{c|}{ Propriedade } & Descrição \\
\hline br.usp.saeg.config.benchmark.reportedResultsFile & $\begin{array}{c}\text { Local onde a ACDRA tentará } \\
\text { localizar o arquivo de resultados } \\
\text { reportados }\end{array}$ \\
\hline br.usp.saeg.config.benchmark.expectedResultsFile & $\begin{array}{c}\text { Local onde a ACDRA tentará } \\
\text { localizar o arquivo de resultados } \\
\text { esperados }\end{array}$ \\
\hline br.usp.saeg.config.benchmark.oracleResultsFile & $\begin{array}{c}\text { Local onde a ACDRA criará o } \\
\text { arquivo de resultados da análise }\end{array}$ \\
\hline
\end{tabular}

\#File in which the results reported were exported br. usp. saeg. config. benchmark. reportedResultsFile=/home/johndoe/reported.csv

\#File in which the expected results are specified br. usp. saeg. config. benchmark. expectedResultsFile=/home/johndoe/expected.csv \#File in which the oracle results will be exported br. usp.saeg. config. benchmark. oracleResultsFile=/home/johndoe/oracle.csv

Figura 32 - ACDRA - Arquivo de configurações

O arquivo de resultados da análise automática é criado pela ACDRA após ela comparar os resultados reportados aos esperados. A Figura 33 contém o arquivo de resultados de análise automática da hipotética comparação entre os arquivos da Figura 30 e da Figura 31. As primeira linha contém o tempo de execução da comparação em milissegundos. A segunda linha é um cabeçalho e indica o início do sumário da análise. A terceira linha indica que a ferramenta reportou dois clones. A quarta linha, no entanto, que o benchmark esperava que apenas um clone fosse reportado. A quinta linha indica o percentual de acertos da ferramenta que gerou o arquivo de resultados, que no caso foi de cinquenta por cento. As linhas seis a nove do arquivo referem-se a uma tabela que compara os resultados positivos aos negativos, sendo que a sexta linha indica que houve um verdadeiro positivo, a sétima linha indica que não houve verdadeiros negativos, a oitava linha indica 
que houve um falso positivo e a nona linha indica que não houve falsos negativos. A décima linha é um cabeçalho e indica o início da seção de detalhes. A linha onze também é um cabeçalho e descreve as colunas da seção de detalhes. A primeira coluna é o primeiro método comparado, a segunda coluna é o segundo método comparado, a terceira coluna é o resultado reportado no arquivo de resultados e a quarta coluna refere-se ao resultado esperado para a comparação. As demais linhas do arquivo são dedicadas aos detalhamentos das comparações, sendo que cada linha refere-se a um par de métodos. No caso do exemplo em questão, a décima segunda e a décima terceira linha referem-se às comparações ente foo.A.método1 e bar.B.método2 e foo.A.método1 e foo.A.método3, respectivamente.

1. Time, 3334345

2. Summary

3. Clones Reported by Tool,2

4. Clones Expected by Benchmark,1

5. Hit Rate, $50.00 \%$

6. True Positives, 1

7. True Negatives, 0

8. False Positives, 1

9. False Negatives, 0

10. Details

11. Method 1, Method 2, Tool Reported as Clone, Oracle Reported as Clone,

12. foo.A.metodo1, bar.B.metodo2, true, true,

13. foo.A.metodo1, foo.A.metodo3, true, false,

Figura 33 - ACDRA - Arquivo de resultados da análise automática dos resultados

A utilização da ACDRA é realizada utilizando-se da execução de comandos na linha de comandos do sistema operacional. É necessário ter um ambiente de execução Java (JRE - Java Runtime Environment) ${ }^{7}$ para executar a ACDRA, que foi compilada em Java. A Figura 34 ilustra uma estrutura de diretórios criada para a execução da análise automática. Com essa estrutura, em um sistema baseado no sistema operacional Linux ${ }^{8}$ os comandos da Figura 35 executariam a ferramenta, que exportaria o arquivo de resultado da análise automática no local definido pelo arquivo config.properties.

A arquitetura de alto nível da ACDRA é descrita no Apêndice D.

\footnotetext{
${ }^{7}$ http://www.oracle.com/technetwork/java/javase/downloads/index.html

${ }^{8}$ http://www.linux.org/
} 


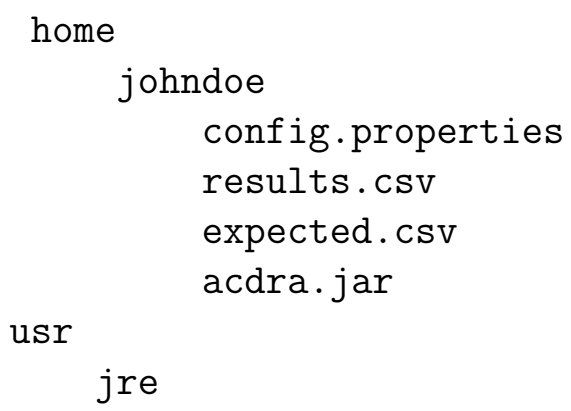

Figura 34 - Exemplo de estrutura de diretórios para execução da ACDRA

cd /home/johndoe

sudo /usr/jre/bin/java - jar acdra.jar

br.usp.saeg.clonedetection. benchmark. Benchmark config.properties

Figura 35 - Comando para executar a ACDRA

\subsection{Conclusão do capítulo}

Este capítulo descreveu os passos realizados para criar um benchmark de ferramentas de detecção de clones. A motivação para a criação de um benchmark foi apresentada. Em seguida um método de obtenção de pares de clones obtidos de programas de código aberto e classificados por programadores da indústria e da academia foi definido. A aplicação do método e a análise dos resultados obtidos por ele foram detalhados. Por fim, a estrutura, a modelagem e a maneira de utilizar o benchmark foram explicados.

Contribuições para a área de pesquisa de detecção de clones foram apresentadas neste capítulo. A primeira foi uma classificação de tipos de clones com base nas diversas definições existentes na literatura. O ganho com essa abordagem é a visão consolidada dos tipos de clones. Um novo tipo de clones foi identificado, o clone interprocedimental. O conhecimento desse tipo de clones é relevante para aplicações de refatoração, visto que os padrões apresentados por esse tipo de clones podem indicar possíveis pontos nos quais aplicar técnicas de extração de métodos e polimorfismo podem trazer benefícios para os sistemas, como a remoção de código duplicado. A identificação desses padrões também auxilia nas atividades de entendimento de sistemas e em manutenções como correções de erros ou evoluções no modelo de negócios.

Outra contribuição apresentada foi a classificação de pares de métodos em clones ou não clones sob o ponto de vista de programadores da indústria e da academia. Essa classificação possibilitou a confirmação de que os clones identificados em pesquisas condizem com o ponto de vista de programadores ativos no mercado e na academia e é uma fonte 
confiável de classificação de clones, visto que cada par foi analisado por três programadores.

O resultado final desta parte da pesquisa foi a construção de uma base centralizada de código para realizar benchmarks de ferramentas de detecção de clones, o PCCB, e um mecanismo de criação automática de relatórios de clones, a ACDRA. O único mecanismo que havia até então era o de Bellon et al. (2007), que baseia-se em programas Java compilados para versões antigas da JVM.

O PCCB e a ACDRA foram utilizados para a validação da pergunta de pesquisa deste trabalho, mas antes da avaliação uma técnica de detecção interprocedimental de clones semânticos foi proposta e desenvolvida. O próximo capítulo detalha a técnica proposta. 


\section{Capitulo 5}

\section{Detecção Interprocedimental de Clo- nes Semânticos}

Em determinados casos, apesar dos códigos fontes de procedimentos comparados em um processo de detecção de clones serem similares em semântica, as chamadas de procedimentos realizadas dentro deles podem alterar o fluxo de maneira que essa similaridade deixe de ser verdadeira. Nesse cenário a técnica de detecção interprocedimental de clones semânticos pode ser aplicável. Outro cenário é na detecção de trechos de código fonte que são clones interprocedimentais. Nesses casos a lógica comum pode ser extraída e a lógica variável executada dinamicamente, utilizando, por exemplo, polimorfismo. O intuito da técnica é realizar a análise de clones também nos métodos invocados pelos métodos em análise para definir se eles são de fato clones semânticos.

Este capítulo descreve a técnica de detecção interprocedimental de clones semânticos criada neste trabalho, assim como os passos executados para desenvolvê-la e validá-la na plataforma Java.

\subsection{Definição da técnica}

A técnica é baseada na do trabalho de Albuquerque, Neves e Chaim (2012). O procedimento geral de detecção de clones é baseado na geração de GDPs a partir dos bytecodes da JVM e a comparação entre os nós dos GDPs é baseada no percentual de instruções similares após o procedimento de normalização, conforme explicado na Seção 3.2.6. Essa técnica será chamada daqui em diante de técnica convencional para facilitar futuras referências. A diferença é que instruções do tipo invoke possuem um passo a mais na análise. Instruções invoke são aquelas nas quais métodos são invocados. A técnica analisa também os GDPs das instruções invoke existentes nos nós dos GDPs. A Figura 36 ilustra um cenário no qual a análise interprocedimental altera o resultado da comparação entre dois nós de um GDP, se comparado à análise convencional. Nesse exemplo os nós 1 e 2 são similares de acordo com a abordagem de comparação de bytecodes pois as quatro 
instruções são iguais. No entanto, se os GDPs dos invokes forem analisados, é possível notar que eles não são $100 \%$ similares. Para facilitar o exemplo, os GDPs dos métodos invocados foram representados com apenas um nó cada. O nó 1.1 refere-se ao GDP do método invocado pela instrução invoke do nó 1 e o nó 2.1 refere-se ao GDP invocado pela instrução invoke do nó 2. Esses dois nós não são 100\% similares pois enquanto o primeiro realiza uma operação de soma o último realiza uma operação de subtração. Segundo a técnica proposta de análise interprocedimental, os invokes dos nós 1 e 2 são, portanto, diferentes, o que torna os nós menos similares.

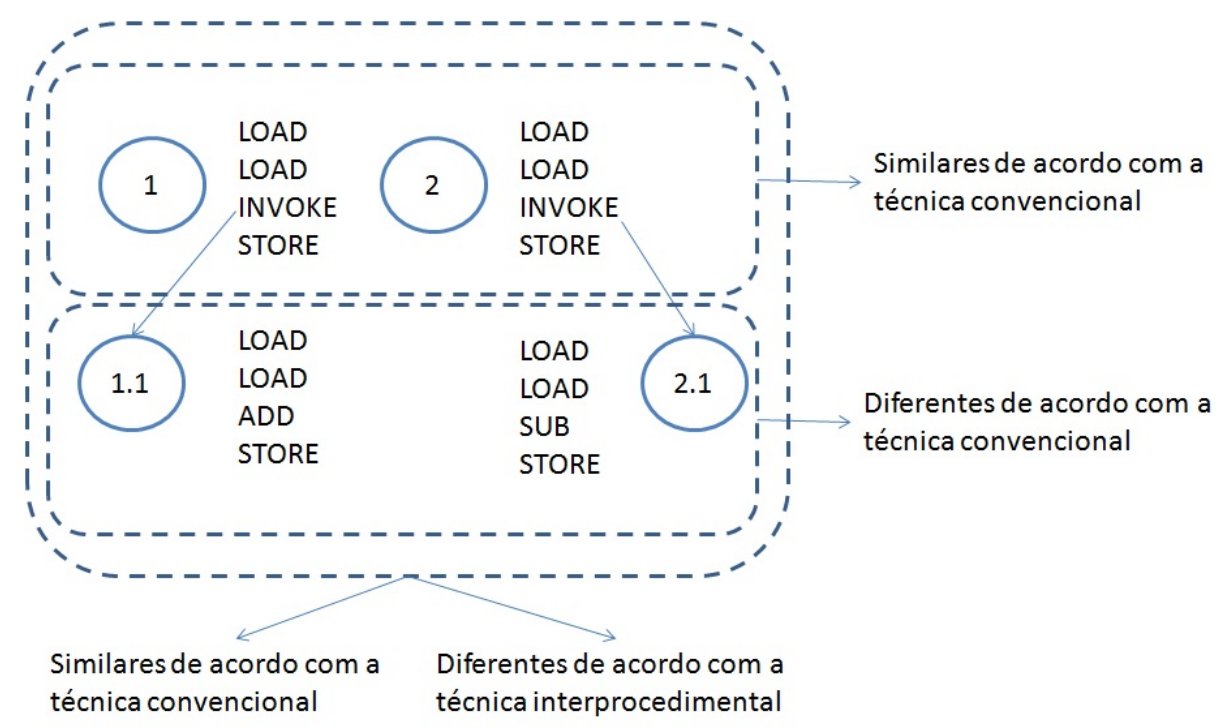

Figura 36 - Análise interprocedimental em bytecodes

A técnica de análise interprocedimental de clones semânticos pode revelar-se, no entanto, custosa para o processo geral de detecção de clones. Os GDPs dos métodos invocados em cada nó devem ser gerados e comparados. Se os métodos invocados invocarem outros métodos, seus GDPs também devem ser comparados, recursivamente. O processo de análise de GDPs, que reconhecidamente consome maiores tempo e memória do que os outros $[4,8,35]$, torna-se ainda mais custoso. Heurísticas e filtros foram propostos para mitigar esse problema. A próxima seção detalhará as três heurísticas e o filtro desenvolvidos neste trabalho.

\subsection{Filtro e heurísticas para análise interprocedimen- tal}

Três heurísticas foram desenvolvidas neste trabalho com o intuito de tornar a análise interprocedimental menos custosa em relação à memória consumida e ao tempo de execução. 
A primeira heurística define que o nome completo das classes dos métodos invocados concatenados aos nomes dos próprios métodos devem ser diferentes. Caso contrário os invokes são considerados iguais. Por exemplo, o método foo.A.metodo1 seria considerado igual a um outro foo.A.metodo1, porém diferente de foo.A.metodo2. A Figura 37 ilustra o cenário. Os invokes dos nós 1 e 2 referem-se ao mesmo conjunto de nome de classe concatenado ao método, portanto os invokes são considerados iguais e a análise interprocedimental não é realizada.

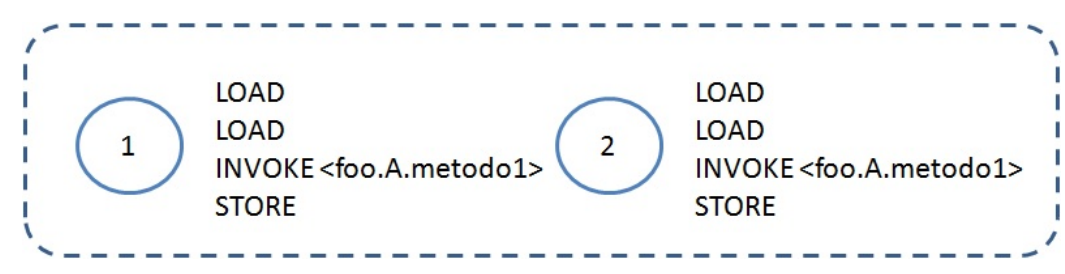

Figura 37 - Análise interprocedimental em bytecodes

A segunda heurística define que a análise intermétodos somente será realizada para nós que tenham sido considerados clones segundo a função convencional de similaridade. Caso contrário não há motivos de comparar os invokes. A Figura 38 ilustra a segunda heurística. Como os nós não são similares, pois o nó 1 adiciona enquanto o nó 2 subtrai, não é necessário executar a análise interprocedimental.

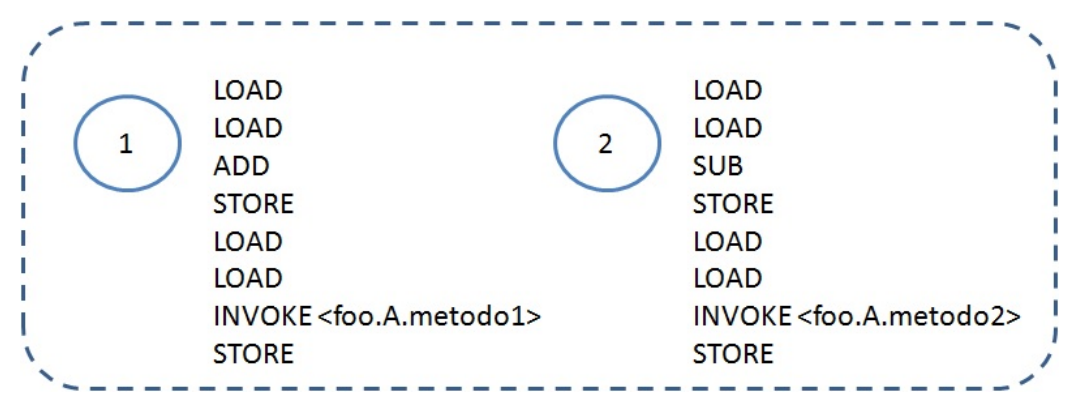

Figura 38 - Análise interprocedimental em bytecodes

A terceira e última heurística define que a comparação interprocedimental é realizada somente em um nível de chamadas, ou seja, a análise tradicional será realizada ao invés da interprocedimental se um método invocado invocar outros métodos. A Figura 39 ilustra o cenário. Apenas um nível (com os nós 1 e 2) é analisado com a técnica de interprocedimental, enquanto o segundo (nós 1.1 e 2.1) utiliza a abordagem convencional. Esse comportamento faz com que os nós 1.1 e 2.1 sejam considerados similares, pois desconsidera os comportamentos específicos dos invokes presentes neles. Por consequência, os nós 1 e 2 são também considerados similares, dado que os métodos invocados por eles foram considerados similares. 


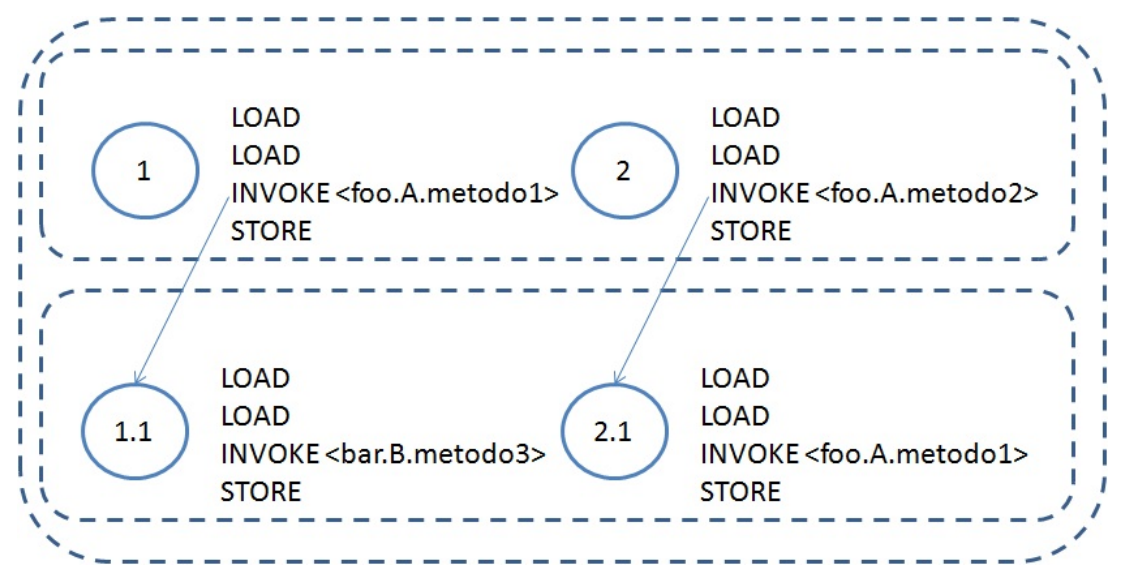

Figura 39 - Análise interprocedimental em bytecodes

Filtros comuns em ferramentas de detecção automática de clones semânticos foram apresentados na Seção 3.3.2. O objetivo de criar filtros é diminuir o número de GDPs analisados durante a detecção automática de clones, também diminuindo a memória consumida e o tempo de processamento da detecção de clones. O filtro de tamanho de GDPs $[3,5]$ foi aplicado neste trabalho. Os GDPs que forem submetidos a esse filtro devem ter um número mínimo de nós para serem analisados pelo algoritmo de detecção de clones. GDPs que não tiverem o número mínimo de nós são descartados.

Uma vez que a técnica e suas heurísticas foram definidas foi possível desenvolver a técnica na ferramenta BJCD, conforme será explicado na seção a seguir, que descreve a modelagem e o desenvolvimento.

\subsection{Modelagem e desenvolvimento da técnica}

Esta seção tem como objetivo descrever os componentes e os passos realizados para modelar e desenvolver a técnica de detecção interprocedimental de clones semânticos. Duas fases podem ser definidas no processo de incorporação da detecção interprocedimental de clones semânticos na BJCD. A primeira foi o desenvolvimento de melhorias no consumo de memória e de diminuição do tempo de detecção de clones. A segunda foi a incorporação da detecção interprocedimental de clones semânticos. As subseções a seguir descrevem as duas fases. 


\subsubsection{Desenvolvimento de melhorias de desempenho na BJCD}

Esperava-se que a detecção interprocedimental de clones semânticos consumisse mais memória e levasse mais tempo para ser executada do que a técnica convencional. Havia intenção de acrescentar a análise interprocedimental na BJCD e sabia-se que ela possuía como ponto fraco o elevado tempo que necessitava para detectar clones [6]. Foi necessário, portanto, desenvolver melhorias com o foco de diminuir esse tempo de análise da BJCD.

Uma análise de vazamento de memória foi realizada na BJCD com auxílio do ambiente Eclipse e do complemento Memory Analyser ${ }^{1}$. Foi possível identificar que havia um vazamento de memória nas classes da JaBUTi, programa que a BJCD utilizava para criar GFCs e árvores de pós-dominância. Decidiu-se então que a BJCD não deveria mais depender da JaBUTi para gerar GFCs, mas sim de um outro programa. A biblioteca $\mathrm{ASM}^{2}$ foi selecionada para realizar essa tarefa. A ASM é um programa que possui como premissa consumir pouca memória para manipular os bytecodes de programas compilados para a JVM.

A ASM é capaz de gerar GFCs, mas não gera árvores de pós-dominância e nem GDPs. Foi necessário desenvolver a geração de árvores de pós-dominância e de GDPs baseados nessa nova tecnologia. Um total de 243 linhas de código foram adicionadas à BJCD para realizar a integração com a ASM. O diagrama da Figura 40 ilustra os passos para a geração de GDPs, dado um método como entrada. As explicações para cada passo são as que se seguem.

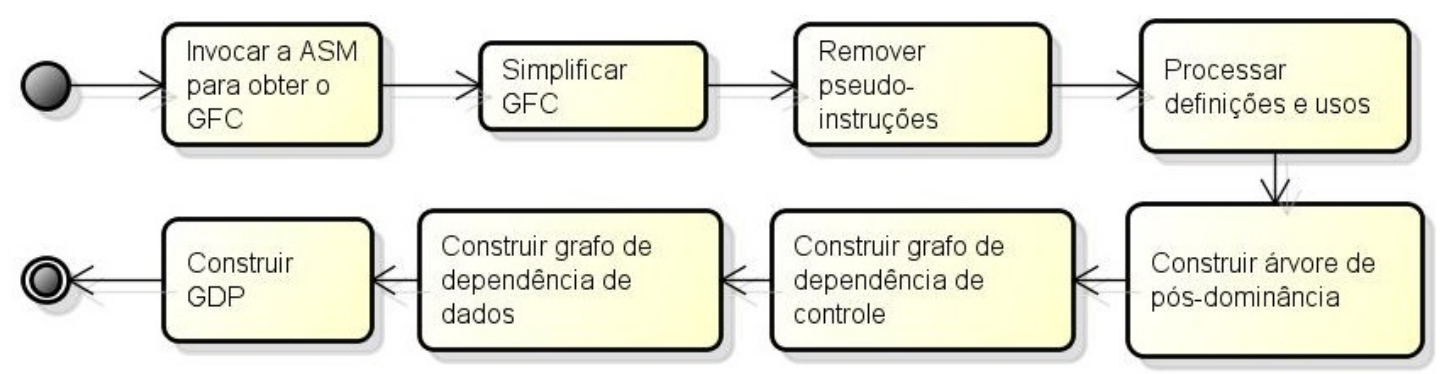

Figura 40 - Passos para a geração de GDPs na BJCD após as melhorias

Invocar a ASM para obter o GFC. A ASM retorna por padrão um nó por bytecode da JVM, criando arestas de fluxo de controle quando necessário.

Simplificar o GFC. A granularidade de instruções e nós retornada pela ASM não é utilizada pela BJCD, sendo portanto necessário simplificar o grafo de modo que instruções

\footnotetext{
${ }^{1}$ http://www.eclipse.org/mat/

${ }^{2}$ http://asm.ow2.org/
} 
que são executadas em sequência estejam no mesmo nó do GFC. Portanto é esperado que nesse passo do algoritmo o número de nós do GFC diminua, mas não o número de instruções.

Remover pseudo-instruções. Pseudo-instruções não são consideradas na detecção de clones semânticos, portanto são removidas dos nós dos GFCs. As instruções frame (mapeamento de operações condicionais), label (rótulos de instruções bytecode), return (retorno de métodos), goto (controle de fluxo de programa) e line number (número da linha) são consideradas pseudo-instruções neste trabalho. As demais instruções são utilizadas na detecção de clones. Nós sem instruções podem existir após o processo de remoção de pseudo-instruções. Esses nós são eliminados do GFC e suas arestas de entrada e de saída são combinadas entre os nós antecessores e sucessores deles.

Processar definições e usos. Informações de definição e uso são adicionadas aos nós do GFC e ele é transformado em um grafo de definição e uso nesse passo. Se o nó possuir instruções load (carregar na memória) de variáveis, o algoritmo considera que ele está usando as variáveis. Se o nó possuir instruções store (gravar na memória) de variáveis, o algoritmo considera que ele está definindo as variáveis. A operação de inc (incremento de números inteiros) computa tanto definições quanto usos para as variáveis.

Construir a árvore de pós-dominância. Os nós do GFC são percorridos em pósordem e a árvore de pós-dominância é construída. A árvore de pós-dominância é utilizada no próximo passo, que é a construção do grafo de dependência de controle.

Construir o grafo de dependência de controle. Primeiramente, todas as arestas de nós que pós-dominam outros são removidas do GFC. Depois, para cada nó do GFC, o algoritmo da Figura 41 é executado. Trata-se de um algoritmo de caminho reverso de todos os antecessores dos nós do GFC. O objetivo é definir quais nós são acionados em decorrência da execução de um predicado. Há uma condição na linha 10 na qual, se o nó antecessor contiver um dos sucessores do nó de origem, todos os filhos do nó antecessor são considerados filhos do nó de origem. Essa condição prevê o cenário no qual um desvio de fluxo de controle é invocado dentro de outro conforme pode ser visualizado na Figura 42. Nessa figura a condição B é invocada dentro da condição A. Nesse caso o bloco de código C depende tanto da satisfação da condição A quanto da condição B para ser executado. Retomando o contexto da Figura 41, a linha 12 tenta encontrar recursivamente possíveis dependências de controle nos nós antecessores ao nó de origem. O resultado final é o grafo de dependência de controle.

Construir o grafo de dependência de dados. Primeiramente as variáveis utili- 


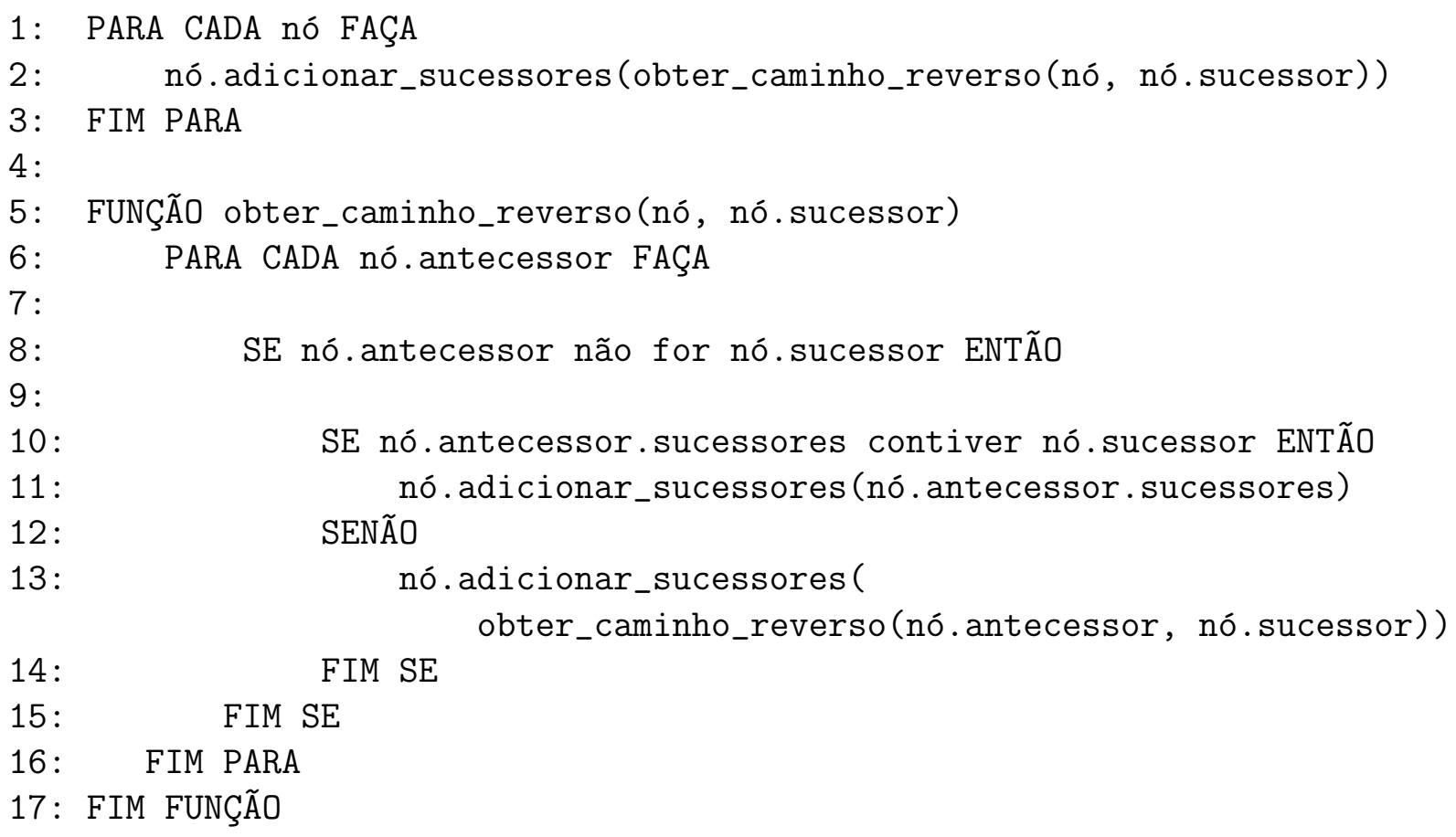

Figura 41 - Algoritmo para construir grafos de fluxo de controle

\author{
SE (A) ENTÃO \\ SE (B) ENTÃO \\ C
}

FIM SE

\title{
FIM SE
}

Figura 42 - Exemplo de dependências múltiplas de fluxo de controle

zadas no grafo de definição e uso (o antigo GFC) analisado são destacadas. O próximo passo é navegar nos nós desse grafo e definir para cada variável destacada quais são os nós que a definem e quais a usam. O último passo da geração do grafo de dependência de dados é gerar arestas entre os nós que usam variáveis e os primeiros a definir essas variáveis antes do uso. Por exemplo, considere quatro nós, N1, N2 e N3. Dado que N1 e N3 definem a variável A e que N2 a utilize. N2 somente possui dependência de dados em relação a N1, pois N3 define A somente depois que N2 realizou o uso. Nesse caso a aresta de dependência de controle seria atribuída entre N1 e N2.

Construir o GDP. O último passo é, para cada nó do método analisado, adicionar tanto as arestas do grafo de dependência de controle quanto as do grafo de dependência de dados. Nesse passo tanto as arestas do GFC quando as da árvore de pós-dominância são descartadas. 
Testes foram realizados após a construção do módulo de geração de GDPs baseado na ASM. O objetivo foi saber se o tempo de execução da detecção de clones havia diminuído. Os programas selecionados para a construção do benchmark do Capítulo 4 foram executados com a BJCD utilizando a JaBUTi para gerar os grafos e depois com a BJCD utilizando a ASM. A Tabela 20 sumariza os resultados obtidos. A BJCD baseada na JaBUTi somente conseguiu executar sem esgotamento de memória no menor dos quatro programas, jtopas-0.8, enquanto a versão baseada na ASM executou para os quatro programas. A BJCD detectou clones em 3,70 segundos utilizando ASM e em 103,11 segundos utilizando a JaBUTi. A diferença de tempo entre as duas execuções foi de 96,00\%. Concluiu-se que o desenvolvimento com a ASM trouxe resultados significativos em relação ao tempo de processamento e ao consumo de memória da BJCD. Optou-se, portanto, por utilizar essa versão da ferramenta na incorporação da detecção interprocedimental de clones semânticos. As execuções mencionadas neste trabalho, inclusive as que geraram o benchmark PCCB, foram realizadas utilizando essa versão da BJCD.

Tabela 20 - Comparação das execuções da BJCD baseada na JaBUTi contra a BJCD baseada na $A S M$

\begin{tabular}{c|c|c|c}
\hline Programa & BJCD com JaBUTi (s) & BJCD com ASM (s) & Diferença (\%) \\
\hline jtopas-0.8 & 103,11 & 3,70 & 96,41 \\
\hline checkstyle-5.5 & Esgotamento de memória & 58,54 & - \\
\hline commons-math3-3.0 & Esgotamento de memória & 138,56 & - \\
\hline weka-3.7.6 & Esgotamento de memória & $3.372,33$ & - \\
\hline
\end{tabular}

\subsubsection{Incorporação da detecção interprocedimental de clones na BJCD}

O módulo de detecção de clones semânticos foi desenvolvido de modo que, dados dois programas, filtros são aplicados. Os pares de GDPs que satisfazem as condições de todos os filtros são submetidos ao conversor de GDPs. O conversor de GDPs transforma os grafos nas estruturas de dados que são utilizadas na análise de isomorfismo. No caso, neste trabalho, foi escolhido manter os GDPs sem alteração e realizar a análise baseada na de Albuquerque, Neves e Chaim (2012). Clones contidos em outros são removidos do processamento. Os resultados finais são exportados em arquivos físicos no final do processo. $\mathrm{O}$ diagrama da Figura 43 ilustra a arquitetura em alto nível do detector interprocedimental de clones semânticos. 


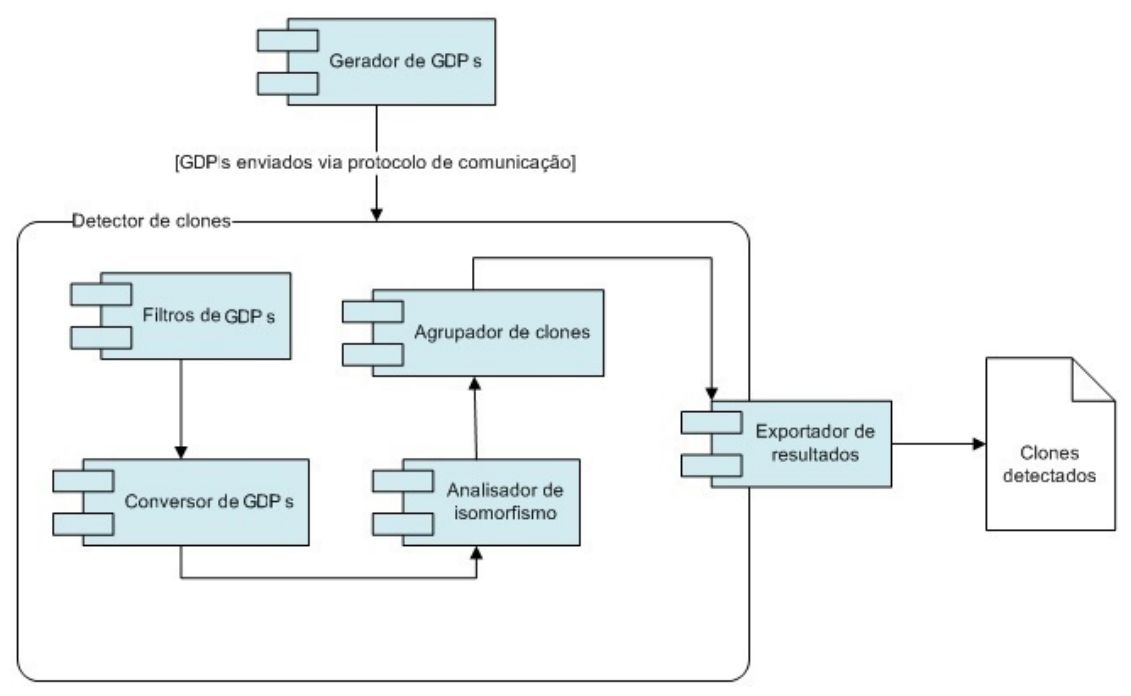

Figura 43 - Arquitetura em alto nivel do detector interprocedimental de clones
semânticos

A análise interprocedimental é realizada com base na estratégia descrita a seguir. Dados dois GDPs $G=(N, A)$ e $G^{\prime}=\left(N^{\prime}, A^{\prime}\right)$, onde $N$ e $N^{\prime}$ são os conjuntos de nós de $G$ e $G^{\prime}$, respectivamente, e $A$ e $A^{\prime}$ são os conjuntos de arestas de $G$ e $G$ ', respectivamente. Se $n \in N$ e $n^{\prime} \in N^{\prime}$ possuírem chamadas de procedimentos, os seguintes passos serão seguidos:

- se o restante dos comandos de $N$ e $N^{\prime}$ forem diferentes entre si, nenhuma comparação será feita;

- se as chamadas forem para procedimentos com nomes iguais e presentes na mesma classe, serão consideradas chamadas iguais, portanto não haverá necessidade de comparação dos GDPs dessas chamadas;

- se as chamadas não forem para procedimentos com o mesmo nome ou da mesma classe, os GDPs desses procedimentos serão submetidos aos filtros e comparados;

- esses passos serão executados recursivamente, até que se possa tomar uma decisão acerca das duas chamadas, de $n$ e $n$, serem clones ou não.

O pseudocódigo da Figura 44 ilustra as regras supracitadas.

Um ponto de atenção nessa heurística é que procedimentos com o mesmo nome podem ter comportamentos diferentes, dependendo dos argumentos deles. Os argumentos não serão considerados, uma vez que a normalização das instruções dos GDPs deve ignorar os 
FUNÇÃO analise_interprocedimental (n1, n2)

SE NÃO similar(n1, n2) ENTÃO

RETORNAR não_similares

SENÃO

SE possui_invokes(n1) OU possui_invokes(n2) ENTÃo

PARA CADA par_de(n1.invokes, n2.invokes)

SE (n1.invoke.classe IGUAL n2.invoke.classe)

E (n1.invoke.metodo.nome IGUAL n2.invoke.metodo.nome) ENTÃo SENÃO RETORNAR similares

SE passa_no_filtro(n1.invoke.gdp)

E passa_no_filtro(n2.invoke.gdp) ENTÃO

RETORNAR analise_interprocedimental(

SENÃO n1. invoke.gdp, n2. invoke.gdp)

RETORNAR não_similares

FIM SE

FIM SE

FIM PARA

SENÃO

RETORNAR similares

FIM SE

\section{FIM SE}

FIM FUNÇÃO

Figura 44 - Pseudocódigo de heurísticas de detecção interprocedimental de clones

tipos dos dados que estão sendo definidos ou usados e considerar apenas o comportamento do programa [8]. A Figura 45 ilustra essa situação. Há dois métodos na mesma classe chamados metodo. Ambos retornam valores do tipo Number, porém seus parâmetros de entrada são de tipos diferentes. Enquanto um método recebe um parâmetro do tipo Integer, o outro recebe um Long. Seus comportamentos são distintos: enquanto o método que recebe um Integer retorna a multiplicação do parâmetro por uma constante, o método que recebe um Long retorna o fatorial desse número utilizando programação recursiva. Esse é um caso no qual a heurística de considerar métodos com mesmos nomes presentes 
da mesma classe indicará um clone que na verdade é um falso positivo. Nesse sentido, é importante que a execução da heurística seja opcional. O ponto negativo de desativá-la é que o tempo de execução do algoritmo de deteç̧ão de clones pode aumentar devido a possíveis análises de isomorfismo em todos pares de GDPs.

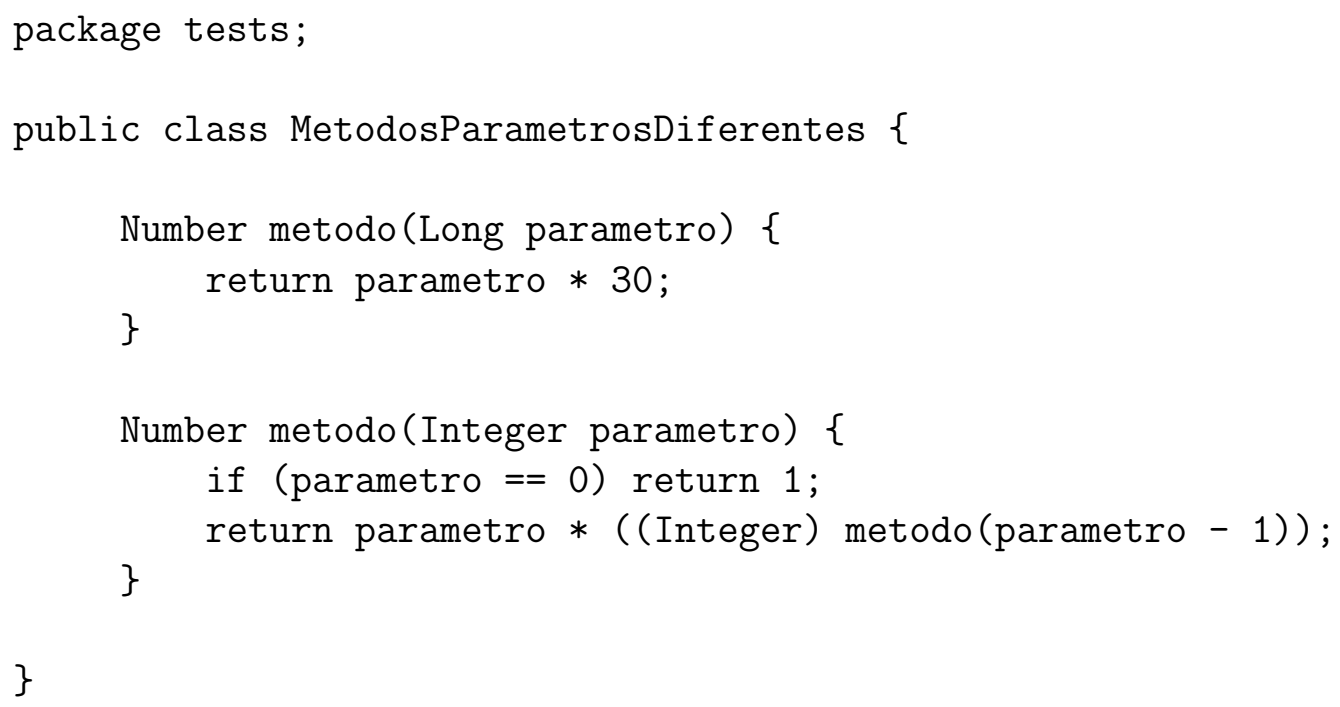

Figura $\mathbf{4 5}$ - Métodos com nomes iguais na mesma classe, mas com comportamentos diferentes

Os componentes descritos nesta seção foram incorporados à BJCD, que evoluiu à sua versão 2.0 como contribuição deste trabalho.

\subsection{Validações das técnicas propostas}

As atividades descritas nesta seção tiveram como intuito validar e avaliar o comportamento das técnicas propostas neste trabalho. Primeiramente a eficiência do filtro de tamanho de GDPs foi avaliada. A segunda atividade teve como objetivo avaliar os consumos de memória e de tempo da técnica de detecção interprocedimental de clones semânticos utilizando diferentes valores para a heurística que define quantos níveis de chamadas devem ser avaliados. A terceira atividade de validação contou com a execução da BJCD no benchmark PCCB duas vezes, sendo que a análise interprocedimental não foi utilizada na primeira execução e foi utilizada na segunda execução. O objetivo dessa terceira atividade foi comparar as taxas de acertos da análise convencional de clones semânticos com a interprocedimental. As subseções a seguir detalham as atividades de validação. 


\subsubsection{Avaliação do filtro de tamanho mínimo de GDPs}

O filtro de tamanho de GDPs foi avaliado como se segue. Os programas jtopas0.8 e checkstyle-5.5 foram selecionados para realizar a avaliação do filtro de tamanho de GDPs. A BJCD foi executada em cada programa, variando as configurações de modo que os GDPs tivessem que possuir um nó no mínimo até três nós. Cinco execuções foram realizadas em cada programa para cada configuração, totalizando quinze execuções por programa. Os tempos de execução em milissegundos foram tomados. Um parâmetro foi adicionado à BJCD, conforme pode ser visualizado na Figura 46. O número informado nesse parâmetro é o mínimo de nós que GDPs deverão possuir para serem analisados pela BJCD.

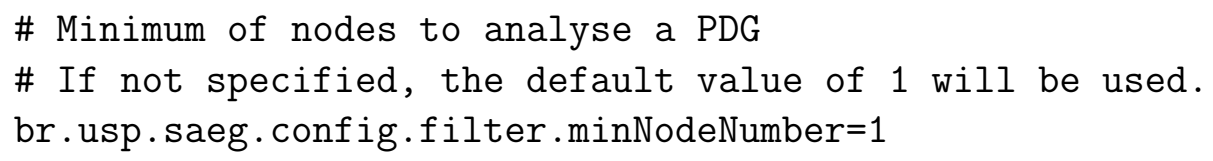

Figura $4 \mathbf{6}$ - Configuração de filtro de tamanho mínimo de GDP na BJCD

A memória máxima consumida em todas as execuções foi de aproximadamente 220 megabytes para a jtopas-0.8 e de 464 megabytes para a checkstyle-5.5. O consumo de memória não variou com a variação do tamanho mínimo de GDPs.

A Tabela 21 apresenta os resultados obtidos para a jtopas-0.8. As linhas representam as execuções. A primeira coluna apresenta o número da execução e as demais apresentam os tempos de execução em milissegundos para cada configuração de filtro de tamanho mínimo de GDP. As exceções são a penúltima e a última linha. A penúltima linha apresenta as médias de execução e a última linha apresenta o percentual de ganho de tempo médio que a configuração da direita apresentou em relação à da esquerda. Quanto maior o número mínimo de nós configurado, mais rápida foi a execução para a jtopas-0.8. Execuções que exigiam que GDPs possuíssem no mínimo dois nós para serem comparados foram em média 9,31\% mais rápidas do que as que exigiam um nó. Analogamente, execuções que exigiam três nós foram em média 10,12\% mais rápidas do que execuções que exigiam dois nós.

A Tabela 22 apresenta os resultados obtidos para a checkstyle-5.5. A organização da tabela é igual à da Tabela 21. Os resultados obtidos reforçam os observados nas execuções para a jtopas-0.8. Quanto maior o número mínimo de nós configurado, mais rápida foi a execução também para a checkstyle-5.5. Execuções que exigiam que GDPs possuíssem no mínimo dois nós para serem comparados foram em média 30,60\% mais rápidas do que 
Tabela 21 - Avaliação de filtro de número mínimo de nós de GDPs para jtopas-0.8

\begin{tabular}{c|c|c|c}
\hline Execução & 1 nó (ms) & 2 nós $(\mathbf{m s})$ & 3 nós $(\mathbf{m s})$ \\
\hline 1 & 3.678 & 3.023 & 2.910 \\
\hline 2 & 3.537 & 3.033 & 2.976 \\
\hline 3 & 3.647 & 2.999 & 2.930 \\
\hline 4 & 3.616 & 3.638 & 2.855 \\
\hline 5 & 3.447 & 3.563 & 2.940 \\
\hline Média & $\mathbf{3 . 5 8 5}$ & $\mathbf{3 . 2 5 1}$ & $\mathbf{2 . 9 2 2}$ \\
\hline Ganho (\%) & - & $\mathbf{9 , 3 1}$ & $\mathbf{1 0 , 1 2}$ \\
\hline
\end{tabular}

as que exigiam um nó. Esse é um resultado ainda mais expressivo do que o apresentado para a jtopas-0.8. Execuções que exigiam três nós foram em média 4,21\% mais rápidas do que execuções que exigiam dois nós.

Tabela 22 - Avaliação de filtro de número mínimo de nós de GDPs para checkstyle-5.5

\begin{tabular}{c|c|c|c}
\hline Execução & 1 nó (ms) & 2 nós (ms) & 3 nós (ms) \\
\hline 1 & 55.664 & 43.005 & 40.376 \\
\hline 2 & 56.388 & 41.408 & 42.945 \\
\hline 3 & 60.202 & 41.767 & 39.693 \\
\hline 4 & 65.646 & 45.429 & 39.699 \\
\hline 5 & 67.677 & 40.449 & 40.426 \\
\hline Média & $\mathbf{6 1 . 1 1 5}$ & $\mathbf{4 2 . 4 1 2}$ & $\mathbf{4 0 . 6 2 8}$ \\
\hline Ganho (\%) & - & $\mathbf{3 0 , 6 0}$ & $\mathbf{4 , 2 1}$ \\
\hline
\end{tabular}

\subsubsection{Avaliação dos consumos de tempo e memória da análise interprocedimental}

O consumo de tempo da análise interprocedimental foi avaliado de maneira análoga à avaliação do filtro de tamanho mínimo de GDPs. Os programas jtopas-0.8 e checkstyle-5.5 foram selecionados para realizar a avaliação. A BJCD foi executada em cada programa, variando as configurações de modo que análises interprocedimentais que analisavam GDPs de zero (sem análise interprocedimental, ou seja, análise convencional) a três níveis de chamadas fossem executadas. Cinco execuções foram realizadas em cada programa para cada configuração, totalizando quinze execuções por programa. Os tempos de execução em milissegundos foram tomados. Um parâmetro foi adicionado à BJCD, conforme pode ser visualizado na Figura 47. Um valor maior do que zero nesse parâmetro indica que 
a BJCD realizará a análise interprocedimental considerando o número de níveis de chamadas configurado. Por exemplo, o valor 1 indica que somente chamadas realizadas nos métodos originais serão consideradas, enquanto o valor 2 indica que chamadas realizadas em métodos invocados pelos originais também serão consideradas.

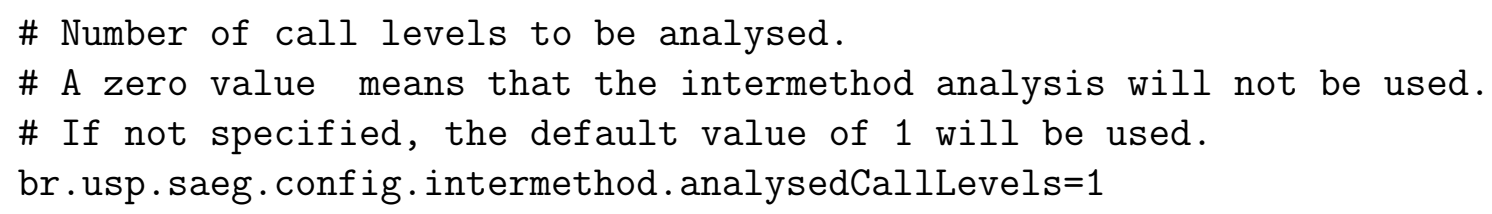

Figura 47 - Configuração de análise interprocedimental na BJCD

A memória máxima consumida em todas as execuções foi de aproximadamente 220 megabytes para a jtopas-0.8 e de 464 megabytes para a checkstyle-5.5. O consumo de memória não variou com a variação do número de níveis analisados com a técnica interprocedimental, diferentemente do que era esperado neste trabalho.

A Tabela 23 apresenta os resultados obtidos para a jtopas-0.8. As linhas representam as execuções. A primeira coluna apresenta o número da execução e as demais apresentam os tempos de execução em milissegundos para cada configuração de quantidade de níveis analisados de maneira interprocedimental. As exceções são a penúltima e a última linha. A penúltima linha apresenta as médias de execução e a última linha apresenta o percentual de ganho de tempo médio que a configuração da direita apresentou em relação à da esquerda. Execuções com análise interprocedimental mostraram-se mais lentas do que as convencionais, porém o número de níveis analisados não influencia negativamente no tempo de execução uma vez que a análise interprocedimental está sendo realizada. Execuções com análise interprocedimental que analisavam um nível de chamadas foram em média 14,87\% mais lentas do que as convencionais. Execuções com análise interprocedimental que analisavam dois níveis de chamadas foram em média 5,89\% mais rápidas do que as que analisavam um nível. Execuções com análise interprocedimental que analisavam três níveis de chamadas foram em média 1,92\% mais lentas do que as que analisavam dois níveis. Esses dados sugerem que a análise interprocedimental é mais lenta do que a tradicional, porém o número de níveis analisados não afeta o tempo de execução para jtopas-0.8.

A Tabela 24 apresenta os resultados obtidos para a checkstyle-5.5. A organização da tabela é igual à da Tabela 23. Os resultados obtidos reforçam os observados nas execuções para a jtopas-0.8. Execuções com análise interprocedimental mostraram-se mais lentas do que as convencionais, porém o número de níveis analisados não influencia negativamente 
Tabela 23 - Avaliação de tempo da análise interprocedimental para jtopas-0.8

\begin{tabular}{c|c|c|c|c}
\hline Execução & Convencional (ms) & 1 nível (ms) & 2 níveis (ms) & 3 níveis (ms) \\
\hline 1 & 2.910 & 3.068 & 3.016 & 3.124 \\
\hline 2 & 2.976 & 3.587 & 3.053 & 3.118 \\
\hline 3 & 2.930 & 3.057 & 3.555 & 3.705 \\
\hline 4 & 2.855 & 3.570 & 3.044 & 3.078 \\
\hline 5 & 2.940 & 3.502 & 3.127 & 3.074 \\
\hline Média & $\mathbf{2 . 9 2 2}$ & $\mathbf{3 . 3 5 7}$ & $\mathbf{3 . 1 5 9}$ & $\mathbf{3 . 2 2 0}$ \\
\hline Ganho (\%) & $\mathbf{-}$ & $\mathbf{- 1 4 , 8 7}$ & $\mathbf{5 , 8 9}$ & $\mathbf{- 1 , 9 2}$ \\
\hline
\end{tabular}

no tempo de execução uma vez que a análise interprocedimental está sendo realizada. Execuções com análise interprocedimental que analisavam um nível de chamadas foram em média 33,84\% mais lentas do que as convencionais. Execuções com análise interprocedimental que analisavam dois níveis de chamadas foram em média 7,35\% mais rápidas do que as que analisavam um nível. Execuções com análise interprocedimental que analisavam três níveis de chamadas foram em média 10,94\% mais rápidas do que as que analisavam dois níveis. Esses dados sugerem que a análise interprocedimental é mais lenta do que a tradicional, porém o número de níveis analisados não afeta o tempo de execução negativamente para checkstyle-5.5.

Tabela 24 - Avaliação de tempo da análise interprocedimental para checkstyle-5.5

\begin{tabular}{c|c|c|c|c}
\hline Execução & Convencional (ms) & 1 nível $\mathbf{( m s )}$ & $\mathbf{2}$ níveis $(\mathbf{m s})$ & 3 níveis $(\mathbf{m s})$ \\
\hline 1 & 40.376 & 64.835 & 74.294 & 48.700 \\
\hline 2 & 42.945 & 47.770 & 43.833 & 45.338 \\
\hline 3 & 39.693 & 52.806 & 43.939 & 43.837 \\
\hline 4 & 39.699 & 44.341 & 46.525 & 43.128 \\
\hline 5 & 40.426 & 62.126 & 43.306 & 43.331 \\
\hline Média & $\mathbf{4 0 . 6 2 8}$ & $\mathbf{5 4 . 3 7 6}$ & $\mathbf{5 0 . 3 7 9}$ & $\mathbf{4 4 . 8 6 7}$ \\
\hline Ganho (\%) & - & $\mathbf{- 3 3 , 8 4}$ & $\mathbf{7 , 3 5}$ & $\mathbf{1 0 , 9 4}$ \\
\hline
\end{tabular}

\subsubsection{Comparação da taxa de acerto da análise convencional com a interprocedimental}

A validação ocorreu como se segue. A BJCD foi executada duas vezes no benchmark PCCB. A primeira vez foi utilizando a análise tradicional e a segunda vez foi utilizando a análise interprocedimental em um nível de chamadas. A ACDRA foi utilizada para validar 
os resultados obtidos nas execuções. O arquivo de resultados esperados foi criado de acordo com os resultados obtidos na criação do PCCB. A Tabela 25 sumariza os resultados obtidos após a execução da ACDRA nos resultados reportados nas duas execuções da BJCD.

Tabela 25 - Comparação de resultados da análise convencional com a interprocedimental

\begin{tabular}{c|c|c|c}
\hline Análise & Falsos Positivos & Falsos Negativos & Taxa de acerto \\
\hline Tradicional & 4 & 0 & $95,0 \%$ \\
\hline Interprocedimental & 2 & 0 & $97,5 \%$ \\
\hline
\end{tabular}

O resultado indica que, de acordo as classificações dos programadores que participaram da construção do benchmark, a análise interprocedimental tem uma taxa de acerto maior do que a convencional. Enquanto a análise convencional teve uma taxa de acerto de 95\%, a interprocedimental acertou 97,5\% das classificações. A análise interprocedimental identificou diferenças nas chamadas dentro dos métodos avaliados, portanto classificou dois dos pares de candidatos citados na Seção 4.2.3 como não clones. Esses pares são os métodos fireEditingStopped() e fireEditingCanceled() e PolyKernel.setOptions(String[]) e AdaBoostM1.setOptions(String[]). Os pares de métodos rotateCW() e rotateCCW() e createRowRealMatrix(double[]) e createColumnRealMatrix(double[]) continuaram sendo identificados como clones. Isso porque rotate $C W($ ) e rotate $C C W($ ) não invocam métodos. Esses métodos apenas manipulam atributos. Já createRowRealMatrix(double[]) e createColumnRealMatrix(double[]) invocam o mesmo método, setEntry(int, int, int). A diferença é a ordem na qual os parâmetros são fornecidos. As classificações dos outros setenta e seis pares de candidatos a clones foram iguais nas análises convencionais e interprocedimentais.

A próxima seção apresenta uma discussão sobre as possíveis ameaças à validade das validações.

\subsection{Ameaças à validade}

A avaliação da taxa de acerto da técnica interprocedimental em relação à convencional foi realizada com base em um benchmark criado com base nas opiniões de programadores. Programadores possuem características inerentes a seus estilos de programação e experiência. Essas características podem ser benéficas ou maus hábitos. Por exemplo, a inserção proposital e descontrolada de clones em sistemas pode ser considerada um mau hábito. 
É possível que alguns dos programadores entrevistados não tenham considerado alguns dos quatro pares de métodos citados na Seção 4.2 .3 como clones porque consideram que é aceitável clonar código se as chamadas presentes nesses métodos forem distintas. É possível que os programadores não tenham pensado na possibilidade de reescrever o código de modo que os clones sejam eliminados ao mesmo tempo que o caráter distinto das chamadas invocadas nos métodos é mantido.

As Figuras 48 e 49 ilustram um cenário no qual os métodos fireEditingStopped() e fireEditingCanceled() são reescritos de forma que deixem de ser clones. O trecho que contém as invocações com comportamento distinto é extraído para a interface ProcessListenerStrategy, que contém como implementações classes que invocam os métodos específicos. A classe FireEditingStoppedProcessListenerStrategy invoca o método editingStopped(ChangeEvent) e a classe FireEditingCanceledProcessListenerStrategy invoca editingCanceled(ChangeEvent). A Figura 49 ilustra a refatoração dos métodos. Um método chamado fireEditing(ProcessListenerStrategy) foi criado. Ele contém a lógica comum a fireEditingStopped() e fireEditingCanceled(), porém recebe como parâmetro um ProcessListenerStrategy, responsável por executar as chamadas com comportamentos distintos de acordo com a implementação que é instanciada. Agora o método fireEditingStopped() somente deve invocar o método fireEditing(ProcessListenerStrategy) informando uma instância de FireEditingStoppedProcessListenerStrategy como parâmetro. Analogamente, o método fireEditingStopped() invoca fireEditing(ProcessListenerStrategy) informando uma instância de FireEditingCanceledProcessListenerStrategy como parâmetro.

Essas alterações no código podem não ter sido consideradas pelos programadores durante a análise dos métodos, isso é, o foco das análises deles foi o uso para manutenção e evolução de software e não para refatoração ou entendimento de código.

Outra ameaça à validade é o número de programadores que participaram da construção do benchmark. É necessário realizar atividades com mais programadores para consolidar as classificações dos pares de candidatos a clones com uma relevância estatística maior.

\subsection{Conclusão do capítulo}

Uma nova técnica de detecção de clones semânticos, a técnica interprocedimental, foi definida neste capítulo. Essa técnica diferencia-se das outras por analisar as chamadas de procedimentos que ocorrem nos fragmentos de código fonte. O objetivo dela é evitar 


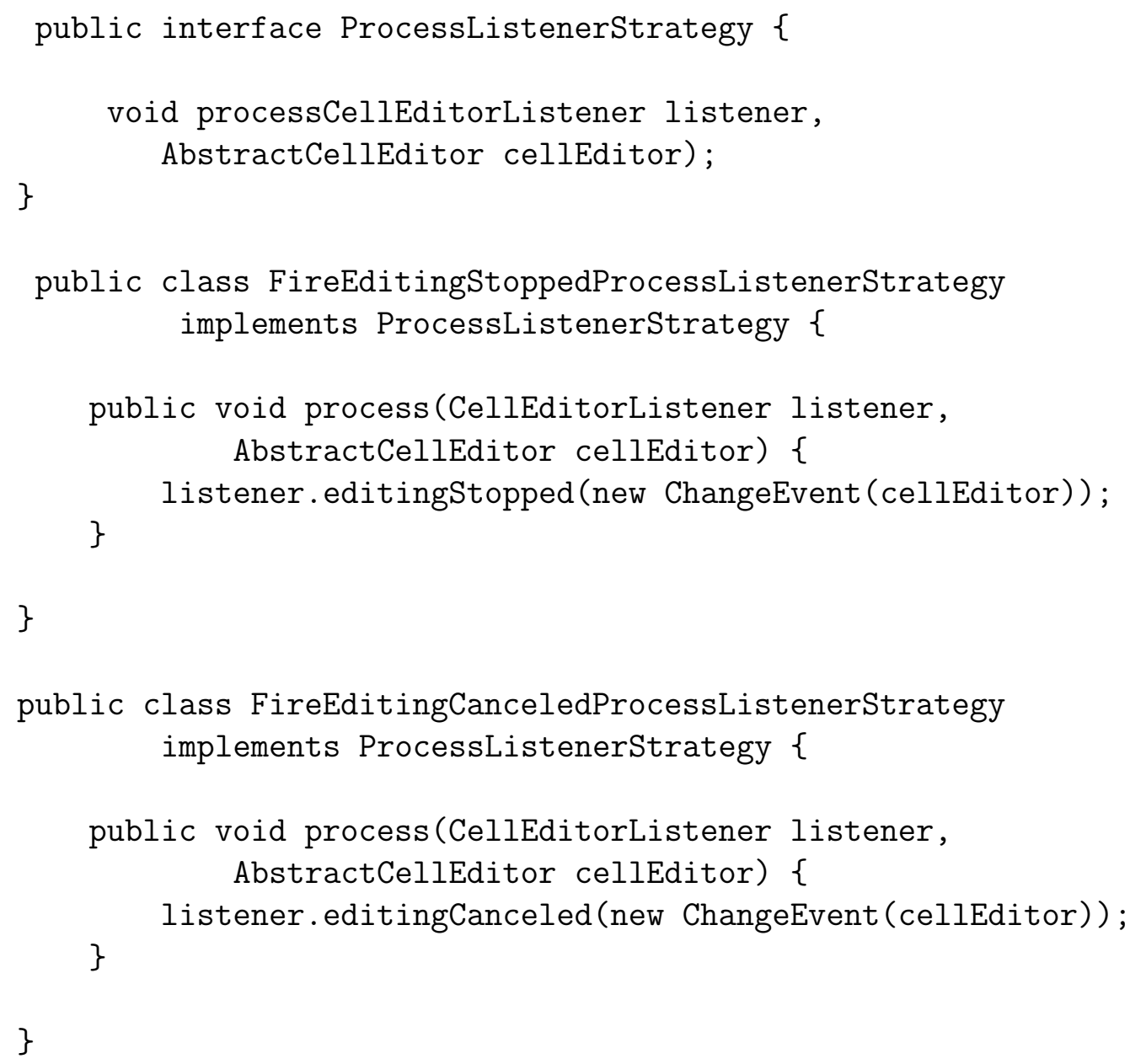

Figura 48 - Novas chamadas a fireEditingStopped() e fireEditingCanceled()

falsos positivos na detecção de clones. Isso porque alguns métodos são similares, mas as chamadas que existem neles mudam a semântica da execução do programa.

A nova técnica foi desenvolvida em um programa já existente, a Bytecode Java Clone Detector (BJCD) [6], como contribuição deste trabalho. Essa ferramenta foi modificada de modo que consumisse menos memória e que seu tempo de execução fosse diminuído. Como resultado, a BJCD evoluiu à sua versão 2.0. A arquitetura de componentes e as regras de execução da técnica, bem como heurísticas e o filtro criados para melhorar o desempenho de execução, também foram apresentadas neste capítulo.

Avaliações da BJCD foram realizadas com as alterações realizadas. O filtro que define o número mínimo de nós que GDPs devem ter para ser analisados mostrou-se uma técnica eficiente para diminuir o tempo de execução da análise semântica de detecção de clones semânticos. Ao mesmo tempo, a análise interprocedimental tende a ser mais lenta do que técnicas que não a utilizam. No entanto, a memória consumida pela análise 


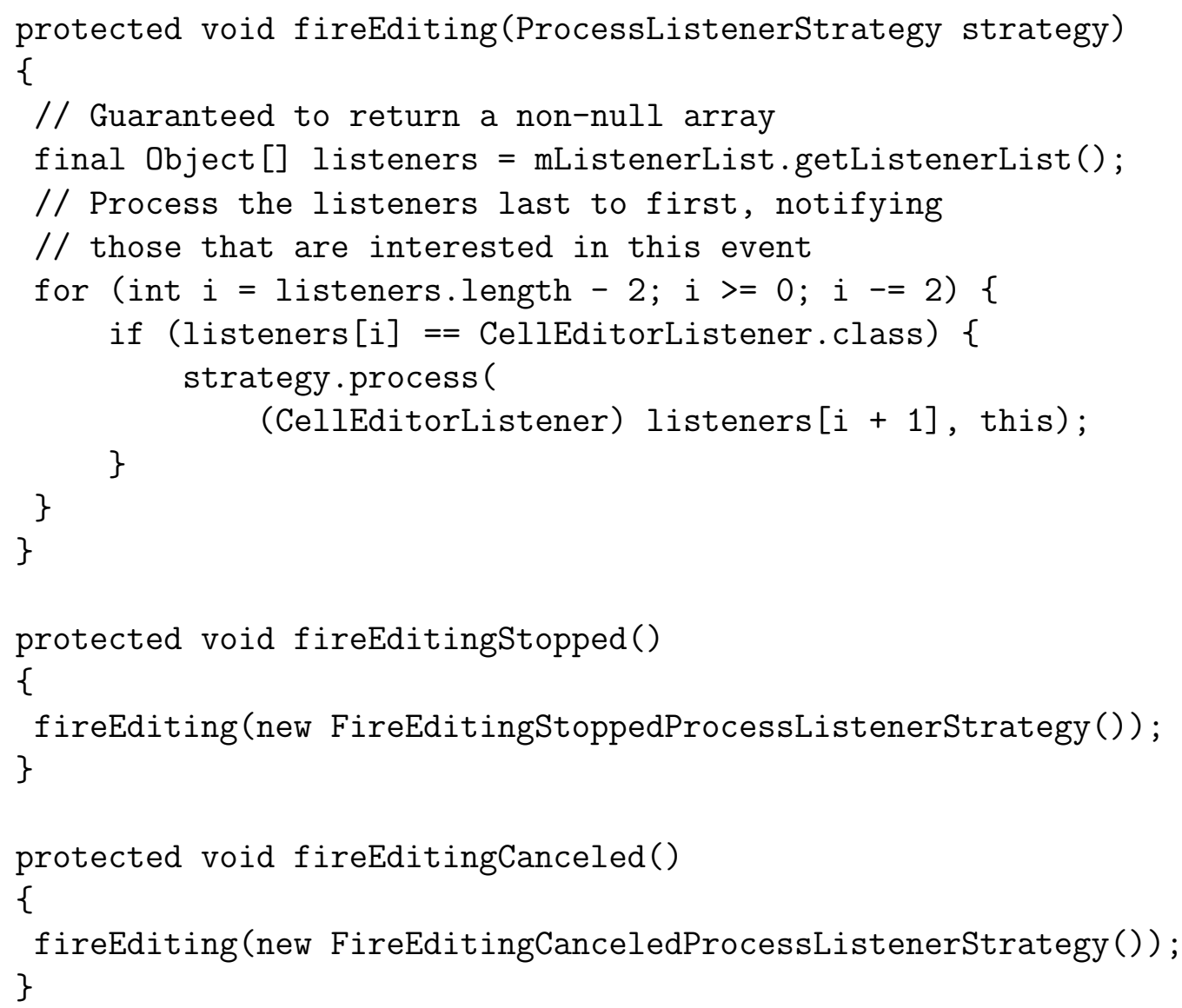

Figura 49 - Novos códigos para fireEditingStopped() e fireEditingCanceled()

interprocedimental não foi maior do que a da análise convencional para os programas utilizados nas avaliações. O tempo de execução também não aumentou quando análises interprocedimentais que consideram mais de um nível de chamadas foram executadas.

A taxa de acerto da técnica interprocedimental foi comparada à da técnica convencional para detecção de clones semânticos com base no benchmark criado no Capítulo 4. A técnica interprocedimental apresentou uma taxa de acertos maior. No entanto, há a possibilidade dos programadores que participaram da criação do benchmark não terem considerado os pares de código classificados como clones pela técnica convencional como clones por terem maus hábitos de programação ou por não terem pensado no uso desses pares de código para realizar refatorações ou entender o código do sistema. 


\section{Capítulo 6}

\section{Contribuições e Trabalhos Futuros}

O objetivo deste trabalho foi propor uma técnica que detectasse clones semânticos analisando as chamadas de procedimentos que ocorrem nos trechos de código analisado. Esse tipo de análise pode auxiliar a diminuir a quantidade de falsos positivos apresentados por ferramentas convencionais de detecção de clones semânticos, pois analisa o comportamento das chamadas presentes nesses supostos clones adicionalmente à análise convencional.

Um benchmark que mede as taxas de acerto de ferramentas de detecção de clones foi criado para avaliar a técnica interprocedimental de detecção de clones semânticos. Doze programadores da academia e da indústria classificaram oitenta pares de candidatos a clones (sendo que cada programador classificou vinte pares) como clone ou não clone. Ou seja, cada par de candidatos a clones foi classificado por três programadores. Os pares de candidatos a clones foram então adicionados ao benchmark com base na classificação fornecida pelos programadores.

Outra contribuição oriunda da atividade de criação do benchmark foi a definição de um novo tipo de clone, com base nas classificações fornecidas pelos programadores. Clones interprocedimentais são cópias de códigos similares em sua lógica de execução, mas que possuem invocações com comportamentos distintos, gerando portanto diferença semântica.

A técnica interprocedimental de detecção de clones semânticos foi definida e desenvolvida em uma ferramenta existente de deteç̧ão de clones semânticos, a Bytecode Java Clone Detector (BJCD). Melhorias de consumo de memória e tempo de execução foram realizadas na BJCD antes de implementar a técnica proposta. Uma melhoria de 96,41\% foi obtida no tempo de execução da ferramenta e ela tornou-se capaz de ser executada para programas para os quais não executava antes devido a problemas de estouro de memória. A técnica interprocedimental foi então desenvolvida na BJCD e validada juntamente a um filtro e a heurísticas de melhoria de consumo de memória e tempo de execução. A BJCD, como resultado, evoluiu para sua versão 2.0.

Avaliações foram realizadas utilizando o benchmark criado e chegou-se à conclusão de 
que a técnica interprocedimental de detecção de clones semânticos pode alcançar taxas de acerto maiores do que a técnica convencional. No entanto, a técnica interprocedimental tende a necessitar de mais tempo para ser executada, apesar de não necessitar de mais memória.

Uma ameaça à validade da validação foi apresentada, referente à classificação dos pares de candidatos a clones com diferenças nas chamadas de procedimentos. Programadores que participaram da criação do benchmark podem os ter classificado como não clones devido a terem maus hábitos de programação ou por não terem considerado os usos desses tipos de clones para atividades de refatoração ou entendimento de código, considerando apenas o uso para manutenção e evolução de software.

Como trabalho futuro, um novo levantamento pode ser realizado com programadores para mitigar essa ameaça à validade. É possível formar grupos nos quais os programadores têm focos diferentes na análise de clones. Por exemplo, em um grupo os programadores tentam detectar clones para manter ou evoluir o código enquanto em outro grupo programadores detectam clones para realizar atividades de refatoração. Os resultados podem ser analisados e comparados de modo que novas conclusões sejam tiradas acerca do comportamento dos programadores na atividade de detecção de clones.

A aplicação da técnica e do tipo interprocedimental de clones em áreas específicas de estudo não foi realizada neste trabalho. Outro trabalho futuro é estudar a aplicação da técnica em áreas específicas, como manutenção e evolução de software, refatoração, reengenharia e entendimento de código.

Finalmente, é possível melhorar o consumo de memória e o tempo de execução da BJCD, mesmo já havendo melhorias neste trabalho. A utilização de caches de grafos de dependência de programas e de bancos de dados orientados a grafos para armazená-los podem levar a BJCD a ser mais escalável e consumir menos tempo e memória no processo de geração de grafos. 


\section{Referências}

1 KOMONDOOR, R.; HORWITZ, S. Using slicing to identify duplication in source code. In: Proceedings of the 8th International Symposium on Static Analysis. London, UK: Springer-Verlag, 2001. (SAS '01), p. 40-56. ISBN 3-540-42314-1. Disponível em: $<$ http://dl.acm.org/citation.cfm?id=647170.718283>.

2 KRINKE, J. Identifying similar code with program dependence graphs. In: Proceedings of the Eighth Working Conference on Reverse Engineering (WCRE'01). Washington, DC, USA: IEEE Computer Society, 2001. (WCRE '01), p. 301-. ISBN 0-7695-1303-4. Disponível em: <http://dl.acm.org/citation.cfm?id=832308.837142>.

3 LIU, C. et al. Gplag: detection of software plagiarism by program dependence graph analysis. In: Proceedings of the 12th ACM SIGKDD international conference on Knowledge discovery and data mining. New York, NY, USA: ACM, 2006. (KDD '06), p. 872-881. ISBN 1-59593-339-5. Disponível em: $<$ http://doi.acm.org/10.1145/1150402.1150522>.

4 BELLON, S. et al. Comparison and evaluation of clone detection tools. Software Engineering, IEEE Transactions on, v. 33, n. 9, p. 577 -591, 2007. ISSN 0098-5589.

5 GABEL, M.; JIANG, L.; SU, Z. Scalable detection of semantic clones. In: Proceedings of the 30th international conference on Software engineering. New York, NY, USA: ACM, 2008. (ICSE '08), p. 321-330. ISBN 978-1-60558-079-1. Disponível em: $<$ http://doi.acm.org/10.1145/1368088.1368132>.

6 AlBUQUERQUE, F.; NEVES, B.; CHAIM, M. Detecção semântica de clones a partir de bytecodes. In: SBQS 2012 Workshop de Manutencao de Software Moderna. [S.l.: s.n.], 2012.

7 KOSKELA, L. Practical TDD and Acceptance TDD for Java Developers. [S.l.]: Manning Publications, 2008.

8 ROY, C. K.; CORDY, J. R.; KOSCHKE, R. Comparison and evaluation of code clone detection techniques and tools: A qualitative approach. Science of Computer Programming, v. 74, n. 7, p. 470 - 495, 2009. ISSN 0167-6423. Special Issue on Program Comprehension (ICPC 2008). Disponível em: <http://www.sciencedirect.com/science/article/B6V17-4VT5TGF1/2/b59307cf749745bcf29991157ecd991e>.

9 LEITãO, A. M. Detection of redundant code using r2d2. Software Quality Control, Kluwer Academic Publishers, Hingham, MA, USA, v. 12, p. 361-382, December 2004. ISSN 0963-9314. Disponível em: <http://dl.acm.org/citation.cfm?id=1016944.1016958>. 
10 FERRAnte, J.; OTTENSTEIN, K. J.; WARREN, J. D. The program dependence graph and its use in optimization. ACM Trans. Program. Lang. Syst., ACM, New York, NY, USA, v. 9, p. 319-349, July 1987. ISSN 0164-0925. Disponível em: $<$ http://doi.acm.org/10.1145/24039.24041>.

11 MENS, T.; TOURWE, T. A survey of software refactoring. Software Engineering, IEEE Transactions on, v. 30, n. 2, p. 126-139, 2004. ISSN 0098-5589.

12 HECHT, M. S. Flow Analysis of Computer Programs. New York, NY, USA: Elsevier Science Inc., 1977. ISBN 0444002162.

13 MaldonAdo, J. C.; BARBOSA, E. F.; VInCEnZI, A. M. R. Introdução ao Teste de Software. 2004. Acesso em: 25 fev. 2012. Disponível em: $<$ http://www.inf.ucv.cl/frames/interface_fr_files/menu_cap/doc_noticias/minicurso.pdf $>$.

14 RAPPS, S.; WEYUKER, E. J. Data flow analysis techniques for test data selection. In: Proceedings of the 6th international conference on Software engineering. Los Alamitos, CA, USA: IEEE Computer Society Press, 1982. (ICSE '82), p. 272-278. Disponível em: <http://dl.acm.org/citation.cfm?id=800254.807769>.

15 SIERRA, K.; BATES, B. Certificação Sun para Programador e Desenvolvedor em Java 2: Guia de Estudos. [S.1.]: Alta Books, 2003.

16 HARROLD, M. J.; MALLOY, B.; ROTHERMEL, G. Efficient construction of program dependence graphs. In: Proceedings of the 1993 ACM SIGSOFT international symposium on Software testing and analysis. New York, NY, USA: ACM, 1993. (ISSTA '93), p. 160-170. ISBN 0-89791-608-5. Disponível em: $<$ http://doi.acm.org/10.1145/154183.154268>.

17 SREEDHAR, V. C.; GAO, G. R.; LEE, Y.-f. Incremental computation of dominator trees. In: Papers from the 1995 ACM SIGPLAN workshop on Intermediate representations. New York, NY, USA: ACM, 1995. (IR '95), p. 1-12. ISBN 0-89791-754-5. Disponível em: <http://doi.acm.org/10.1145/202529.202531>.

18 KUCK, D. J. et al. Dependence graphs and compiler optimizations. In: Proceedings of the 8th ACM SIGPLAN-SIGACT symposium on Principles of programming languages. New York, NY, USA: ACM, 1981. (POPL '81), p. 207-218. ISBN 0-89791-029-X. Disponível em: <http://doi.acm.org/10.1145/567532.567555>.

19 STALLMAN, R. M. The GNU Project. 2012. Acesso em: 28 fev. 2012. Disponível em: <http://www.gnu.org/gnu/thegnuproject.html>.

20 ZIVIANI, N. Projeto de Algoritmos: com Implementações em Pascal e C. [S.1.]: Thomson Pioneira, 2004.

21 JOHNSON, J. H. Identifying redundancy in source code using fingerprints. In: Proceedings of the 1993 conference of the Centre for Advanced Studies on Collaborative research: software engineering - Volume 1. IBM Press, 1993. (CASCON '93), p. 171-183. Disponível em: <http://dl.acm.org/citation.cfm?id=962289.962305>. 
22 DUCASSE, S.; RIEGER, M.; DEMEYER, S. A language independent approach for detecting duplicated code. In: Proceedings of the IEEE International Conference on Software Maintenance. Washington, DC, USA: IEEE Computer Society, 1999. (ICSM '99), p. 109-. ISBN 0-7695-0016-1. Disponível em: $<$ http://dl.acm.org/citation.cfm?id=519621.853389>.

23 APPEL, A. W. Modern compiler implementation in Java. New York, NY, USA: Cambridge University Press, 1998. ISBN 0-521-58388-8.

24 BAKER, B. S. A program for identifying duplicated code. In: Computing Science and Statistics: Proceedings of the 24th Symposium on the Interface. [S.1.: s.n.], 1992.

25 KAMIYA, T.; KUSUMOTO, S.; INOUE, K. Ccfinder: a multilinguistic token-based code clone detection system for large scale source code. IEEE Trans. Softw. Eng., IEEE Press, Piscataway, NJ, USA, v. 28, p. 654-670, July 2002. ISSN 0098-5589. Disponível em: <http://dl.acm.org/citation.cfm?id=636188.636191>.

26 BAKER, B. S.; MANBER, U. Deducing similarities in java sources from bytecodes. In: Proceedings of the annual conference on USENIX Annual Technical Conference. Berkeley, CA, USA: USENIX Association, 1998. (ATEC '98), p. 15-15. Disponível em: $<$ http://dl.acm.org/citation.cfm?id=1268256.1268271>.

27 LINDHOLM T.; YELLIN, F. The Java(TM) Virtual Machine Specification. [S.1.]: Prentice Hall, 1999.

28 BAXTER, I. D. et al. Clone detection using abstract syntax trees. In: Proceedings of the International Conference on Software Maintenance. Washington, DC, USA: IEEE Computer Society, 1998. (ICSM '98), p. 368-. ISBN 0-8186-8779-7. Disponível em: $<$ http://dl.acm.org/citation.cfm?id=850947.853341 $>$.

29 MAYRAND, J.; LEBLANC, C.; MERLO, E. Experiment on the automatic detection of function clones in a software system using metrics. In: Proceedings of the 1996 International Conference on Software Maintenance. Washington, DC, USA: IEEE Computer Society, 1996. (ICSM '96), p. 244-. ISBN 0-8186-7677-9. Disponível em: $<$ http://dl.acm.org/citation.cfm?id=645544.655888>.

30 WEISER, M. Program slicing. In: Proceedings of the 5th international conference on Software engineering. Piscataway, NJ, USA: IEEE Press, 1981. (ICSE '81), p. 439-449. ISBN 0-89791-146-6. Disponível em: $<$ http://dl.acm.org/citation.cfm?id=800078.802557>.

31 GROVE, D. et al. Call graph construction in object-oriented languages. In: Proceedings of the 12th ACM SIGPLAN conference on Object-oriented programming, systems, languages, and applications. New York, NY, USA: ACM, 1997. (OOPSLA '97), p. 108124. ISBN 0-89791-908-4. Disponível em: <http://doi.acm.org/10.1145/263698.264352>.

32 BAKER, B. S. On finding duplication and near-duplication in large software systems. In: Proceedings of the Second Working Conference on Reverse Engineering. Washington, DC, USA: IEEE Computer Society, 1995. (WCRE '95), p. 86-. ISBN 0-8186-7111-4. Disponível em: <http://dl.acm.org/citation.cfm?id=832303.836911>. 
33 MANBER, U. Finding similar files in a large file system. In: Proceedings of the USENIX Winter 1994 Technical Conference on USENIX Winter 1994 Technical Conference. Berkeley, CA, USA: USENIX Association, 1994. p. 2-2. Disponível em: $<$ http://dl.acm.org/citation.cfm?id=1267074.1267076>.

34 KOSCHKE, R. Frontiers of software clone management. In: Frontiers of Software Maintenance, 2008. FoSM 2008. [S.l.: s.n.], 2008. p. $119-128$.

35 ROY, C.; CORDY, J. Scenario-based comparison of clone detection techniques. In: Program Comprehension, 2008. ICPC 2008. The 16th IEEE International Conference on. [S.l.: s.n.], 2008. p. 153 -162. ISSN 1063-6897.

36 RATTAN, D.; BHATIA, R.; SINGH, M. Software clone detection: A systematic review. Information and Software Technology, v. 55, n. 7, p. 1165 - 1199, 2013. ISSN 0950-5849. Disponível em: <http://www.sciencedirect.com/science/article/pii/S0950584913000323>.

37 WHITNEY, H. Congruent graphs and the connectivity of graphs. In: American Journal of Mathematics. [S.l.]: The Johns Hopkins University Press, 1932. v. 54, n. 1, p. 150-168.

38 KOCHAN, S. G. Programming in C. [S.l.]: Sams, 2004.

39 KERNIGHAN, B. W.; PIKE, R. Unix Programming Environment. [S.1.]: Prentice Hall Ptr, 1984.

40 KONTOGIANNIS, K. et al. Pattern matching for clone and concept detection. Automated Software Engineering, Kluwer Academic Publishers, v. 3, n. 1-2, p. 77-108, 1996. ISSN 0928-8910. Disponível em: <http://dx.doi.org/10.1007/BF00126960>.

41 JIANG, L. et al. Deckard: Scalable and accurate tree-based detection of code clones. In: Proceedings of the 29th international conference on Software Engineering. Washington, DC, USA: IEEE Computer Society, 2007. (ICSE '07), p. 96-105. ISBN 0-7695-2828-7. Disponível em: <http://dx.doi.org/10.1109/ICSE.2007.30>.

42 VINCENZI, A. et al. Jabuti: A coverage analysis tool for java programs. XVII SBES-Simpósio Brasileiro de Engenharia de Software, Manaus, AM, p. 79-84, 2003.

43 LASKI, J.; STANLEY, W. Dynamic program analysis. In: Software Verification and Analysis. Springer London, 2009. p. 203-219. ISBN 978-1-84882-239-9. Disponível em: $<$ http://dx.doi.org/10.1007/978-1-84882-240-5_9>. 


\section{$A P \hat{E} N D I C E A$}

\section{Automação do sorteio de clones}

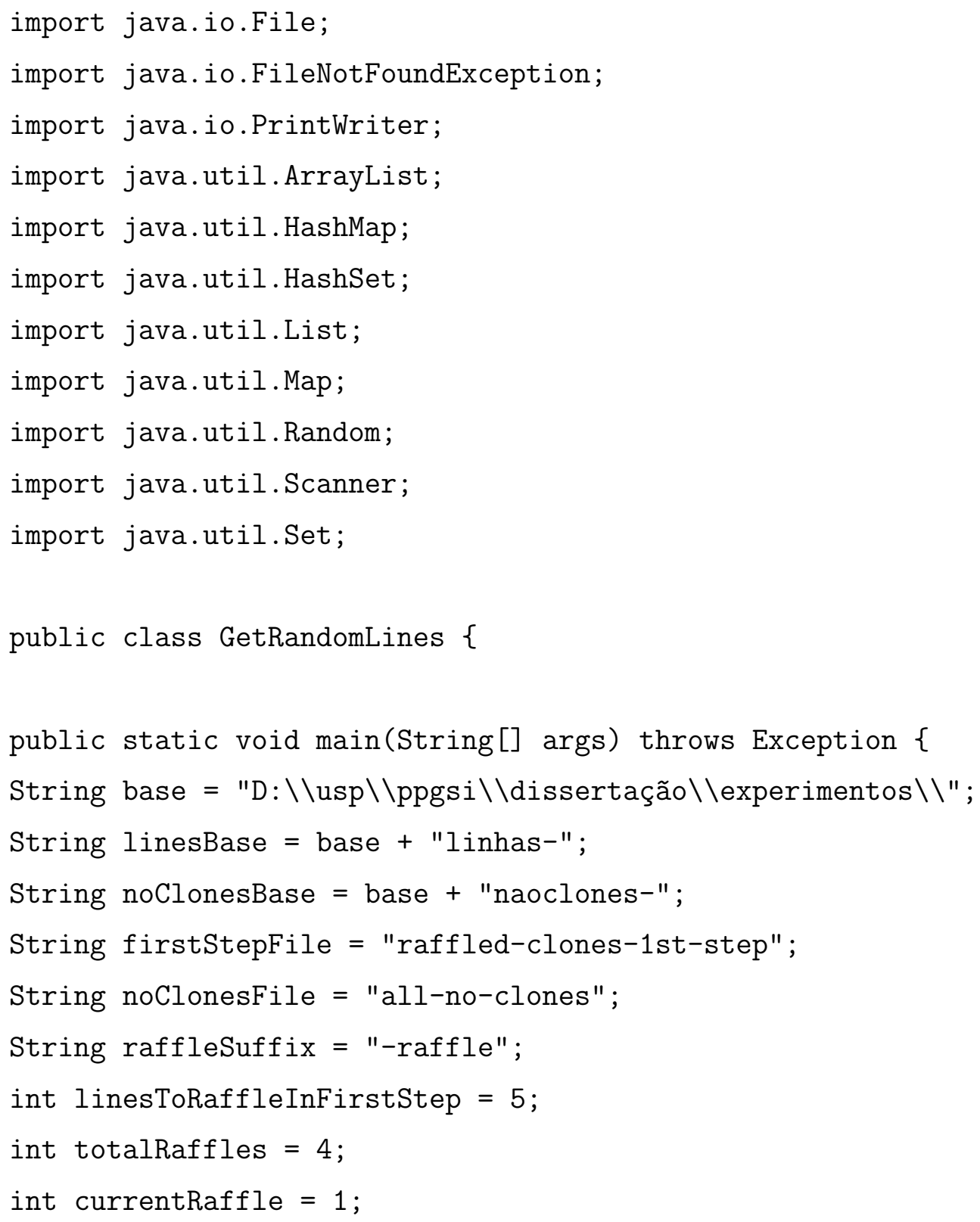




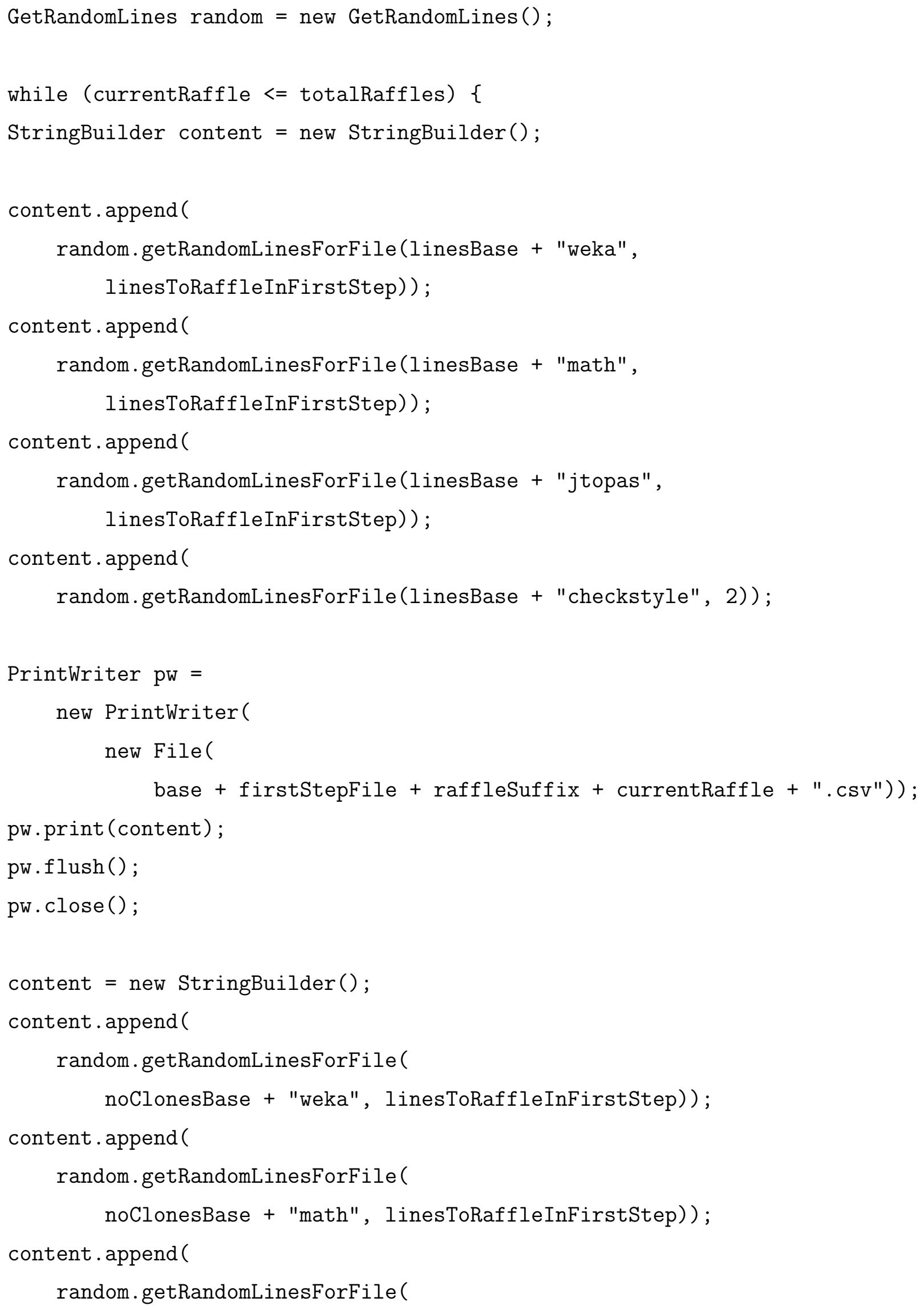




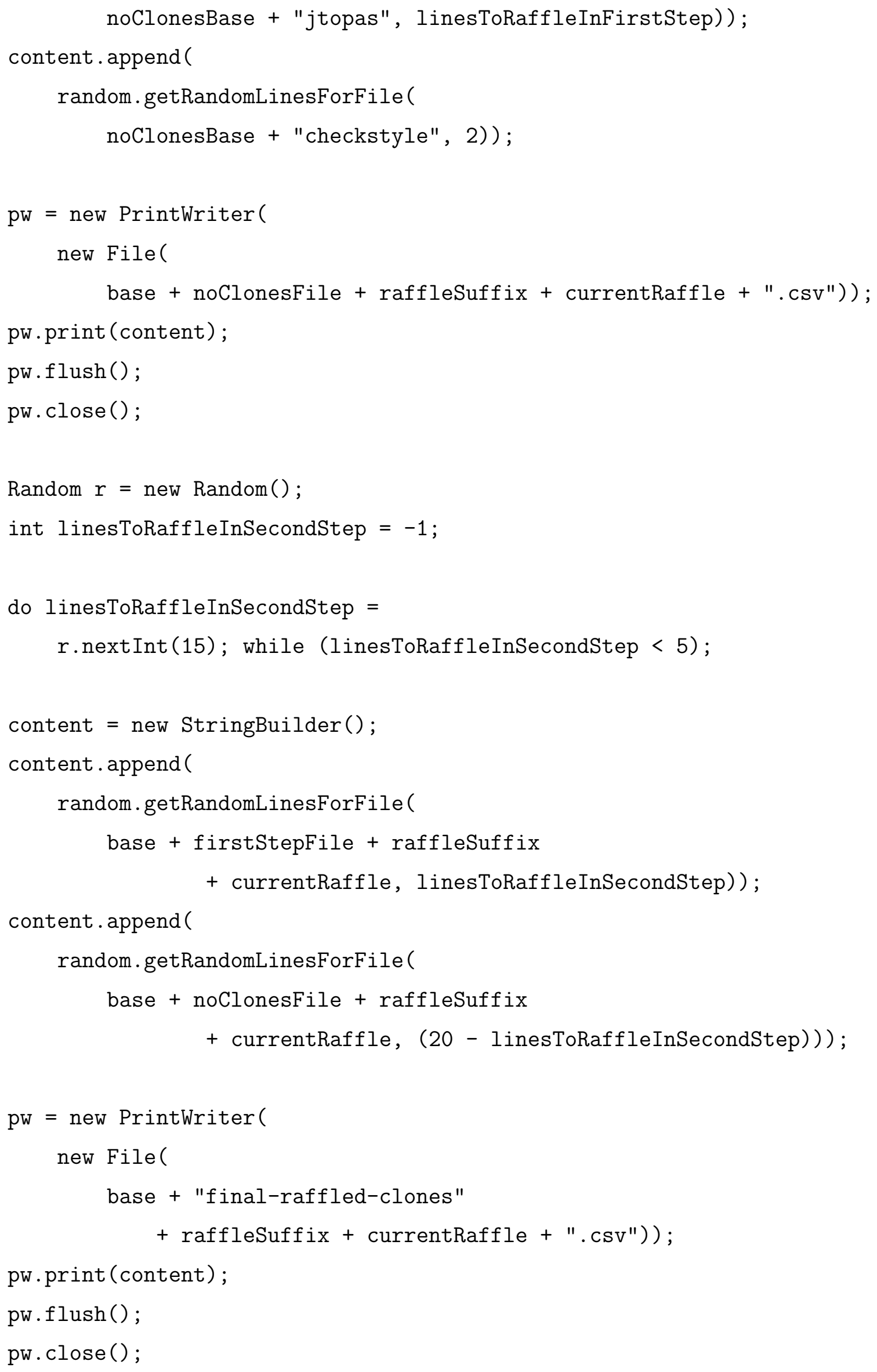




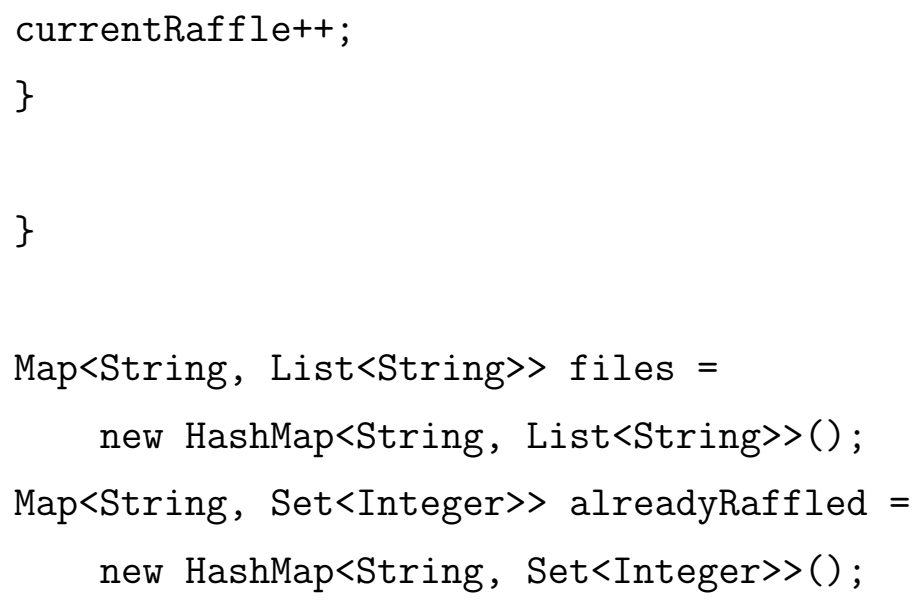

String getRandomLinesForFile(String file, int linesToGet) throws FileNotFoundException \{

if (!files.containsKey(file)) \{

loadFileToMemory (file);

\}

int gotten $=0$;

Random random $=$ new $\operatorname{Random}()$;

StringBuilder raffledLines = new StringBuilder () ;

if (!alreadyRaffled.containskey(file)) \{

alreadyRaffled.put(file, new HashSet<Integer>());

\}

List<String $>$ lines $=$ files.get $(f i l e) ;$

while (gotten < linesToGet) \{

int pos $=-1$;

do $\operatorname{pos}=$

random.nextInt (lines.size());

while (!alreadyRaffled.get (file).add(pos));

raffledLines.append (lines.get (pos)) 
.append (System.getProperty ("line.separator")) ;

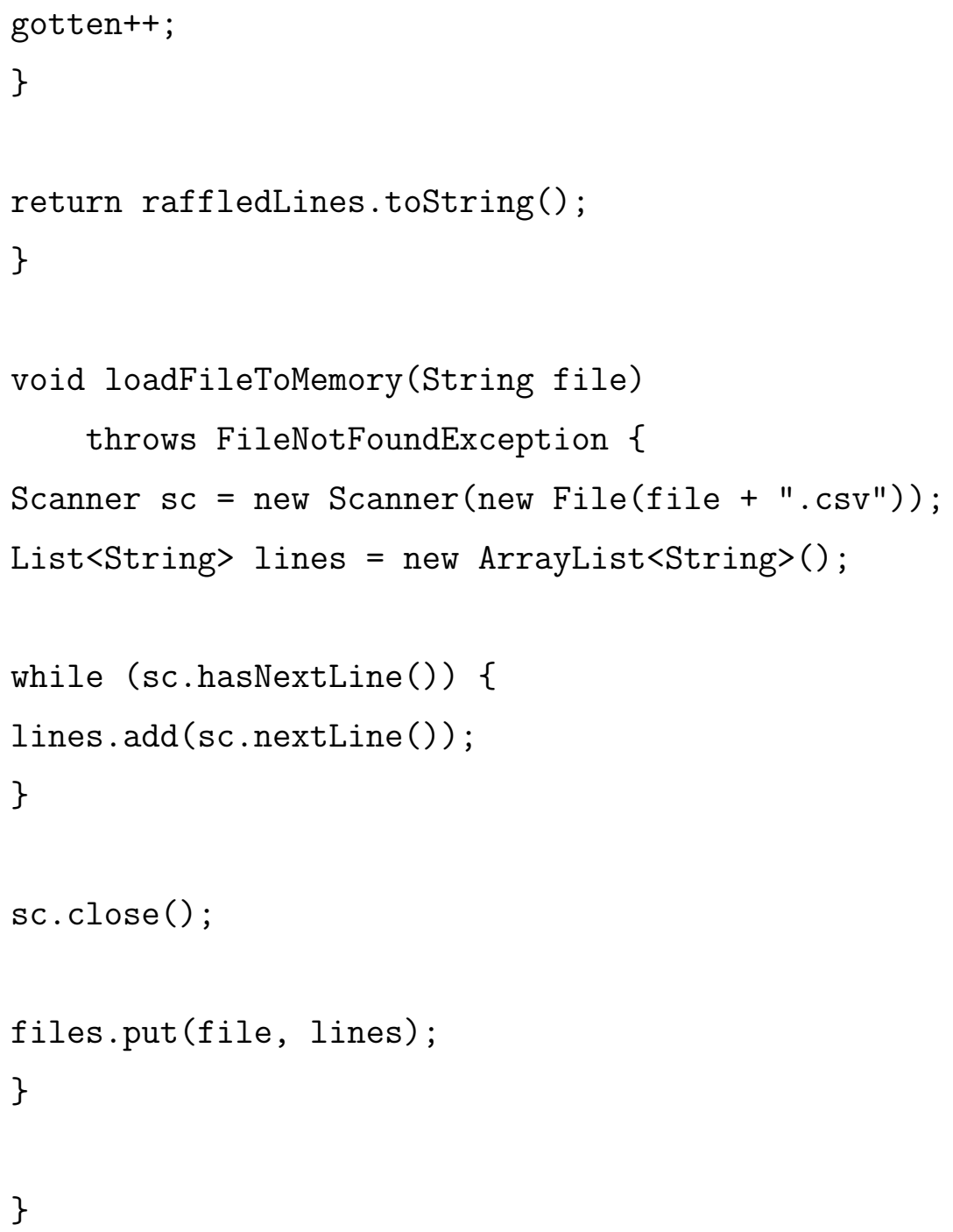




\section{$A P \hat{E} N D I C E B$}

\section{Formulário de ciência da criação do benchmark}

\section{Formulário de Aceitação}

\section{Título do Projeto e Objetivo:}

Classificação dos resultados obtidos das análises da ferramenta Bytecode Java Clone Detector (BJCD) realizada por oráculos humanos não relacionados ao projeto.

Objetivos:

\begin{tabular}{|c|c|c|}
\hline Proposta & Analisar & Os resultados obtidos das análises da ferramenta BJCD. \\
\hline & Com propósito de & $\begin{array}{r}\text { Definir se os resultados reportados pela ferramenta } \\
\text { são corretos ou incorretos e utilizar } \\
\text { essas classificações em um benchmark. }\end{array}$ \\
\hline & Com respeito & $\begin{array}{r}\text { A eficácia da ferramenta, isto é, o número de } \\
\text { resultados falsos positivos e falsos negativos } \\
\text { e à utilização do benchmark para avaliar } \\
\text { ferramentas de deteç̧ão de clones. }\end{array}$ \\
& & Programadores de projetos \\
\hline Perspectiva: & Do ponto de vista de & \\
\hline
\end{tabular}

\section{Procedimentos:}

O procedimento do experimento é o que segue. Primeiramente haverá a aplicação de um treinamento de aproximadamente uma hora sobre clones de código e tipos de clones, envolvendo a aplicação imediata de exercícios de classificação de clones para fixação do conteúdo apresentado. Pares de métodos analisados pela BJCD, que podem ou não ser clones, serão apresentados aos programadores sem que eles saibam qual foi a decisão da BJCD. Esses pares serão, então, analisados pelos programadores, que dirão se são clones de acordo com suas concepções. 


\section{Confidencialidade:}

Todas as informações coletadas no experimento são confidenciais e meu nome não será identificado em momento algum. Confirmo que sou maior de 18 anos e que desejo participar do experimento conduzido pelo professor Marcos Lordello Chaim e pelo mestrando Felipe de Alencar Albuquerque. Eu entendo que não serei remunerado pessoalmente por participar dessa avaliação e que os dados coletados poderão ser usados em publicações científicas. Eu compreendo que ficarei livre para fazer perguntas ou para deixar de participar da avaliação a qualquer momento sem sofrer penalidades.

$\mathrm{Eu}$, aceito participar do experimento de acordo com o descrito acima.

Local: Data: Assinatura: 


\section{$A P \hat{E} N D I C E C$}

\section{Formulário de avaliação da criação do benchmark}

\section{Formulário de Avaliação}

\section{Título do Projeto e Objetivo:}

Avaliação da condução do experimento que teve como objetivo classificar os resultados obtidos das análises da ferramenta Bytecode Java Clone Detector (BJCD) realizada por oráculos humanos não relacionados ao projeto.

Objetivos:

\begin{tabular}{|c|c|c|}
\hline Proposta & Avaliar & $\begin{array}{c}\text { A condução do experimento de análise } \\
\text { dos resultados da BJCD. }\end{array}$ \\
\hline & Com propósito de & $\begin{array}{c}\text { Definir se o procedimento de condução do } \\
\text { experimento deve ser replanejado. }\end{array}$ \\
\hline Perspectiva: & Do ponto de vista de & $\begin{array}{c}\text { Programadores que foram submetidos ao } \\
\text { procedimento. }\end{array}$ \\
\hline
\end{tabular}

\section{Questões:}

Por favor, responda as seguintes questões:

1. O treinamento foi suficiente para identificação dos clones? ( ) SIM ( ) NÃO

2. Pares de programas dentre os apresentados não se encaixavam em nenhum tipo de clone apresentado no treinamento, apesar de terem sido considerados clones por você? ( ) SIM ( ) NÃO

3. Quanto tempo de experiência você tem com programação em Java? R: ANOS 


\section{Confidencialidade:}

Todas as informações coletadas no experimento são confidenciais e meu nome não será identificado em momento algum. Confirmo que sou maior de 18 anos e que desejo participar do experimento conduzido pelo professor Marcos Lordello Chaim e pelo mestrando Felipe de Alencar Albuquerque. Eu entendo que não serei remunerado pessoalmente por participar dessa avaliação e que os dados coletados poderão ser usados em publicações científicas. Eu compreendo que ficarei livre para fazer perguntas ou para deixar de participar da avaliação a qualquer momento sem sofrer penalidades.

$\mathrm{Eu}$, aceito participar do experimento de acordo com o descrito acima.

Local: Data: Assinatura: 


\section{$A P \hat{E} N D I C E D$}

\section{Arquitetura de alto nivel da $A C D R A$}

A arquitetura de alto nível da ACDRA está ilustrada na Figura 50. A classe principal do sistema é a Benchmark, que inicia e orquestra o processo de análise. Ela primeiramente utiliza um ResultsReader para ler o arquivo de resultados reportados e em seguida invoca o Oracle. O Oracle é a classe responsável por realizar a análise automática, ou seja, comparar o arquivo de resultados reportados com o de resultados esperados. Para isso ele utiliza um ResultsReader para ler os resultados esperados e compará-los com os reportados. Ambos os tipos de resultados são representados pela classe CloneDetectionResults, que é um conjunto de CandidatePairAnalysis que, por sua vez, refere-se à análise reportada ou esperada de um candidato de métodos, representado pela classe CandidatePair. O Oracle gera um Summary no final do processo de comparação. O Summary é então exportado pelo Oracle como arquivo separado por vírgulas. O Summary calcula e contém os dados do sumário da análise, como a taxa de acerto e as quantidades de positivos e negativos verdadeiros e falsos. 


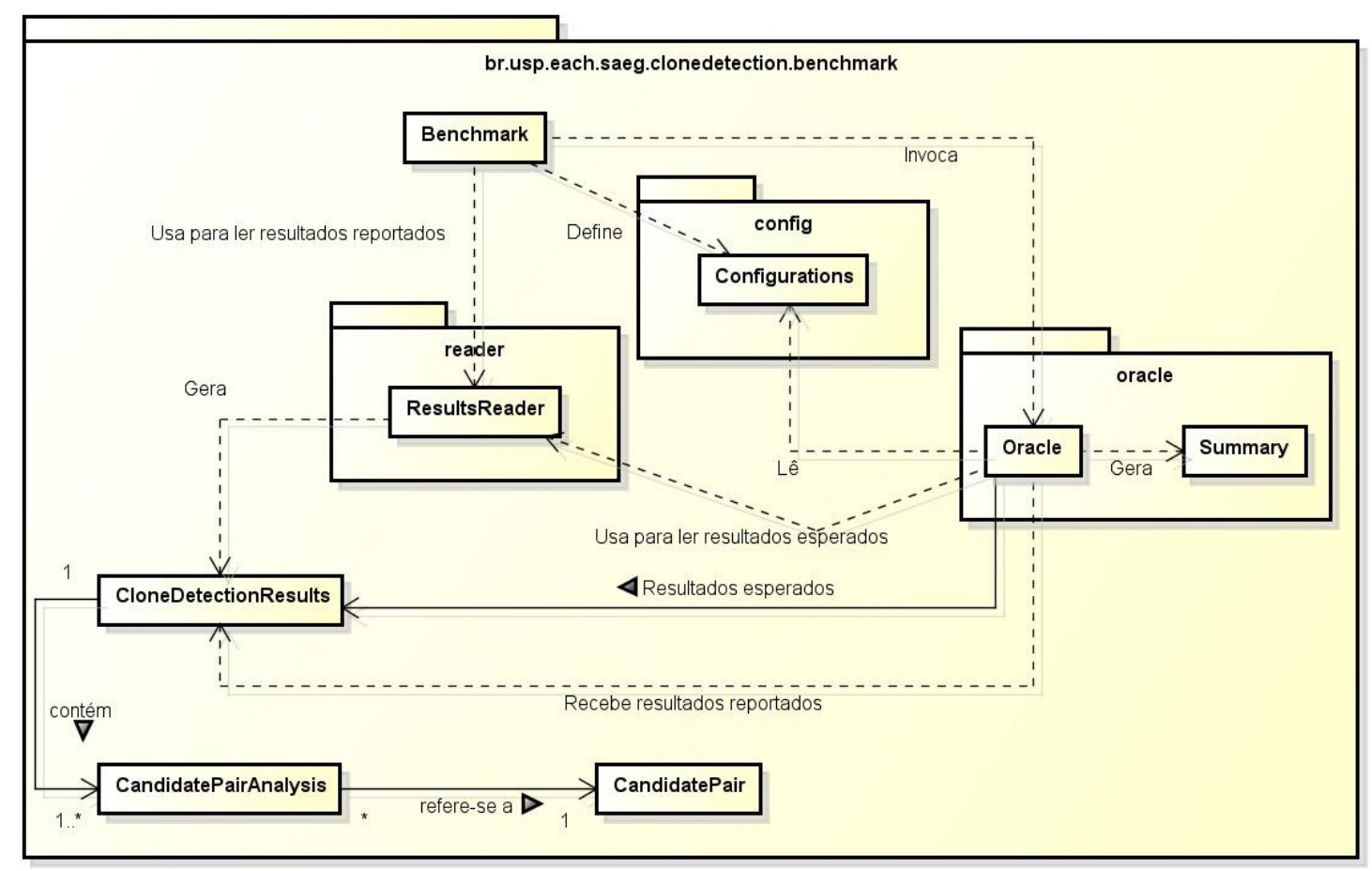

Figura 50 - Arquitetura de alto nível da ACDRA 